\title{
Assembling the Smart Grid \\ On the Mobilization of Imaginaries, Users and Materialities in a Swedish Demonstration Project
}

\author{
Anna Wallsten
}

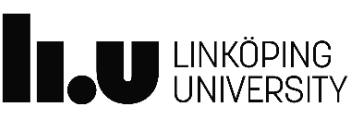

Linköping Studies in Arts and Science No. 730

Faculty of Arts and Sciences

Linköping 2017 
Linköping Studies in Arts and Science $\cdot$ No. 730

At the Faculty of Arts and Sciences at Linköping University, research and doctoral studies are carried out within broad problem areas. Research is organized in interdisciplinary research environments and doctoral studies mainly in graduate schools. Jointly, they publish the series Linköping Studies in arts and Science. This thesis comes from the Department of Thematic Studies - Technology and Social Change.

Distributed by:

Department of Thematic Studies - Technology and Social Change

Linköping University

SE-581 83 Linköping

Sweden

Anna Wallsten

Assembling the Smart Grid

On the Mobilization of Imaginaries, Users and Materialities

in a Swedish Demonstration Project

Edition 1:1

ISBN 978-91-7685-407-5

ISSN 0282-9800

CAnna Wallsten

Department of Thematic Studies - Technology and Social Change 2017

Printed by: LiU-Tryck, Linköping 2017

Cover by: Erik Berglund 
This thesis is based on work conducted within the interdisciplinary graduate school Energy Systems. The national Energy Systems Programme aims at creating competence in solving complex energy problems by combining technical and social sciences. The research programme analyses processes for the conversion, transmission and utilisation of energy, combined together in order to fulfil specific needs.

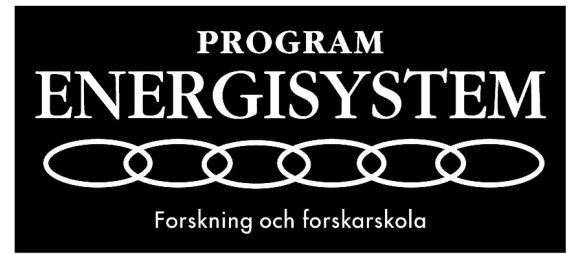

The research groups that constitute the Energy Systems Programme are the Department of Engineering Sciences at Uppsala University, the Division of Energy Systems at Linköping Institute of Technology, the Research Theme Technology and Social Change at Linköping University, the Division of Heat and Power Technology at Chalmers University of Technology in Göteborg as well as the Division of Energy Processes at the Royal Institute of Technology in Stockholm. Associated research groups are the Division of Environmental Systems Analysis at Chalmers University of Technology in Göteborg as well as the Division of Electric Power Systems at the Royal Institute of Technology in Stockholm.

www.liu.se/energi 



\section{Contents}

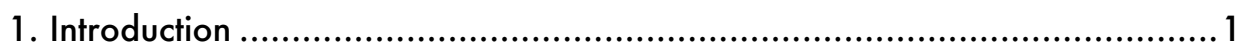

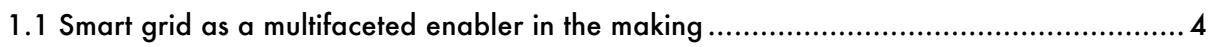

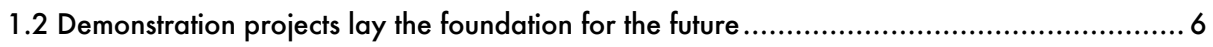

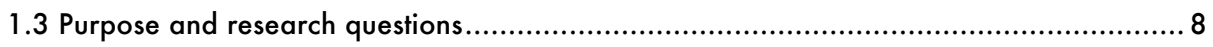

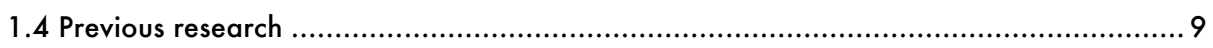

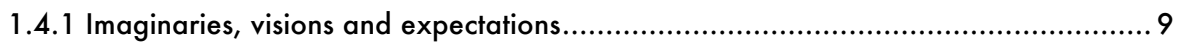

1.4.2 Making smart grids functional: experiments, trials and tests ............................... 13

1.4.3 Smart grid households' engagements, desires and practices .............................. 16

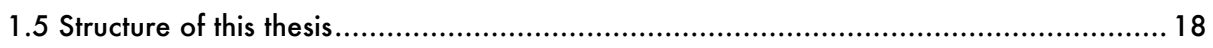

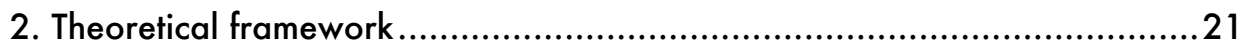

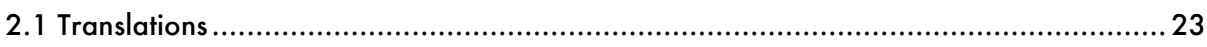

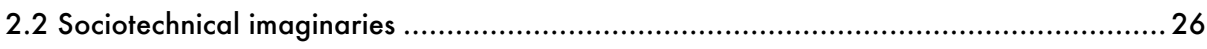

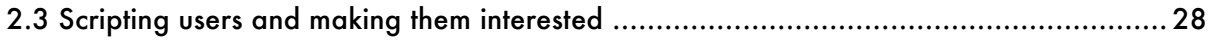

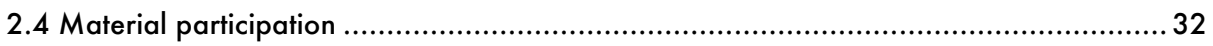

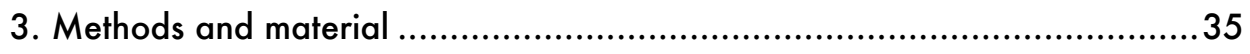

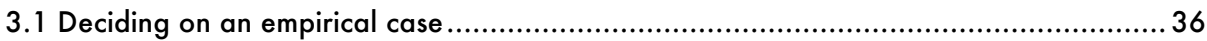

3.2 Methods of compiling material about Smart Customer Gotland .................................. 38

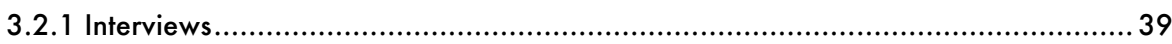

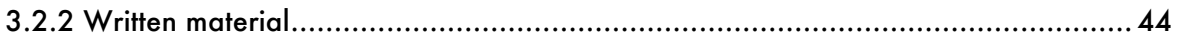

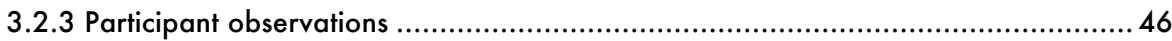

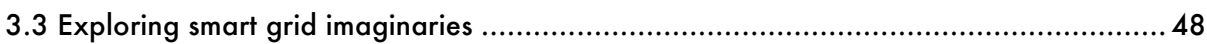

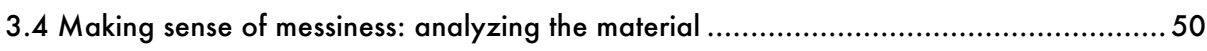

4. Smart Grid Gotland: shaping the future of Swedish smart grids ................55

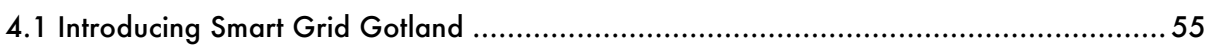

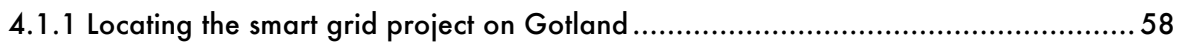

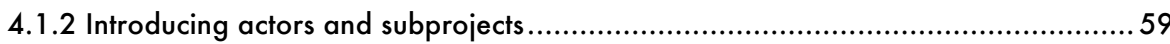




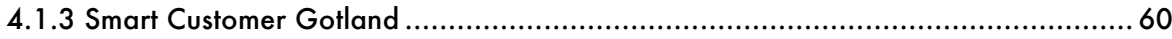

5. Swedish sociotechnical smart grid imaginaries ....................................65

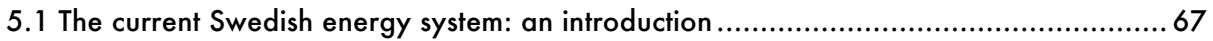

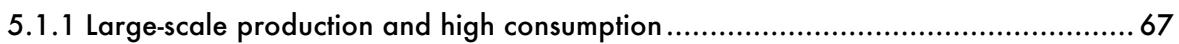

5.1.2 The energy system operating on a liberalized market....................................... 70

5.1.3 Initial steps towards a Swedish smart grid implementation .................................74

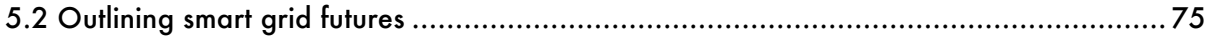

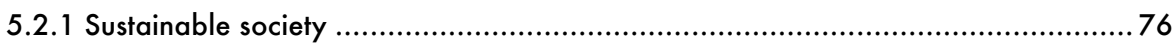

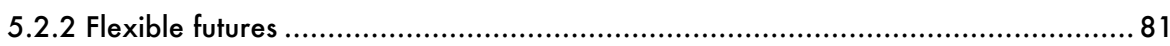

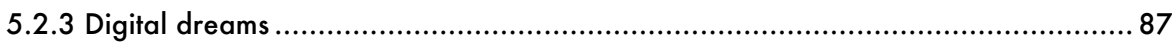

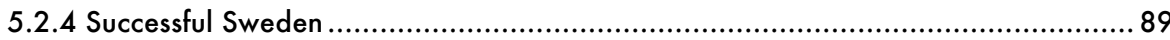

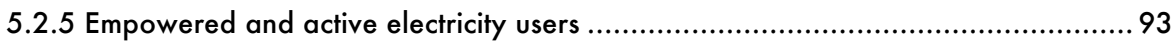

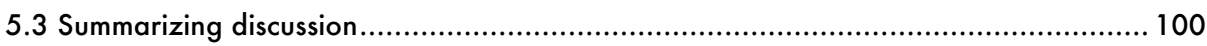

6. Making smart grids work: a process of exclusions and inclusions............. 105

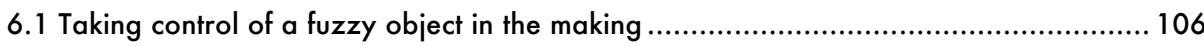

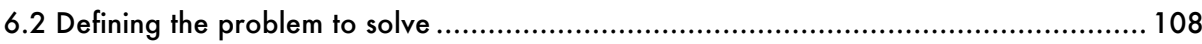

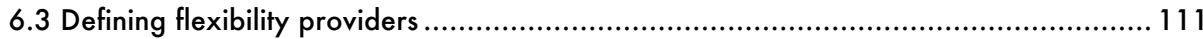

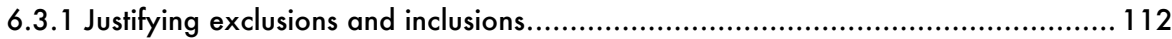

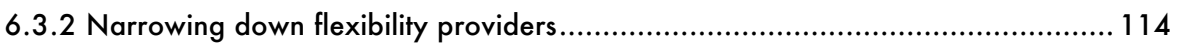

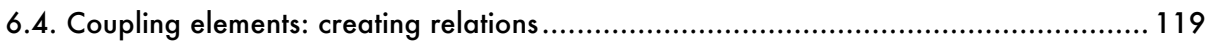

6.4.1 Fluctuating electricity tariffs as a predetermined actor .....................................119

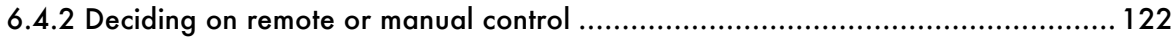

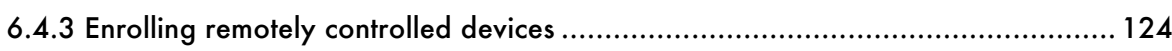

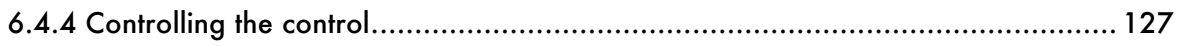

6.4.5 Collecting, compiling and presenting information ......................................... 131

6.4.6 Encountering problems with existing entities in households............................. 134

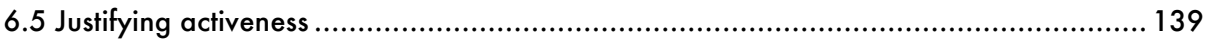

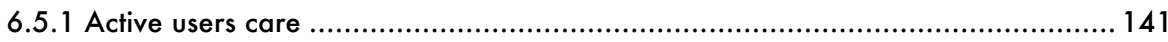


6.5.2 Passively active users

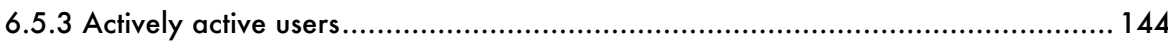

6.6 Making people interested: charging smart grids with matters of concern .................. 146

6.6.1 Connecting the project with economy ........................................................ 148

6.6.2 Connecting the project with sustainability ....................................................... 152

6.6.3 Connecting the project with the good of Gotland .......................................... 155

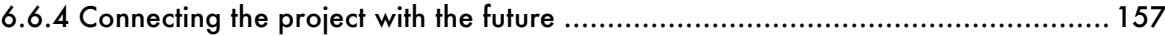

6.6.5 Connecting the project with enhanced information .......................................... 158

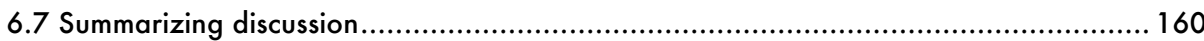

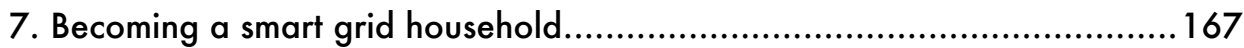

7.1 Articulating participation in Smart Customer Gotland ............................................... 169

7.1.1 Participating as a means of obtaining personal benefits.................................... 169

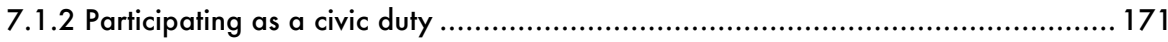

7.1.3 Participating to actively support a certain kind of energy system ....................... 175

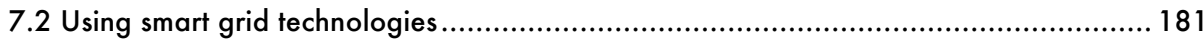

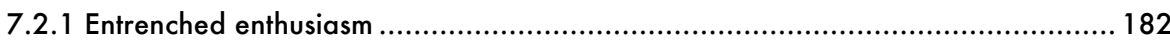

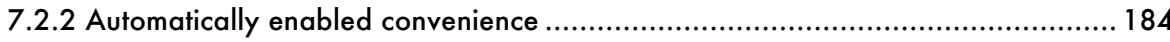

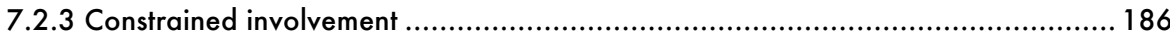

7.3 Prosumers reasoning about attractive smart grids .................................................. 190

7.3.1 Questioning the market and economic doctrine of smart grids........................... 190

7.3.2 Producing electricity as part of a larger transition ........................................... 192

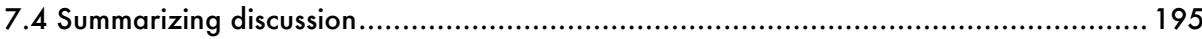

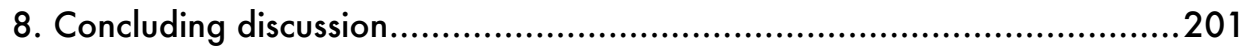

8.1 Following the assembling of a smart grid through time and space .............................202

8.1.1 Demonstration projects as arenas intended to influence the future .......................202

8.1.2 Sociotechnical smart grid imaginaries as performative frameworks..................... 203

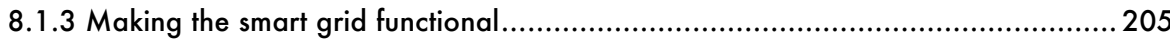

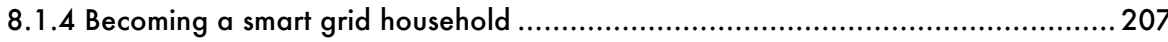


8.2 Tracing tensions, doubts and contradictions in smart grid translations

8.2.1 On the mobilization and tweaking of imaginaries ........................................... 210

8.2.2 Paying attention to inclusion and exclusion processes .................................... 212

8.2.3 Tensions in a market-based regime with economic incentives............................ 213

8.2.4 Empowerment and activeness: re-negotiated notions of users ............................ 216

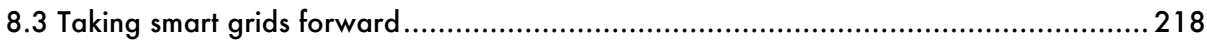

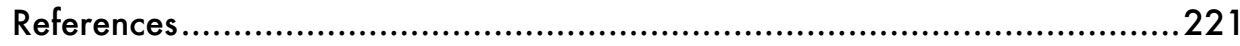

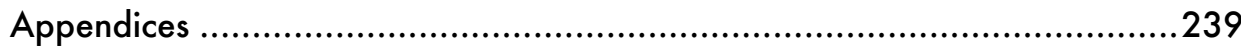

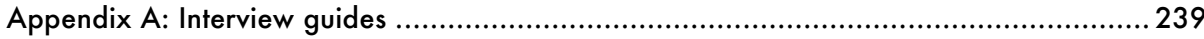

Appendix B: Participant observations and fictitious names of interviewees ..................... 245 


\section{Acknowledgements}

Writing a dissertation is a diverse and stretched-out procedure. At times, this has been a challenging and lonesome journey that has felt very frustrating and difficult to master. At other times, it has been an incredibly rewarding, fun and very stimulating task. Over the last years, I have encountered many fantastic people who have contributed to the making of this study; people who have challenged me, pushed me, encouraged me and provided me with insights and comfort, and people who have brought intense amounts of laughter into this process. I want to direct a special thanks to these individuals.

My warmest thanks goes out to all the people that I have interviewed during this study. This dissertation would not have been possible without you. To all the employees working with or in close relation to Smart Customer Gotland - thank you! I am enormously grateful that you took the time to answer my (occasionally confusing) questions, and that you openheartedly enlightened me regarding the promises and challenges of smart grids. I am especially thankful for all the informal occasions you invited me to! I also owe a great deal of thanks to all the individuals I interviewed in their role as prosumers or as participators in Smart Customer Gotland. Thank you for your inspiration and for showing me what civic engagement can look like. I am particularly grateful to all those individuals who invited me into their homes!

I also want to thank several people within academia. I could not have dreamt of a more supportive, engaged and encouraging main supervisor than Harald Rohracher. You turned the writing of this thesis into a task I took on with delight; your way of formulating critique made the most comprehensive rewritings feel manageable. Even with extensive piles of work on your desk, you always took the time to answer my desperate emails and carefully read through my drafts. I am 
especially grateful that you showed me how fun research can be; this book would not have been completed without you!

To Jonas Anshelm, my co-supervisor: your comments on how to structure a text have been invaluable during these years. You always say, "You think too much, just write!". It took me quite some time to realize what you meant, but I have learned to enjoy the power of putting words to my thoughts; you have taught me how to appreciate the process of developing a text over time. Jonas, I especially want to thank you for acting in my best interests in developing this thesis and for encouraging me through tough times.

To Vasilis Galis, my second co-supervisor: thank you for always being up for challenging theoretical discussions, no matter what time it was and no matter how contradictory my questions could seem. Also, thank you for hosting me in Malmö and Copenhagen; the months I spent there will always be very dear to my heart.

My PhD education was carried out within the Energy Systems Programme, which was financed by the Swedish Energy Agency. Within this interdisciplinary research programme, I learned a great deal about complex energy issues and had the opportunity to meet and exchange ideas with researchers from other disciplines and universities - discussions that were often very intriguing! I also want to thank Kajsa Ellegård for accepting me as a PhD candidate to this very inspiring $\mathrm{PhD}$ programme.

Thank you, Henrik Karlstrøm, Lotta Björklund Larsen and Dick Magnusson, for your encouraging words after having read the manuscript for my $60 \%$ seminar. Andrés Luque-Ayala did a thorough reading of the manuscript for my final seminar - thank you for challenging questions that pushed me to improve the text by "killing many darlings". Also, I give many thanks to the final seminar reading group: Thomas Berker, Jenny Palm and Josefin Wangel Weithz. Your insightful comments and recommendations guided me through the last months of finishing this thesis. 
During my time as a $\mathrm{PhD}$ candidate, I was part of two different seminar groups at the Department of Thematic Studies: the Environmental Humanities/Green Critical Forum and ValueS. I owe both of these environments sincere thanks for demonstrating the diversity of academic writing, for proving a safe harbor to test out unfinished ideas, for providing me with inspiration and for supportive comments on texts that were of varied quality over the years.

I owe thanks to the people who made academia a collegial, warm and caring environment; you made all the difference! I started my academic journey together with the PhD collective D-10. Réka Andersson, Maria Eidenskog, Linnea Eriksson, Mattias Hellgren, Linus Johansson Krafve, Lisa Lindén, Katharina Reindl, Hanna Sjögren and Josefin Thoresson: thank you all for making my time as a $\mathrm{PhD}$ a less lonesome experience. Sharing the many sides of academic life with all of you was tremendously important for me, and I am especially grateful for all our meetings outside Tema. Thank you, Lisa, Maria and Réka, for all the "pep lunches”. Being able to ask for your opinions on everything, no matter how trivial the issue might be, was often absolutely crucial for me. My dear friend Malin Henriksson, thank you for all the joyful writing days. Thank you, Hanna Sjögren, for your positive attitude and for inspiring me to indulge in unexpected turns of life! Thank you, Anna Morvall, for all the cheering text messages and for motivating me at crucial times. Thank you, Anna Kaijser and Ann-Sofi Kall, for being an inspiration for how to tackle academic challenges, for influencing my thinking and helping me unravel theoretical relations. Thank you, Jelmer Brüggemann, Jenny Gleisner, Hannah Grankvist, Lisa Guntram and Kristina Trygg for all the fika and for countless conversations about how to finish a thesis in the final stages of this work. Thank you, Fredrik Envall, for always being open to smart grid discussions - the fun has just begun! Also, thanks to everyone taking part in Tema T's writing Fridays group pressure at its best! 
Thank you, Daniel Andersson, Veronica Brodén Gyberg, Baki Cakici, Per Gyberg, Anders Hansson, Johan Hedrén, CF Helgesson, Martin Hultman, Francis Lee and Darcy Parks, for valuable and highly appreciated feedback on my texts at different times in this process. Lisa Lindén, thank you for your comments just before the final submission. Thank you, Technologies in Practice research group at the IT University of Copenhagen, for hosting me as a guest researcher in 2014.

I also want to thank some of my friends outside of the world of academia. Thank you, Daniella, Frida and My - you pull me down to earth and laugh with me when I get carried away in my academic ivory tower. Promise me that you will never stop challenging my views and providing me with other alternatives on the perspectives I take for granted. Thank you, Matlaget: Malin, Emin, Emmy, Gregory, Selma, Doris, Elin, Nisse, Mio, Love, Sabina, David, Nea and Vilma! I am forever grateful for the extended family you all provided us with here in Linköping. Thank you for sharing your everyday family life experiences with us, and for all the important talks about the essence of living a good life! During my time as a $\mathrm{PhD}$ candidate, I was part of a feminist discussion group. Thank you, Belen, Elin, Emmy, Hanna, Malin A, Malin H, Monireh, Sarah, Sepideh, Silje and Åsa: our joint ponderings enriched me tremendously. The life experiences of this circle of wise, strong and inspiring individuals taught me so much and motivated me to carry on with this study.

Also, I want to thank my family. Thank you, mum, AnnKatrin, for being my feminist source of inspiration and for teaching me girl power at an early age lessons that were indispensable in academic life! Thank you for being a playful grandma to my children and for always being there for me. I also want to thank my mother-in-law, Eljena, for your endless efforts taking care of my children in the final stages of this work; it has been delightful seeing them grow near to you and the ways you bring joy, laughter, gravlax och croissanter into their lives. 
Björn, thank you for sharing this academic journey with me! Thank you for giving me strength when I was lacking. Thank you for caring about me and our family when I had to care about finishing this book. Vilhelm and Sixten, thank you for letting me experience life as it is through your eyes - what a bliss! You taught me more about life than any academic study ever could. You have had a mum writing on her thesis for the whole of your lives, but no longer. Now I long for Vibyhyttan, let us all play Blokus and drink hot chocolate in front of the fire. Let's open the window and let the sound of the creek pour in. 

Smart grids deserve more attention, not least because they contain an important part of the answer to how we should achieve a sustainable energy supply, how our welfare can be developed and how we can achieve our environmental and climate ambitions. (Former Swedish IT and Energy Minister, Hatt, 2012)

Smart grid is a buzzword that has arisen since suppliers of equipment think this is hip, dressing products up in a smart grid suit is a new way to sell, or a new concept to sell. The suppliers have taken advantage of this in order to launch hip and publicly funded projects in order to promote new products. That's what it's all about. (Interview, utility middle manager, Smart grid demonstration project, 2013)

\section{Introduction}

"Smart grid" is a combination of words that frequently are part of visions about the future energy system. Powerful international organizations, governments, local authorities and commercial actors proclaim the need for an updated energy alternative and urgently advocate the installation of smarter grids. The European Commission (2006) envisions smart grids as the "electricity networks of the future", and the US Department of Energy claims that they represent an "unprecedented opportunity to move the energy industry into a new era" (US Department of Energy, 2017). Similar expectations of smart grids can be seen in countries such as Australia, China, South Korea, India, Brazil and Japan (Giordano et al., 2011), and Sweden follows the same tendencies. In 2012, the former Swedish IT and Energy Minister established the Swedish Coordination Council for Smart Grid with the assignment of facilitating a Swedish smart grid implementation (Government Office of Sweden, 2012) and creating an action plan with the overall vision that "Sweden is a smart grid leader" (Swedish Coordination Council for Smart Grid, 2014a:33). In the written motivations behind this initiative, Sweden was positioned against other countries with similar ambitions: "Sweden has a chance to become a 
winner when it comes to tomorrow's energy technology. Let's take that chance." (Hatt \& Khorsand, 2012). In this way, smart grids were positioned as a watershed between the winners and losers of tomorrow. With phrases such as, "the future is not here yet, but we can imagine it” (Hatt, 2012 ), a Swedish smart grid was frankly presented as the future energy system.

There are various reasons for why smart grids receive so much attention. They are ascribed with the potential to provide solutions to one of the major challenges society is facing on a global scale: the transition to a more sustainable society through a large-scale introduction of intermittent energy sources such as wind and solar energy. There are different applications and approaches to smart grids; however, in Western industrialized countries, their establishment is frequently motivated by the perspective that the introduction of such energy sources will pose challenges to the current electricity system. For a long time, these countries have relied on a configuration in which electricity is produced in large-scale and centralized facilities, which can adjust production to meet consumption demands. In such a system, electricity flows in one direction: from production units to endusers (Swedish Coordination Council for Smart Grid, 2013a). This traditional arrangement is challenged by the introduction of intermittent energy sources since their capacity cannot be steered but rather varies during the day and over the year. Furthermore, these renewable energy sources tend to be much more distributed in space, and therefore require electricity to be able to flow in different directions - in contrast to today's arrangement (Wolsink, 2012).

One way to cope with these challenges is to reinforce the grids that often were installed decades ago, with new cables and lines that can carry more electricity (Verbong, Verkade, Verhees, Huijben, \& Höffken, 2016). However, such reinforcements are often presented as an expensive and inefficient solution, and influential actors instead promote the installation of a smart grid. The International 
Energy Agency argue that the "development of smart grids is essential if the global community is to achieve shared goals for energy security, economic development and climate change mitigation" (International Energy Agency, 2011:5). Smart grids are by their supporters regarded as an economically sound solution that can enable a secured electricity supply and sustained electricity quality (European Regulators Group for Electricity and Gas, 2010). Smart grids are thus embedded in discourses of climate change, economic growth and energy security (Luque, McFarlane, \& Marvin, 2014).

A smart grid transition does not only entail purely technical reconfigurations of the electricity system; it also entails various types of social change, in which an altered role for electricity users may be the most challenging. Future electricity users are not only imagined as becoming their own electricity producers, so called prosumers, they are also supposed to store electricity in electrical vehicles and adjust their consumption to meet production patterns (Swedish Coordination Council for Smart Grid, 2013a). Smart grid stakeholders thus position users, and primarily households, in a pivotal position within the smart grid. In this sense, users are expected to transform from a traditional passive role into a role in which they engage with the electricity system more actively (Mah, van der Vleuten, Hills, \& Tao, 2012). However, little is known on how to enable residential users to actively participate in smart grids (Geelen, Reinders, \& Keyson, 2013:152). Katzeff and Wangel (2015) also note, visions about the smart grid future rarely discuss households' opportunities or willingness to make the suggested changes. The success and characteristics of the future smart grid will inevitably depend on whether users accept these changes in their homes and daily practices (Verbong, Beemsterboer, \& Sengers, 2013). Households thus appear to have a prominent role in conceptualizations of the future smart grid; however, the question of exactly what role they are able and willing to play is far from certain. 
In this thesis, I follow the process in which a Swedish smart grid is assembled. I study the making of a smart grid as a socio-material practice and examine how national imaginaries, logics and interests are mobilized and enacted in this process. In particular, I investigate how households are enrolled and actively participate in achieving a functional smart grid. In this introduction, I begin with a brief conceptualization of smart grids, and then present the role of demonstration projects as arenas that set the direction for future smart grid configurations. Next, I present the purpose and research questions that have guided my work, followed by a summary of previous research, in relation to which I position this study. The chapter ends with a description of the chapters of this thesis.

\subsection{Smart grid as a multifaceted enabler in the making}

Despite the amount of attention that is directed towards smart grids, there is still a high degree of uncertainty regarding what the concept of a smart grid actually means. Even though the potential impact of "smartening" the electric grid is described as enormous, and the expectations of what such an intervention might achieve are even greater, no general definition exists that indicates how smart grids should be understood. As the opening quotes of this chapter imply, smart grids mean different things to different people. While the former Swedish IT and Energy Minister implies that smart grids are a sustainable necessity Sweden cannot live without, the quoted utility middle manager working with smart grid implementations argues that smart grids are commercially driven by actors who are interested in selling products labelled as environmentally friendly, while not really promising anything other than traditional solutions. Smart grids are thus connected to different connotations: they mean "many things to many people" (Hledik, 2009:30) and are characterized by a large degree of interpretative flexibility (Christensen Haunstrup, Gram-Hanssen, \& Friis, 2013). Smart grids are soaked in various promises and, as an anticipated saviour to numerous problems, they appear 
as "jack(s) of many trades" (Skjølsvold, Ryghaug, \& Berker, 2015:1). Although the meaning of smart grids can differ both within and between countries, certain aspects reoccur in many of the descriptions. In general terms, a smart grid can be understood as a digitalized electricity grid, meaning that the current electric grid becomes "smart" as it is interlaced with ICTs that add intelligence to the "dumb" grid (Nyborg \& Røpke, 2013; Verbong et al., 2013; Wissner, 2011). In this sense, the smart grid relates to the current electricity grid as a smart phone relates to a traditional phone: both are ICT-enhanced versions of their predecessors. Others, however, stress the importance of not regarding smart grid intelligence as something that is restricted to technologies alone; rather, they claim that people are the only entities that are entitled to be called smart (Honebein, Cammarano, \& Boice, 2011). Such a standpoint thus emphasizes the role of humans in smart grids, and implies that the smart grid is not only a technical upgrade but also a new sociomaterial configuration.

Following from this, smart grids can be understood as a large infrastructural endeavour that influence all entities that are connected to the electric grid, including users, markets and homes, making the smart transformation of the grid into a socio-material project with far-reaching societal implications. In other words, smart grids can alter current relations between actors in the energy system and entail fundamental alterations of its social dimensions. In particular, smart grid stakeholders envision the role of electricity users to be altered (Goulden, Bedwell, Rennick-Egglestone, Rodden, \& Spence, 2014). Having said that, it is not yet clear what role they will play, and what the smart grid future will entail (Verbong et al., 2016). Stephens, Wilson, and Peterson (2015) have illustratively described the smart grid as a concept that holds many meanings: for some, it signifies a "technological nirvana" while for others, it is a "revolutionary social movement". Others attach less radical changes to this term suggesting that smart grid is just a way of maintaining current system configurations, or regard the smart grid as an 
"empty signifier" due to its extensive but imprecise implications (Stephens et al., 2015:186f). The enactment of smart grids is thus an open, contested and political process in which social relations between actors such as utilities, grid owners, households and so forth are at stake.

In the past, imaginaries and promises of technological change have most often turned out otherwise. Smart grids are still at a very early stage of development, and a multitude of actors with various interests are involved in shaping what smart grids will become in the future. However, there are ongoing attempts to turn these prospects into a materialized form in the present and thereby close down alternative future pathways of smart grid development.

\subsection{Demonstration projects lay the foundation for the future}

Large-scale demonstration projects ${ }^{1}$ are currently used as the main instrument to achieve limited implementation of smart grids and lay the groundwork for further roll-outs and up-scaling. For example, a report of the European Commission's Joint Research Centre lists more than 450 European smart grid projects with a total budget of $€ 3.15$ billion, and expects these numbers to continue to increase (Covrig et al., 2014). At the same time, the United States has established an Energy Act $^{2}$ that has financed almost 100 smart grid projects with a total budget of $\$ 8$ billion (US Department of Energy, 2016). Influential smart grid actors assign a great deal of hope to such projects. The European Commission claims that "smart grid (SG) projects are playing a key role in shedding light on how to move forward in this

\footnotetext{
${ }^{1}$ The terms "pilot projects" and "demonstration projects" are often used interchangeably. However, demonstration projects are often larger and tend to focus on the implementation and demonstration phases of smart grid configurations. Pilot projects, on the other hand, are primarily focused on configurations that are more premature, such as tests before market introduction. Given these slight differences, I use the term demonstration project in this thesis.

2 The Energy Act can be found at: https://www.energy.gov/sites/prod/files/oeprod/ DocumentsandMedia/EISA_Title_XIII_Smart_Grid.pdf
} 
challenging transition" (Giordano et al., 2011:10). The Swedish case follows a similar pattern, as the national smart grid action plan describes demonstration projects as arenas for the development of the next generation's electricity grids (Swedish Coordination Council for Smart Grid, 2014a:206).

In this way, these demonstration projects have the task of consolidating the design and meaning of smart grids by narrowing down sprawling, fuzzy or even inconsistent ideas into functional configurations. In other words, their objective seems to be to translate the smart grid as a "partially existing object" (Schick \& Winthereik, 2013:83) into a concrete and tangible form, and reduce the extent to which they appear as a catchphrase with "a lot of secrets" (Wissner, 2011:2509). In this thesis, I do not regard the making of smart grids as the mere implementation of a concept or an idea, nor as the successful execution of new technology. Instead, I engage with demonstration projects as arenas in which ideas about the smart grid future congeal into functional socio-material configurations. Smart grids are established through processes that entail complex interactions between various actors and that involve negotiations of, for example, which problems should be resolved, which technologies should be included and which users are appropriate to invite as participators.

In this thesis, I follow the way in which a smart grid unfolds in practice within a large-scale Swedish demonstration project, and I examine the various tensions that arise in the process of making this smart grid functional. My focus is motivated by the fact that Swedish authorities have given demonstration projects the mandate of influencing which socio-material configurations work and which do not. In other words, the outcome of these demonstration projects will guide the future setup of Swedish smart grids; these projects contribute to the stabilization of certain alternatives in favour of others, and thus set the direction for future smart grid configurations. 


\subsection{Purpose and research questions}

The purpose with this thesis is to describe and analyse the process of assembling a smart grid within a Swedish demonstration project. I explore smart grids as an unfolding socio-material practice, that is, I follow how smart grids are made, and how such a process depends on historical contexts, visions about the future and actor interests. I also shed light on how this process is shaped by materialities such as technical appliances and buildings in which smart grid technologies are installed. In particular, I engage with the roles of smart grid users living in households; I explore the tactics used in enrolling users, the socio-material practices users become part of, and their expectations and material engagements. The main research question guiding this thesis is:

\section{How are smart grids assembled through demonstration projects?}

More specifically, I ask:

How does a smart grid configuration emerge within the demonstration project under study? What negotiations and struggles are at play when making the smart grid functional within the project?

What national imaginaries of the smart grid future are dominant in Sweden, and how are they evoked and mobilized by the project actors?

What user roles are favoured in the demonstration project and what user engagements are encouraged? How is the project framed as appealing for users?

How do users who participate in the project legitimize their engagement? How do they make sense of and use the smart grid technologies? How do excluded users define attractive smart grid configurations? 
By exploring these questions, I seek an enhanced understanding of how smart grids are made, of the different forces that shape this process and, ultimately, of the reality of Swedish households as part of a smart grid in the making.

\subsection{Previous research}

Smart grid studies have primarily been an area for technically oriented research questions, even though social scientists have begun to engage with the societal and political implications of these solutions. In recent years, several special issues have been published that focus on the social dimension of energy issues and infrastructures, and that especially deal with smart grid technologies. Nevertheless, the social science of smart grids is still a novel and emergent research field. In this section, I will briefly present some of the literature that is relevant for my study. As such, this brief review should not be understood as encompassing all previous social science research on smart grids; rather, I have chosen literature that is of relevance for this specific thesis. In a broad sense, I situate this study at the intersection of smart grids and Science and Technology Studies (STS); however, since this is not a research field with neat borders, I have included studies within adjacent areas that are important for this study. In particular, this thesis is related to previous research focusing on the smart grid household - a topic that has been explored from different perspectives, and that I will now describe.

\subsubsection{Imaginaries, visions and expectations}

The first strand of literature from which I position this thesis includes studies on how influential actors such as experts, authorities or developers imagine the smart grid future. This literature often relates to the research area Sociology of Expectations (Borup, Brown, Konrad, \& van Lente, 2006; Brown \& Michael, 2003; van Lente, 2012; Van Lente \& Rip, 1998) or draws on concepts such as 
sociotechnical imaginaries (Jasanoff \& Kim, 2009, 2013). These studies conceptualize visions, imaginaries and expectations about the smart grid as performative, in that future prospects influence the making of the future. Moreover, these studies show that smart grid prospects are based on a national context including historical, institutional and cultural dynamics (Ballo, 2015; Skjølsvold, 2014). In this study, I make use of these findings as I explore the characteristics of future smart grid societies as evoked in Swedish strategy and planning documents, and conceptualize these notions as laying the groundwork for the kinds of smart grid that can be constructed within a Swedish smart grid demonstration project. There are a few studies that have been particularly influential in my research on smart grid futures. For example, Vesnic-Alujevic, Breitegger, and Pereira (2016) based their work on an analysis of EU policy initiatives and interviews with smart grid stakeholders, and examined the smart grid future as a sociotechnical imaginary. They describe how these actors considered the smart grid as a project that would solve economic growth, energy security and sustainability challenges, and would thus serve the public good. However, the study concludes that the role of citizens in the smart grid needed to be examined further. Ballo (2015) is another example of a paper in the same field and analysed the smart grid future as a sociotechnical imaginary. She examines how the future is expressed by Norwegian authorities and experts, and finds that their imaginaries have a utopian character that is primarily focused on technological and economic aspects, and that these imaginaries also entail the construction of users. Ballo identifies a sociotechnical smart grid imaginary in which users are active consumers, intermittent energy sources are smoothly introduced, automatic solutions are commonly adopted and security of supply is rigorously handled. She further argues that in their desire to create this future, these influential actors communicate an idealized smart grid version to users that may be far from realistic. Ballo argues that this is an awkward strategy that can create alienation problems. Skjølsvold (2014), a study also 
conducted in a Norwegian context, makes use of the Sociology of Expectations (Borup et al., 2006; Brown \& Michael, 2003). Skjølsvold attends to the Norwegian debate of the smart meter implementation from a retrospective. He discusses how expectations about the future influence policy outcome and finds that such expectations can initiate debates and legitimize recommendations for regulatory frameworks.

Previous research about who will use smart grid technologies in the future is of particular importance for this thesis. STS have a long tradition of examining the relation between technology design and future users, and have suggested that designers develop technologies with certain users in mind and that these technologies influence users' behaviours and actions (Akrich, 1992; Woolgar, 1991). An increasing number of studies engage with the role of users in the smart grid future. A frequent critique found in these studies is that prospects about the smart grid future are often informed by a techno-economic approach based on the assumption that as long as the right technologies are implemented, they will enable economic savings for users (Mah et al., 2012; Verbong et al., 2013). These visions thus include the idea of a neoliberal individual who is primarily motivated by economic motives. Within such assumptions, electricity is primarily presented as an economic issue - at the expense of other matters that could be of importance for people (Throndsen \& Ryghaug, 2015). In this way, people are predominantly referred to as "consumers" or "customers" in energy policies and research literature, rather than as "citizens" or "the public". These words have implications for what kinds of engagement are expected of people in the future energy system (Cotton \& Devine-Wright, 2012; Heiskanen, Matschoss, \& Repo, 2015).

One of the more influential scholars that explores how smart grid users are imagined by smart grid stakeholders is Strengers (2013). In her book about smart grid technologies in everyday life, she analysed international research reports 
conducted by actors from governments, energy utilities, technology providers or academics. She put forward the notion of a future energy consumer who is conceptualized as a "Resource Man - a data-driven, information-hungry, technology-savvy home energy manager, who is interested in and capable of making efficient and rational resource management decisions" (Strengers, 2013:51). Of particular importance for my study is her perspective of this imagined user as embodying both activeness and passiveness, as the user both passively assigns management to automatic technologies, and actively engages with resource management tools (Ibid: 32).

This perspective aligns with findings from Mah et al. (2012) who show that the most prevalent vision among smart grid stakeholders is that today's passive electricity users are expected to transform into well-informed, active, rational and price-responsive consumers. Verbong et al. (2013) engage with imagined smart grid users using similar conceptualizations, in a paper that is based on interviews with stakeholders from the smart grids field and the energy sector, as well as on an inventory of ongoing smart grid projects. That study finds that these actors expect users to engage more actively with energy in the future, and express a firm belief that economic incentives will encourage such behaviours. This conclusion resonates with arguments made by Ghanem and Mander (2014), who depict how smart grid households are envisioned by designers and engineers, and who report on their attempts to realize smart grid technologies in a European large-scale R\&D project. Through the analytical lens of the Sociology of Expectations, Ghanem and Mander describe how developers envision users in an idealized environment, where their needs are catered for through the use of home automation, and believe that users, encouraged by price signals, will act "rationally". 


\subsubsection{Making smart grids functional: experiments, trials and tests}

The second research field I situate this study in relation to comprises studies of how smart grids are materialized; such studies are often carried out on smart grid rollouts in household settings and report from smart grid demonstration projects. There are different ways to conceptualize demonstration projects. One way is to view them as arenas within which technological performances are tested - that is, as a "finite initiative to test hypotheses about a technology" (Karlström \& Sandén, 2004:287). From an innovation perspective, demonstration projects can be conceptualized as representing "bridges between generating basic knowledge and technological breakthroughs on the one hand, and industrial applications and commercial adoption on the other" (Hellsmark, Frishammar, Söderholm, \& Ylinenpää, 2016:1743). Others present them as associated with the potential to create innovation for the common good (Brown \& Hendry, 2009).

This viewpoint seems to imply that smart grid demonstration projects can be understood as objective incubators that can generate solutions for the general public - solutions that can be scaled up and implemented more widely. However, STS with a long tradition of analysing the role and setup of tests, experiments and trials propose alternative conceptualizations: that such arenas cannot be regarded as neutral; and that the facts produced in this way are not the output of unbiased experiments, but are rather the result of co-constructive processes of technological equipment and social practices (Latour \& Woolgar, 1986). Thus, public demonstrations can be conceptualized as political, in the sense that they are intended to affect people (Barry, 2001:178). In addition, since public demonstrations influence the kinds of roles users have in relation to a specific technology, they reconfigure socio-material relations (Marres, 2009). Smart grid demonstration projects thus operate at the intersection of technology and politics since they establish certain configurations above others (Grandclément \& Nadaï, 
2015). I make use of this notion in this study, as I follow the way in which a smart grid is put in place in a smart grid demonstration project, and conceptualize this project as laying the groundwork for future smart grid implementations.

Some previous studies have explored the undertakings that occur within such projects, and have followed the engagements made by professionals such as designers, developers or engineers. Some of these studies summarize reviews of several ongoing smart grid projects. For example, Gangale, Mengolini, and Onyeji (2013) used questionnaires to study ongoing European smart grid projects, with the aim of presenting a snapshot of these projects' strategies for involving consumers. Christensen Haunstrup et al. (2013) note that because a smart grid carries different meanings, it generates conflicting tendencies of how to design technologies; as a result, different solutions are based on different conceptualizations of households and their interests. That study shed light on the activities that were performed in Danish smart grid projects, and discussed how these solutions could guide the everyday lives of people and how they could influence the smart grid. Christensen Haunstrup et al. showed that such activities often have contradicting implications: some smart grid stakeholders argue for active participation, which generates solutions with continuous information about real-time prices; and others argue for solutions with as little active participation as possible, such as remotely controlled devices.

Skjølsvold and Ryghaug (2015) also explored smart grid projects with a comparative approach, and reported from four different Norwegian smart grid demonstration projects. Through interviews and on-site visits, they examine how smart grids are developed on a household level. Skjølsvold and Ryghaug illustrate how a smart grid is not a "silver bullet" that can solve all issues; nor does it comply with the idea of "one model fits all". Rather, they show that a smart grid is a situated technology, and that the social, political and physical landscapes shape what the 
smart grid becomes in each specific case. These researchers describe how smart grids are interpreted and materialized differently in various projects. In contrast to such comparative approaches, I will follow one smart grid project in depth and explore the undertakings in this specific case. A few similar studies are particularly worth mentioning for my research. For example, Skjølsvold and Lindkvist (2015) followed a micro-grid project in Germany and Italy, and described a project that was characterised by ambivalent and paradoxical user perceptions. They investigated a process in which the technology developers had the initial ambition to include users in the design work, a strategy that was abandoned, as the project proceeded. They showed that the developers initially expressed their opinions of users as being skilled, price sensitive and techno-savvy, but eventually argued that they could not invite users to influence the technology as they perceived them to be deficient and incompetent. Following this specific case in detail, Skjølsvold and Lindkvist showed that notions of users guided the design process: ideas of giving control to users were rejected because that would allow them to engage with the technologies in ways other than those envisioned by the designers.

Nyborg \& Røpke (2013) reported on an in-depth exploration of a smart grid demonstration project taking place in Denmark, and described how users are simultaneously constructed during the process of envisioning and testing smart grid technologies. They conceptualize smart grid demonstration projects as a way to construct and normalize smart grid trajectories and as a way to open up the "black box" of households' role in smart grids. In this thesis, I also engage with one specific smart grid demonstration project and follow the undertakings performed by those who are employed to make the smart grid functional. I follow a request from Schick and Gad (2015), who urge social scientists to be attentive to the critiques formulated by smart grid stakeholders, as I follow the actors involved in a smart grid demonstration project and explore the tensions, difficulties and doubts that these actors articulate in the process of assembling a smart grid. 


\subsubsection{Smart grid households' engagements, desires and practices}

The final strand of literature that this study relates to, is grounded on discusses whether households actually have the potential, aspiration and willingness to engage with smart grid technologies. Some studies within this literature ask questions about acceptance, and focus on what incentives motivate households to engage with smart grid technologies (Bartusch, Juslin, Persson-Fischier, \& Stenberg, 2014). Other studies analyse smart grids from a practice-based perspective: they explore the relation between everyday practices and smart grids (Bell et al., 2015; Katzeff \& Wangel, 2015); investigate what it is like to live in a smart home, using theories of domestication (Hargreaves, Hauxwell-Baldwin, \& Wilson, 2017); or combine domestication theory and practice theory with innovation studies (Nyborg, 2015).

Research on how people practically use technologies is often positioned against the "deficit model", which has traditionally been used to explain why people do not engage with energy issues. This model is based on the assumption that if people receive more information, they will change their attitudes, behaviours and choices (Shove, 2010). In contrast, practice-based studies suggest a focus on the kinds of socio-material systems that enable or disable certain practices above others; such studies thus focus on the collective features of practices rather than on the individuals who perform them. Instead of asking questions about how "people's behaviour can be changed", these studies encourage smart grid designs to not only regard people as electricity users, but also regard them as humans who are busy with everyday practices (Katzeff \& Wangel, 2015). Yet another kind of literature that explores smart grids from a household perspective engages with households' expectations and material engagements. These kinds of studies are highly relevant for my thesis, as they focus on how households make sense of their role in the future energy system, and recognize that electricity consumption is also a political 
endeavour, with implications beyond the walls of the home. Bertoldo, Poumadère, and Rodrigues Jr (2015) examined the meanings and representations that are articulated when people who are part of a smart grid demonstration project express their experiences with the technologies. Through focus group interviews with French communities where smart meters had been installed, these researchers found individuals who conceptualized their engagement as highly political. They concluded that these devices are not simply technical, but can also be conceptualized as "socially invested objects" and "public policy tools".

Throndsen and Ryghaug (2015) attended to users who participated in a Norwegian smart grid project. Through focus group interviews, that study illustrate how the users articulated different modes of material engagement. Making use of Marres' (2012b) notion of "material publics", they combine the idea of people as "informed citizens" with the idea that people engage with technology in order to actively make a difference. In this sense, these researchers conceptualize individuals as having the ability to express the societal implications of their smart grid engagements. The study conclude that some people are open to being constructed as materially engaged citizens, and encourage initiatives that invite users to discuss the policy and technology design of the smart grid they are involved with. These researchers share this finding with Schick and Winthereik (2013), who argue for smart grid configurations that recognize people as politically motivated citizens. In the last empirical chapter of this thesis, I continue along this path of smart grid research as I explore the meanings households that participate in a smart grid demonstration project attach to smart grids.

Although the research described in this thesis builds on the literature reviewed above, it also goes beyond them by studying the emergence of a smart grid in a Swedish demonstration project from different angles. I study this process by 
viewing the smart grid as an imaginary, as assembled through socio-material practices in a demonstration project and as a material engagement in households.

\subsection{Structure of this thesis}

In this last section, I will explain the outline of the chapters that constitute the remainder of this thesis. In Chapter 2, Theoretical framework, I introduce and explain my theoretical approach. I situate this study within material-semiotics and draw on concept such as translations, sociotechnical imaginaries and material participation. Chapter 3, Methods and material, comprises a description and motivation of the methods I have used to gather and analyse material for this study. In this thesis, I have combined interviews and participant observations with document analysis. In this chapter, I also provide information about the actors behind the material, and discuss methodological implications. I then move on to the empirical section of this thesis. Chapter 4, Smart Grid Gotland: Shaping the future of Swedish smart grids, is an introduction to the demonstration project under study. In this chapter, I introduce the actors behind the project, its purpose, how it was set up and where this was done. This chapter primarily serves as a contextualization for the upcoming empirical chapters. In Chapter 5, Swedish sociotechnical smart grid imaginaries, I describe the current Swedish energy system and analyse notions of smart grid futures as evoked in Swedish smart grid strategy and planning documents. I conceptualize these imaginaries as influencing the kind of smart grid that was possible to construct within the demonstration project. In Chapter 6, Making smart grids work: A process of exclusions and inclusions, I follow negotiations, exclusion versus inclusion mechanisms and tensions that occur in the process of putting a smart grid together within the demonstration project under study. I examine the narratives told in the recruitment campaign of this project, and I analyse how the project was framed as appealing for potential participators and what tensions this framing resulted in. In Chapter 7 , 
Becoming a smart grid household, I attend to the users that participated in the project and analyse how they motive their participation, their expectations of the smart grid and how they engage with the smart grid technologies. I also attend to actors that represent user roles that were excluded from the project, and analyse what they expressed as desirable smart grid configurations. In the final chapter, Chapter 8, Concluding discussion, I present a condensed version of the findings presented in the empirical chapters and some of the themes that have reoccurred throughout this study. I discuss how a smart grid emerged within the smart grid demonstration project, and the tensions, doubts and contradictions that appeared in this process. The chapter ends with comments on certain issues that I in particular would like to stress as important for taking smart grids forward. 



\section{Theoretical framework}

In this chapter, I introduce and explain the theoretical framework that has helped me to see and articulate relations I otherwise would not have been able to identify; I also define the body of theoretical concepts that underpin my analysis. It starts with an introduction to the overall analytical perspective guiding my research: materialsemiotics, which is a wide take on the formation of socio-material relations. Material semiotics focuses on how the material and social aspects are jointly arranged and re-arranged, and pays particular attention to which relations are enabled and maintained, and which are not (e.g. Akrich \& Latour, 1992; Law, 2009). The key essence of material semiotics is that objects, such as smart grids, cannot be reduced to only a material component, but are rather enacted within a particular context by particular people who are engaging with particular practices. The word "enacted" implies that reality is performed rather than observed (Gad \& Jensen, 2010). Inspired by this perspective, I view everything in the social and natural world as effects of the relational webs in which they are located (Law, 2009:141f). This means that a smart grid is not constructed in isolation, but is rather given meaning through written text and through visual and material components. These elements cannot be separated without losing meaning; they are all entangled and intrinsically dependent. As I analyse smart grids from a material- 
semiotic perspective I draw on Actor-Network Theory (ANT). Despite its name, ANT is not a theory in the traditional sense; rather, it is an approach that focuses on the relations between humans and non-humans. Law (2009) describes ANT as a diverse family of various material-semiotic tools, sensibilities and analytical methods:

Like other material-semiotic approaches, the actor-network approach thus describes the enactment of materially and discursively heterogeneous relations that produce and reshuffle all kinds of actors including objects, subjects, human beings, machines, animals, 'nature', ideas, organisations, inequalities, scale and sizes, and geographical arrangements (Law, 2009:141).

It is essential for a stable network, that is, a socio-material configuration, that all human and non-human entities have assigned roles or, in other words, " $d o$ something and don't just sit there" (Latour, 2005:128 orginal emphasize). ANT approaches everything that can make a difference and thus acts, as an actor. This means that actions can be performed by assemblages of humans and non-humans that together make up a new actor (Latour, 2005). In this sense, actors are brought into being and are realized as they are enacted in practical activities (Woolgar \& Lezaun, 2013). In this way, the particular entities themselves are not focused on in ANT, but rather the relations between them; in Latour's words, "[r]eally, we should say 'worknet' instead of 'network'. It's the work, and the movement, and the flow, and the changes that should be stressed" (Latour, 2005:143). In this thesis, I am inspired by ANT as a toolkit for telling stories of how associations and connections are established between human and non-human entities, or for how these actors assemble into heterogeneous webs of relations (Law, 2009:141f). This perspective inspired me to engage with smart grids as an infrastructure in the making, and to approach the human and non-human components of this infrastructure as intimately connected. In other words, I engage with smart grids as a socio-material configuration that is built up by various components that cannot easily be separated 
from one another without losing meaning. Smart grids, like any other technology, "participate in the social world, being shaped by it, and simultaneously shaping it" (Law, 2004:12 original emphasis). This means that the making of smart grids not only entails the arrangement of technological components, but also entails the construction of social entities and, in particular, the making of relations and linkages between various elements. In this process, social and material entities are brought into coexistence. Based on this general analytical conceptualization, I will now introduce the theoretical concepts that form the basis of this thesis.

\subsection{Translations}

Translation is a key concept within ANT for understanding how entities are merged into coexistence. In ANT, translation refers to the process in which a sociomaterial configuration is established, which involves individual elements becoming interconnected. In the words of Callon (1986:224), "Translation is the mechanism by which the social and natural worlds progressively take form. The result is a situation in which certain entities control others." As Callon points out, elements are made and remade in a translation process; they are defined, ordered, and constructed to relate to one another. Translation thus involves alteration: It is "about moving terms around, about linking and changing them" (Law, 2009:144). By attending to translations, I trace how seemingly unrelated elements become associated, are merged together, and are given meaning as parts of a smart grid.

Callon (1986) suggests that the process in which a socio-material configuration is established can be analysed using four analytical stages. However, Callon emphasizes that these stages are not easily separable; rather, they are often highly intertwined. The first stage, problematization, involves the identification of a problem that those who set up the configuration - the network builders - argue that they can resolve. In this stage, elements that should be part of the emerging 
configuration are identified and made relevant to each other. This process also involves the establishment of an obligatory passage point, which is the core of the configuration that all other elements need to relate to. In this central position, the network builders often either place themselves or a specific assemblage that appears to be indispensable for the identified problem to be resolved and for the configuration to be formed. As a direct consequence of defining what is problematic, other issues are simultaneously dismissed as being of less importance; in other words, "whole sections of reality are pushed into the shadows" (Callon, 1981:209). The problematization stage thus defines not only those who are included in the configuration but also the excluded; for "every constructed 'obligatory passage point' there can be a number of 'points of irrelevance' that thwart actors in their desire to define a problem” (Galis \& Lee, 2014:160). In other words, when the network builders define what is problematic, they prioritize certain issues above others, and when they define which entities should be part of the solution, they simultaneously exclude alternatives.

The second stage, interessement, involves the network builders' attempts to enforce and stabilize the identity of the elements they want to include in their configuration. These attempts are based on certain ideas of what these entities are, what they want and what other elements they are connected to. When entities become interested in forming a network, that interest simultaneously weakens their links to other configurations that would potentially define their role, interest and motivations differently. Interessement is thus a process of transforming desires and goals; in other words, "[t]o translate is to displace" (Callon, 1986:223).

If the network builders succeed with the interessement, the translation process evolves to the next stage: enrolment. In this stage, the actual socio-material configuration is established. Entities can be enrolled in different ways, such as through force, seduction or consent without discussion. The final stage involves the 
mobilization of allies, which means that the network builders try to standardize their configuration. This stage raises questions about the generalizability of the enrolled elements, as it is necessary to evaluate whether they can live up to the condition "[t]hat which is true for a few is true for the whole of the population" (Callon, 1986:214). In the empirical parts of this thesis, I make use of these analytical stages to unpack how a smart grid emerges within a smart grid demonstration project. I will trace the aspects that the people in charge of setting up the smart grid define as problematic, along with the inclusion and exclusion mechanisms at play when these network builders decide which entities to base their smart grid on. I will attend to their strategies to interest and enrol entities in the smart grid, and I will ask questions regarding whether the configuration established within this demonstration project can become a role model for future smart grid configurations.

Since translation processes establish relations between human and non-human entities, they cannot be regarded as neutral. As Callon (2007a) points out, different socio-material configurations are related to different possible worlds; out of all the alternatives that were once equally possible, only a small number prevail. This decline in alternatives results in sociotechnical lock-ins that lay the ground for trajectories of future solutions, leaving many desires, demands and expectations unfulfilled (Callon, 2007a). This means that to establish a specific socio-material configuration is to favour certain futures at the expense of others. Since a smart grid is a socio-material configuration in the making, it is reasonable to suspect that the smart grid versions that are established today will lay the ground for future alternatives. In this thesis, I also argue for the opposite relation: namely, that the future sets the direction for what is made possible today. The smart grid that emerges within the demonstration project does not rise in isolation; rather, I conceptualize this process as being guided by notions of what smart grids can become in the future. Such notions constitute normative agendas for smart grid 
implementations and function as a frame in which the smart grid demonstration project operates. To unpack the smart grid future, I turn to the concept of sociotechnical imaginaries.

\subsection{Sociotechnical imaginaries}

Paying attention to the notions that influential smart grid stakeholders attach to smart grids permits an exploration of what kind of configuration was deemed possible within the demonstration project. Here, I draw on the concept of sociotechnical imaginaries as defined by Jasanoff and Kim (2009; 2013). Sociotechnical imaginaries combine "the normativity of the imagination with the materiality of networks" (Jasanoff, 2015:19) and are in that sense connected to translations. Unlike translations, however, sociotechnical imaginaries operate on a different scale, as they link the future with the past. Whereas translations cannot easily capture the belief systems out of which materialities emerge, sociotechnical imaginaries acknowledge that the past and the future are powerful influencers of what is materialized in the present (ibid).

Jasanoff and Kim engage with the future as a sociotechnical imaginary, described as "collectively imagined forms of social life and social order reflected in the design and fulfillment of nation-specific scientific and/or technological projects" (Jasanoff \& Kim, 2009:120). According to such a view, technological projects such as the smart grid are embedded in ideas of what kind of society suits the particular technology in a specific country. Sociotechnical imaginaries "operate for us in the understudied regions between imagination and action, between discourse and decision, and between inchoate public opinion and instrumental state policy" (Jasanoff \& Kim, 2009:123). They thus occur in the phase before final decisions are made - before ideas consolidate into concrete state policies. In that sense, imaginaries are related to policies; however, they are much vaguer than policies 
because they are not as explicit, instrumental or goal-oriented. They also lack the same degree of political liability and are not as concentrated on specific issues (Jasanoff \& Kim, 2009). In this thesis, I use sociotechnical smart grid imaginaries as an umbrella term for what kinds of notions of the future smart grid society that are evoked in Swedish strategy and planning documents. I also describe the Swedish energy system that these imaginaries build on.

Sociotechnical smart grid imaginaries have a normative stance, in the sense that they entail expectations of what the smart grid can enable in its full potential; in other words, they involve ideas about what a smart grid utopia could look like. In this way, imaginaries "project visions of what is good, desirable, and worth attaining for a political community; they articulate feasible futures" (Jasanoff \& Kim, 2009:123). Such ideas of the future are frequently produced by a society's elite, who infuse these notions with their own ideals and norms, and with what they consider desirable. Their ideas about the future thus reflect their societal values (Tutton, 2017). Therefore, sociotechnical smart grids imaginaries entail expectations not only about technology but also about what kinds of society the technology enables and relies upon. Sociotechnical imaginaries contain normative expectations about the future, but these expectations do not simply exist as such; rather, they do something, as they have the potential to influence what the future will become. In this way, I conceptualize ideas about the future not as simply being imaginative but rather as being part of a social practice, and influencing the formation of different materialities in the present. In other words, "Rather than being reducible to merely descriptive statements of what may or may not happen in the future, expectations, visions, scenarios, and other forms of anticipation affect what may actually happen. They are performative" (Konrad, van Lente, Groves, \& Selin, 2016:465). This means that expectations about the future contain scripts that is, descriptions of future relations between humans and technologies (Van Lente \& Rip, 1998). Expectations can thus be compared with self-fulfilling 
prophecies that guide upcoming ideas of what the future can entail. To put it differently:

...expectations can be seen to be fundamentally 'generative', they guide activities, provide structure and legitimation, attract interest and foster investment. They give definition to roles, clarify duties, offer some shared shape of what to expect and how to prepare for opportunities and risks. (Borup et al., 2006:285f)

Thus, expectations about a smart grid future are not distant hopes without meaning; rather, they are performative and affect what the future society will become. This argument aligns with Jasanoff and Kim's claim that sociotechnical imaginaries are "associated with active exercise of state power" that is applied through priorities, allocation of money and investments in infrastructures (2009:123). In this thesis, I conceptualize sociotechnical smart grid imaginaries as performative notions of the future that set the framing for what kinds of smart grid can be constructed within a Swedish smart grid demonstration project. Although I conceptualize imaginaries as setting the broader framing, I do not consider them to be deterministic, they are mobilized and translated in different ways by the actors involved in the demonstration project. As I explore the sociotechnical smart grid imaginaries, I examine notions of future societies and notions of what kinds of users are inhabiting these futures.

\subsection{Scripting users and making them interested}

In this thesis, I pay special attention to users' roles in smart grids, and to how users become engaged with smart grid technologies. To explore the process of assigning roles to users within the smart grid, I make us of the concept user configuration as defined by Woolgar (1991). A user configuration refers to the process in which a technology defines, enables and constrains the people that use it. The term “configuration" suggests that people are shaped by the socio-material configuration 
of which they are part; in other words, configuring users means "defining the identity of putative users, and setting constraints about their likely future actions" (Woolgar, 1991:59). Such a conceptualization is compatible with translation, since the network builders try to enrol users in a particular configuration that shapes their identities; this is a process in which the network builders assign particular roles to users, and ascribe particular interests and desires to these users. Thus, as the network builders enrol users, they configure them to play certain roles in relation to the other entities that make up the socio-material configuration.

In order to analyse how this configuration is enacted in the smart grid demonstration project, I make use of the concept of script as developed by Akrich (1992). She illustrates this concept with the empirical example of the home installation of electricity meters, and shows that the government in the Côte d'Ivoire turned households into political subjects: as users were enlisted as consumers of electricity, they were simultaneously enrolled into a nation-state in the making. Akrich argues that the designers behind these meters had certain ideas regarding their future users - not only how they should act, but also which particular characteristics they should possess and what kind of future the suggested socio-material relations implied. Akrich finds that designers inscribe such ideas into the devices they are designing, and denotes the result of this work a script. A script is a call to users on how they should interact with the device. It is a way to encourage users to play the roles that are suggested for them; in other words, it is a way to 'groom' the users. A script "offers a set of rewards and punishments that is intended to teach proper rules of conduct" (Akrich, 1992:218f). She argues that technology designers decide what should be delegated to machines and what should be left to humans to decide, in a process that cannot be understood as neutral but is rather carried out with the intention of achieving particular outcomes. I will explore the kinds of ideas about users that are inscribed into the smart grid within the 
demonstration project, and I will attend to how users are scripted to play these suggested roles.

The socio-material relation envisaged by the designer may not be accepted by the users, as the users can engage in a de-inscription process in which they dismiss the script and "try to extract themselves out of it or adjust their behavior or the setting through some negotiations" (Akrich \& Latour, 1992:261). As I attend to the users who participate in the smart grid demonstration project, I trace how they engage with the smart grid technologies that are provided to them and analyse whether they accept their suggested roles or engage in de-inscription processes.

In addition to exploring how the network builders inscribe ideas of users into their technologies, I also examine the strategies they use to convince users to sign up for the demonstration project and be part of the smart grid. That is, I pay special attention to the second stage in the translation process, interessement, as defined above. Even though Callon does not especially emphasize this point, interessement also applies to people, and one way to convince them is through rhetoric that creates "an association of interests that give people the will to do something" (Cooren, 2000:184 original emphasis). I will attend to the recruitment campaign and explore how the smart grid demonstration project was framed as appealing, prompting users to sign up. In order to explore this process, I make use of the concept issuefication. Marres (2012a) argues that issuefication is different than inscription; scripted objects have a normative effect in the sense that they encourage certain behaviours, whereas issuefied objects emphasize the issues that the object is able to invoke. In this sense, Marres claims that a script can be political but may fly under the radar of the users, whereas an issuefied object is openly political through its explicit association with particular issues (Marres, 2012a). Marres finds that an analysis based on hidden programmes is insufficient when technological practices are openly framed as political, which is the case when 
domestic energy technologies are presented as a way of engaging with environmental issues (Marres, 2007:374). She bases her argument on campaigns in which people are urged to "green their homes", and finds that the campaigners position material things as necessary tools for public involvement in environmental issues. In such campaigns, objects are assigned the ability to bridge the divide between people "in here" and issues "out there". Marres argues that "in these campaigns, material things are placed in the forefront as crucial tools or props for the performance of public involvement in issues" (Marres, 2010:179 original emphasis).

Objects become associated with such larger issues through an issuefication process, which "refers to the dynamic in which an object comes to 'resonate' with particular matters of concerns" (Marres \& Rogers 2005 referred to in Marres, 2012a:265). She thus refers to Latour (2004), in which the notion of matters of concern describes how public issues emerge. Latour shows that such issues are not pure entities that simply belong to a specific aspect of common goods; rather, they are messy bundles that require the activation of various problems of, for example, an economic, political and moral nature (Latour, 2004). Marres (2012a) claims that an object becomes charged with such public issues as it is equipped with visual, textual and technical hints. She gives the example of a teapot that is illustrated as "Planet Earth" in a poster, accompanied by the heading "Only boil what you need" and descriptions of how much carbon dioxide emissions and money can be saved if everyone complies with the stated instruction. Through these various hints, the object (a teapot) becomes associated with the issue (the environment) (Marres, 2012a). Issuefication is thus the process in which an object becomes overlaid with larger issues. Using a perspective of issuefication, I examine the process by which the recruitment campaign framed the smart grid demonstration project as appealing for users. In other words, I unpack how smart grids and the project become charged with particular matters of concern. 


\subsection{Material participation}

Next, I examine the users that engage with the smart grid as a domestic technology. This part of the thesis explores how users living in households justify their participation in the demonstration project, how they use smart grid technologies and what they argue are attractive smart grid solutions. In other words, I explore smart grids from the users' perspective. However, the term "user" primarily positions people as a counterpart to the designers of the technology (Rohracher, 2006:65). It thus defines people as the receivers of solutions that are provided by someone else. However, as Kuutti (2001) points out, "humans usually do not use a system for the sake of using; the use is just a means to achieve something else that is much more characteristic and important to a person using a system.” Inspired by the understanding that people use technologies as a means to achieve something that is valuable for them, I make use of the concept of material participation as defined by Marres.

Marres argues that when it comes to climate issues, traditional ways of acting politically, such as voting for a political party, engaging in public debates or becoming members of certain organizations, are being challenged by material practices for political engagements (Marres, 2007). She claims that citizenship has traditionally been associated with the ability to express ideas or values, but advocates that politics and democracy cannot only be limited to human participation. Rather, she stresses that politics and democracy are socio-material arrangements. Marres argues that such a conceptualization is "a way of recognizing that non-human entities are capable of actively making a difference in the organization of social, political and economic arrangements" (Marres, 2010:188). Following this, I regard human reflexivity as crucial for achieving a political change, but recognize that the ability to achieve such change is not a result of human 
interactions alone, but rather a conjoined effect of humans and non-humans (cf. Bennett, 2005).

Marres proposes a device-centred approach that "brings into relief the artefactual nature of people's capacities to take environmental issues into account" (2012b:145). She thus emphasizes the materialization of participation - that is, how participation is materialized, or "how the material form of participation is actively accomplished with the aid of devices" (Marres, 2012b:66). Marres suggests that everyday devices can materialize participation in different ways, or can grant participation different logics. In particular, she stresses two such logics: "involvement made easy" and "the more invested the more engaged" (Marres, 2012b: Chapter 3). She illustrates the first of these logics with a teapot that changes colours in accordance with the capacity of the grid. This device indicates when it is a good or bad idea to make a cup of tea. She finds that when environmental participation is enacted as 'doable', people are configured as generally uninterested in engaging with environmental issues in ways that influence their everyday lives. This logic codifies participation in public affairs with the least possible effort, cost and disruption. The aim is that everyday practices should become environmentally friendly without demanding or resulting in any change in the state of the things, settings or things involved: the shift is simply a "change of a no change" (Marres, 2012b:79).

In contrast, "the more invested the more engaged" logic applies to operations that amplify investments and seek to produce material effects. As an illustration of such a logic, Marres mentions blogs in which people present the everyday efforts, costs and disruptions they tolerate for sustainable living, and demonstrates that this translates to material effects such as a "house smelling of vinegar or the garden turning into a war zone" (Marres, 2012b:79). These blogs produce accounts of the social, economic and material implications of letting environmental issues become 
part of people's everyday lives. In this way, she shows that technologies can grant very different logics to material participation and that, by doing so, technologies enable different politics of participation.

Marres (2012a) argues that studies of material participation can enable explorations of the societal distribution of the efforts involved in environmental change. She claims that publically displaying how much work, cost and disruption people bear when taking the environment into consideration is a way of raising questions of unfair societal distributions, simply by raising questions such as "if we can do it, without any resources, why can't government and industry?" (Marres, 2012b:78). Marres thus combines the idea of citizens as knowledgeable enough to make informed decisions with the idea of them as engaged with normative material practices; this means that she understands people as being able to express the relation between their material engagements and larger societal issues (Marres, 2012b). Inspired by her conceptualizations, I will explore how users articulate their material participation with smart grid technologies. I will attend to their motives for engagement, and examine which logics their participation rests on.

To summarize, in this thesis, I analyse smart grids using theoretical concepts that examine relations between the material and the social. Combining these theoretical concepts into a framework enables analyses of how these relations are made, arranged and reshuffled, and of what kinds of relations are enabled, disabled, encouraged or discouraged. It allows me to trace how interests, desires and goals take materialized form and what kinds of engagements the technologies allow. Engaging with this framework, I move between three different analytical perspectives on smart grids: smart grids as an imaginary of the future, smart grids as materialized in the present and smart grids as a material engagement. In the following chapter, I describe the methods and materials used to conduct these analyses. 


\section{Methods and material}

In this chapter, I describe the material my thesis is based on and the methods I used to gather and analyse this material. To begin, let me clarify my epistemological standpoint. I do not view methods as a means of disclosing reality; they are not tools that help me expose aspects that simply lie there and wait to be discovered by the researcher. Rather, I understand methods to be a way of enacting realities, or, as articulated by Law:

[O]ur own stories weave further webs, it is never the case that they simply describe. They too enact realities and versions of the better and the worse, the right and the wrong, the appealing and the unappealing: There is no innocence. (Law, 2009:154)

Hence, the methods and material I have used contribute to the stories that I tell in this thesis, and through these stories, I enact certain realities above others. This means that what I have been able to see and hear has been mediated by where, how and when I have searched for answers; in other words, "[t]he world never speaks directly to us but is always encoded via recoding instruments like field notes and transcripts" (Silverman, 2006:113). In this chapter, I describe my process of 
compiling and analysing material. I do not regard research as a procedure that can be easily dissected into distinct stages; rather, it is a highly entangled process that I find difficult to give justice to or to narrate in detail. However, I will do my best to shed light on the methodological considerations upon which I base this thesis. I begin this chapter by describing the process of deciding on an empirical case on which to base this thesis. I describe the methods I used to follow the emergence of a smart grid within the demonstration project and to study how households make sense of and use smart grid technologies. I then describe how I explored notions of smart grid futures. In these sections, I convey the methods I used for compiling materials, the context in which they were produced, the actors behind them and my analytical process. I end this chapter with a description of how I analysed my gathered material.

\subsection{Deciding on an empirical case}

The idea of writing a thesis about smart grids began when I read a debate article in a Swedish newspaper. In this piece, the CEO of the Swedish Consumers' Association, Jan Bertoft, argued that politicians and the industry speak euphorically about smart grids while assuming that users will embrace it in the same manner. This article caught my attention because it raised questions of power relations between experts and users:

The question is: Will consumers really be winners in the smart grids? How would that occur? Do we know that? If not - should we really launch this whole process, to the cost of billions? (Guess who will pay in the end?) (Bertoft, 2012)

This formulation made me curious about what smart grids entailed, how they were assembled, what interests guided such a process and how users received them. I started searching for a way to follow such a process in depth, and found case studies to be a suitable format for such an analysis. A case study enables in-depth 
explorations of how a particular phenomena evolves over time, and are especially appropriate for studies that search for answers regarding who and what are given priority in a situation (George \& Bennett, 2005).

Sweden contains several smaller smart grid projects that have been set up to enable the examination of specific aspects of smart grids such as improved grid surveillance, the charging of electrical vehicles or the design of electricity tariffs. However, there are only three Swedish large-scale demonstration projects. One is located in Sweden's capital, Stockholm, is named the Stockholm Royal Seaport and concerns a newly built urban area (City of Stockholm, 2016). Another project is located in Hyllie, which is another newly built city district on the outskirts of Malmö, Sweden's third largest city (Samsyn Hyllie, 2015). The third Swedish largescale smart grid project is the focus of this thesis. This project had a different setup than the other two, since it did not concern an urban area built from scratch in a larger city, but rather the modernization of a pre-existing grid and the inclusion of users living in detached houses on Gotland, an island in the Baltic Sea. I followed the demonstration project Smart Grid Gotland, a four-year project that took off in 2012 and continued until the end of 2016, with a particular focus on the undertakings of the subproject Smart Customer Gotland ${ }^{3}$.

Smart Grid Gotland gathered powerful actors from the Swedish energy sector and was conducted as a cooperation between representatives from utility companies, grid owners, technology providers and academia (Smart Grid Gotland, 2016g). The Swedish Energy Agency functioned as a co-funder, and contributed a total of more than 45.5 million SEK to the project (Swedish Energy Agency, 2016a), placing high expectations on it in terms of deliverables. Smart Customer Gotland was primarily conducted by Vattenfall, an electricity company owned by the Swedish state with international operations, and by its local subsidiary GEAB. (for details of the actors

\footnotetext{
${ }^{3}$ My translation of the Swedish name Smart Kund Gotland
} 
behind the project, see Chapter 4). As one of three large-scale Swedish demonstration projects, and as the first of these to finish, Smart Grid Gotland provided the opportunity to follow an extraordinary process. The choice of this project as a case study thus resonated with Flyvbjerg (2001) recommendation to choose a case that is extreme or critical, since conventional cases may not be the most informative. Furthermore, I found this project appealing because, unlike the other two major demonstration projects, it concerned households already living in pre-existing houses; therefore, this project could provide insight into the process of implementing smart grids outside of areas built for that purpose. Moreover, my choice was guided by the fact that Smart Customer Gotland was conducted during a period that suited my $\mathrm{PhD}$ project.

However, getting access to this project was a lengthy process. I had several email and phone conversations over a period of half a year, followed by a personal meeting with the people in charge of Smart Customer Gotland. I was asked to specify my interest in the project and clarify why my research could be of interest for them; finally, I was required to sign a confidentiality agreement stating that I would not reveal any business secrets. I made contact with the people in charge of Smart Grid Gotland in October 2012, and was granted access in April 2013.

\subsection{Methods of compiling material about Smart Customer Gotland}

I followed Smart Customer Gotland during its initial phases, throughout the process of assembling a smart grid until smart grid technologies had been used by households for a couple of months. As is common in case studies I used a variety of methods to compile my material. which is generally considered to enhance research validity since findings from different sources can then be compared (George \& Bennett, 2005). The process I followed required a multiplicity of sources and different kinds of methods that I now will describe. 


\subsubsection{Interviews}

I primarily based this study on interviews. As Byrne (2004) points out, an interview does not provide facts about reality or to the sequence of certain events. They do not allow me to "get inside someone's head", rather, they provide insights into people's opinions about a certain event or matter (Byrne, 2004:182). I also want to clarify that my ambition has not been to reveal any hidden agendas or lies; rather, I have treated the responses from my informants as their honest interpretations of how they remember a certain process or as their opinions of specifics aspects (cf. Berner, 2007).

I interviewed three different actor groups: people working within the project, households participating in the demonstration project and actors representing prosumers, a household role, that were excluded from the smart grid established on Gotland. Although the interviews with project employees gave me insight into the opinions of individuals who could describe the process of assembling a smart grid, the other actor groups allowed me to explore how households articulated their motives and participation with smart grids. These interviews also allowed me to shed light on some neglected or dismissed alternatives of how a smart grid could be assembled. Thus, I chose to set up the study in a way that responded to critiques of studies that focus only on the construction of a socio-material configuration that emphasizes the perspectives of privileged actors (e.g. Star \& Griesemer, 1989). On the contrary, my objective was to gather opinions from persons with different roles and mandates. Baxter and Eyles (1997:512) also stress the importance of such an approach; they argue that in order to achieve credibility, researchers must rely on the assumption that there is no such thing as a single reality, "but rather multiple realities, mentally constructed by ourselves" and they therefore urge researchers to strive to include respondents with different backgrounds and experiences. 


\subsubsection{Describing and recruiting interviewees}

I interviewed all the project team members of Smart Customer Gotland who worked with the project on a daily basis. I also interviewed people who held leading positions in GEAB or the overall demonstration project, who had deep insight into the subproject's undertakings. In total, I carried out 19 interviews with 14 people (five persons were interviewed twice) who were working directly with or in close relation to Smart Customer Gotland. I conducted the first interviews in the project's early phases, and the second set of interviews when the project was in the middle of household recruitment. The project employees I interviewed were all employed by Vattenfall or by GEAB. Some were Gotlanders, and were therefore familiar with local conditions for this specific island; others came from other parts of Sweden and possessed expert knowledge in particular fields.

After I was given access to Smart Customer Gotland, the people working with the project were, by the project leaders, informed about my existence and my research interests. This may explain why I did not experience any problems with recruiting people for interviews. I interviewed the project leader for Smart Grid Gotland, the project leader for Smart Customer Gotland, the CEO of GEAB, the executive for GEAB's electricity grid, the project leader for Smart Customer Gotland's technical solutions, a technical specialist, GEAB's representative on the board of Smart Grid Gotland, two persons working with the marketing of Smart Customer Gotland, an energy adviser and three persons working with GEAB's electricity sale. I performed one-on-one interviews with these individuals, except for one occasion when, at their request, I conducted the interview with two respondents. To protect my informants' identities, I will omit any information that may easily reveal them. In the upcoming chapters, I have therefore given these individuals names that start with $\mathrm{E}$, for "Employees". For the same reason, I have not connected interviewees' names with their professions, and only refer to an interviewee's role in the project when I have found this connection to be of particular importance. 
The second actor group I interviewed comprised users living in households that participated in Smart Customer Gotland. I carried out interviews with representatives from 14 households; five of these interviews were carried out with two household members, making the total number of respondents 19. I have given these persons names beginning with $\mathrm{H}$, for "Households". I first encountered these interviewees at recruiting events arranged by Smart Customer Gotland. I attended eight such events, some of which took place in Visby, the largest town on Gotland and some in Slite, a smaller town in the northeast part of Gotland. On these occasions, I asked all the households who signed up for the project whether they would be interested to speak with me as a researcher. I contacted all the participants that gave me their contact information, and arranged interviews with those who still were interested. The first two households I interviewed had only had the smart grid technologies for a few months while later interviews were done with users who had lived with the smart grid technologies for almost ten months.

Some of these households consisted of a single person, some were families with children and some were couples. The ages of the household members ranged from the mid-30s to the mid-70s, and they lived in Visby, in smaller cities on Gotland or in the countryside. Some household members were born and raised on the island, while others were originally mainlanders. Most participants had smart grid technologies installed in their permanent residence, but one had the installations made in their vacation home. The majority of the interviewees were men; women participated only in the interviews I carried out with two household members together. All the interviewees were Caucasians and were fluent in Swedish. Due to requirements set by Smart Customer Gotland, all the participants in the project lived in a detached house, which on Gotland does not necessarily correspond to a high income level; both white-collar and blue-collar workers were represented among the interviewees. I want to emphasize that out of the 260 households who participated in Smart Customer Gotland, I interviewed 14. These thus constitute a 
special group of actors who not only signed up for the demonstration project but also agreed to talk with me as a researcher. Thus, statements from these interviews cannot be regarded as generalizable claims that are applicable to all households; rather, they are views from some of the users that participated in Smart Customer Gotland.

The last actor group I interviewed comprised people representing prosumers, a household role that was excluded from Smart Customer Gotland, but given a central position in dominant smart grid imaginaries. I interviewed six different actors, who, in different ways, actively support households on Gotland in producing their own electricity - some individuals with professional engagements with microproduction, and some whose engagement concerned their private homes. On two occasions, two members of these households were present, making the total number of respondents eight. I have given these individuals names beginning with P, for "Prosumers". I interviewed an electrician who installs solar cells for households; a person who teaches courses in microproduction; a person who works with energy issues on the municipal level (and who also produces solar electricity for personal use); and an individual who arranges excursions to view and exhibitions of small-scale electricity production (and who also works to encourage the use of electrical vehicles on Gotland). Furthermore, I interviewed a couple who work as hostel managers, and who feed electricity and warm water to their private and commercial activities using solar cells and heaters. Finally, I interviewed a couple that not only are prosumers but also refurbished their house using energy efficiency measures. I found these respondents primarily using a snowball method, meaning that I asked my respondents to recommend suitable persons to interview next. I treat these interviews in the same way as the interviews with participating users, I make no generalizable claims from them; rather, I take these interviews as stories from people who actively support reconfigurations of the energy system but who were not involved in Smart Customer Gotland. 


\subsubsection{Conducting the interviews}

All the interviews were semi-structured, meaning that I prepared questions to ask during the interviews but regarded these questions as a guideline rather than as a strict protocol. I used this structure because I wanted the interviews to be characterized by a natural conversational tone, even though I as the interviewer was the one asking the questions. This structure also enabled me to guide the interview in directions I found relevant while remaining flexible towards what the respondent wanted to emphasize during the interview. In practice, this meant that when respondents started talking about issues that I had not prepared for, or that appeared later on in my guide, I let them continue. I also asked follow-up questions in those cases where I found the change of topic to be relevant.

All the interviews were audio-recorded with the respondents' approval. This allowed me to engage more in the interviews instead of being focused on taking detailed notes. I conducted the interviews with the people working within the demonstration project in their workplaces in Stockholm or in Visby, except for one that I carried out in a restaurant over lunch. I carried out 11 household interviews and two prosumer interviews in their homes; the rest of the interviews were conducted in interviewees' workplaces or in official places such as coffee shops. Conducting an interview in someone's home is special for various reasons. Some of the interviewees lived deep in the Gotlandic countryside, so it was necessary to drive long distances on unlit roads, in areas without phone connections, to houses that were not indicated on digital map services, while using directions given to me on the phone. This gave me a feeling of uncertainty as a researcher: whom was I going to meet? However, this feeling always turned into gratitude when entering the respondents' homes. Even though I had previously explained who I was and what I was interested in, I often detected an initial tension; they seemed curious or even nervous of who they had invited into their home, probably thinking "What is a researcher, and what is going to happen now?" It may have made me appear a bit 
more human in their eyes that I conducted many of these interviews while being clearly pregnant.

An interview in someone's home also creates a certain intimacy in the sense that I was present as an invited guest; I always brought flowers as a gesture of gratitude for this. These interviews also provided me with the opportunity to gain insight, albeit limited, into the interviewees' private life. They often had coffee or cakes prepared to share during the interview, and on one occasion the respondents even invited me for dinner. During another interview, the household cat walked on the table between the respondent and me, alternately brushing against each of us. Although these were small signs, they made the situation less frightening and opened up the conversation.

After the interviews were transcribed, either by me or by a professional transcriber, I checked the accuracy of all transcripts that I had not transcribed myself. When using direct quotes from interviews, I took the liberty to change them in regards to repetitions, pauses or grammar, because articulations that are natural in oral speech can be difficult to comprehend when presented in written form (Brinkmann \& Kvale, 2015). I conducted all interviews in Swedish and I therefore translated direct quotes into English. In this translation, I put extensive effort into capturing the informants' expressions; however, the implications behind certain idioms that cannot be directly translated may have been lost.

\subsubsection{Written material}

In addition to the interviews, I gathered written information about Smart Customer Gotland. I was not selective in this process; rather, I collected all types of material that could be of relevance. A key source for compilation was Smart Grid Gotland's own website. On this website, I found information on the project's aims and ambitions, and on how it was organized and set up; descriptions of why this was an 
important project; a pre-study report, slide presentations, press releases, and status reports to the Swedish Energy Agency; and various news articles. I also analysed the funding approval from the Swedish Energy Agency.

The subproject Smart Customer Gotland used part of GEAB's homepage as a channel to distribute information about the project to households, initially for recruitment purposes and later to communicate with participating households. As a result, the information on the website was continuously updated throughout the project, and I tried to follow these updates and download information. On this website, I found specific information about the subproject along with arguments that were intended to encourage households to sign up for the project. Moreover, I retrieved information folders on the smart grid technologies that were installed in the households. These folders contained detailed information, including pictures showing what the interfaces and technologies looked like. Some additional information about the technologies was available on Vattenfall's homepage. Finally, I downloaded the app for households onto my personal phone, which enabled me to see the various functions - although my app was a very limited version, as it was not connected to any technology in my home.

In order to follow the way in which the project was framed towards households, I analysed the recruitment campaign's printed material. This material was heterogeneous, consisting of information folders, pamphlets, a candy case and slide presentations used at recruitment events. During my stays on Gotland, I collected every piece of recruitment material I could find. In particular, when I participated in recruitment events, I gathered all the material that was handed out to households; I also collected the material that, for example, was laid out in the entrance of the GEAB office or was given to me by persons working on the project. Within this material, I could trace ideas of how the households were expected to 
interact with the technology, and identify the arguments being used to encourage households to sign up.

\subsubsection{Participant observations}

Finally, I have used participant observation as a method of gathering information about Smart Customer Gotland. This method mainly allowed me to enhance my understanding of the context of the interviews and documents, rather than being a primary source for new material. Through participant observation, I was able to observe situations myself, instead of solely relying on written accounts or on how my interviewees recalled situations. However, I want to clarify that these observations were very modest in relation to observations that are performed during an extended period of time, with the objective to for example observe everyday practices (Hammersley \& Atkinson, 2007). Rather, engaging in participant observation was a way for me to solidify my findings, as it allowed me to compare previously gathered material with what I observed in the field (Creswell \& Miller, 2000).

In particular, events directed at households that were arranged by Smart Customer Gotland served as occasions for me to follow the project through participant observation. I attended two full-day fairs on Gotland in which exhibitors presented their products and services related to energy issues. Smart Customer Gotland participated as an exhibitor in these fairs, with the objectives of promoting the project and recruiting households. They brought information folders, samples of the smart grid technologies to be installed in households and tablets with apps through which fair visitors could test interfaces; in addition, they particularly focused on talking with potential participants. I listened in on these conversations and took notes during the discussions on how those who worked within the project framed Smart Customer Gotland or described the technologies' functionalities. I was also 
attentive to what kinds of questions visitors asked and the issues they raised, which gave me some hints on how they responded to the project's ambitions and setup.

When the people who worked within the project were not talking with potential participants, I took the opportunity to ask detailed questions on matters about the project I wanted to have clarified. During these fairs, I also listened in on presentations about Smart Customer Gotland that were given by representatives from GEAB to larger audiences. These events also gave me the opportunity to follow conversations between the people who worked within the project; I received insight into what they found difficult to explain to households and their own doubts and concerns about the project. Furthermore, I attended eight information meetings lasting $2 \mathrm{~h}$ each, to which households who had showed an interest in the project had been invited. These were the events where I recruited household interviewees. Most of these events took place in the GEAB head office in Visby, while others were located in Slite, a smaller town on Gotland. During these events, household members could walk between presentations about the project's specifics, hold and see smart grid technologies, and ask questions. On these occasions, I listened in on conversations, asked clarifying questions and took notes on details I found intriguing.

Aside from these more formal participant observations, I also engaged in participant observation in a more informal sense. As the project was set up as a temporary test, many project employees travelled to Gotland when working with the project. I often planned my trips to the island on occasions that coincided with special project events when many of these individuals were on the island. I therefore spent days on Gotland together with people working within the project: we travelled together, stayed in the same hotels, and ate breakfast, lunch and dinner together. They made me feel like an external member of the project, and I was even invited when they celebrated an important milestone. This casual time together 
with the people working in the project was crucial for my understanding, as it enabled me to talk to them and ask detailed questions in more informal settings than are possible during interviews. Creswell and Miller (2000) highlight that by spending a long time in the field, the researcher can establish relations and build trust with informants so that they are more comfortable sharing information. For me, spending time with people working within the project also meant that I could "see" the people behind the interviews: I could see their struggles and came to view them as intelligent individuals who had been given the difficult task of turning smart grids into something meaningful and functional.

\subsection{Exploring smart grid imaginaries}

When following Smart Customer Gotland, I repeatedly received the impression that this project did not emerge on its own in a vacuum, but was rather entrenched in wider ideas about the role of smart grids in a future energy system. Smart Customer Gotland started in 2013; at that time, the Swedish government had assembled a group to write an action plan for how smart grids should be implemented on a national level - the Swedish Coordination Council for Smart Grid that existed between the middle of 2012 and the end of 2014. In order to explore the kinds of sociotechnical smart grid imaginaries that were dominant in Sweden at that time, I analysed all the official documents that were produced in the course of writing this action plan.

The analysed texts were written by actors who were summoned due to their expert knowledge on smart grids, giving this group a strong authoritative status. The Swedish Coordination Council for Smart Grid consisted of 15 members who were assigned by the Swedish government. This heterogeneous group of actors included representatives from authorities, organizations, industries and various research centres, all of whom held top positions such as managing directors, executives, 
senior advisers or professors ${ }^{4}$ (Swedish Coordination Council for Smart Grid, 2013a). Furthermore, the council was connected to a group of experts especially assigned from the government offices. The council also set up a number of reference groups that consisted of more than 70 actors from authorities, organizations and companies who were assigned the roles of providing creative ideas, identifying and analysing key issues, and commenting on ongoing investigations initiated by the council. Moreover, the council assigned experts to write backgrounds reports about issues they found to be of particular importance (Swedish Coordination Council for Smart Grid, 2013a).

This group was thus an influential constellation of experts with backing from the Swedish political arena. I analysed all official documents produced by these actors while the Swedish Coordination Council for Smart Grid was operating. I found all texts on the council's website, which the council, as urged by the governmental directive behind the council, had set up with the purpose of gathering and spreading information about smart grids (Government Office of Sweden, 2012). In total, the analysed material encompassed more than 1800 pages from more than 40 reports, texts and articles, and in Chapter 5 , I refer to almost half of this material.

These documents primarily consist of the council's official reports to the Swedish Government and background reports written by assigned experts. Another key source of material has been transcripts from dialogue forums to which the council invited actors to discuss specific topics. I also analysed short articles published on

\footnotetext{
${ }^{4}$ The Swedish Coordination Council for Smart Grid consisted of the following actors: Authorities: Director General Swedish Energy Agency, Director General Swedish Energy Markets Inspectorate, Head Director National Defence Radio Establishment, Director General Authority for Sweden's transmission system; Research institutes: CEO SP Technical Research Institute of Sweden, Professor KTH Royal Institute of Technology, Head of Research Sustainable Innovation, Head of Business Area Smart Energy Interactive Institute; ICT Organizations: Senior Adviser Power Circle, President IT- och Telekom-företagen, CEO The Swedish Consumer Energy Markets Bureau; and Companies: Business Developer Smart Grids ABB, Vice President Industry and Research Relations Ericsson, CEO E.ON Nordic, CEO Trollhättan Energi (Swedish Coordination Council for Smart Grid, 2013a).
} 
the website, in which the council members expressed their personal opinions about smart grids, along with an information folder to the public. Of significance for my analysis were documents in which the smart grid stakeholders described possible futures in the form of different scenarios. The council assigned a great deal of importance to this way of portraying the future and explicitly mentioned that such scenarios are important tools in their work to develop an action plan (Swedish Coordination Council for Smart Grid, 2014c). They presented the scenarios in a two-by-two matrix, with a slow versus a fast increase of "Intermittent Electricity Production" on the $y$-axis and with an insignificant versus a significant "Perceived Customer Benefit” on the $x$-axis. The council argued that these entail the core issues for a future smart grid development (Swedish Coordination Council for Smart Grid, 2014c). This led me to interpret the scenario that scored high on both of these axes as representing the council's imagined future with a fully established smart grid.

In addition to the documents published on the website for the Swedish Coordination Council for Smart Grid, I have included a few key documents on smart grids published by Swedish authorities. Although these documents are not part of the work coordinated by the council, they are referred to in documents found on the council website. I also included a few statements that the head of the council and the former Swedish IT-and-Energy Minister made as they launched the council. With a few exceptions, these statements were written in Swedish, so I translated the quotes into English. In this translation process, I have tried to capture the essence of the original statements.

\subsection{Making sense of messiness: analyzing the material}

The process of analysing the empirical material for this thesis was characterized by the interchanging activities of thinking, writing and coding. I did not start my analysis back at the office with piles of material to go through. Rather, my analysis 
has been a continuous work that has engaged me since the early phases of this project. In this way, my work has followed the process described by Berner (2007), in which the researcher, already in the initial stages of fieldwork, tries to identify central problems and speculates about what can be relevant to investigate further. In my case, during the initial interviews with people working in Smart Customer Gotland, I paid attention to which questions engaged the interviewees, and I interpreted these questions as signs of what they themselves pondered about. I was also observant of the issues the interviewees discussed among themselves, and used them as indications of the aspects the employees found especially difficult to handle or comprehend. All of these initial observations provided hints of which directions to move in to continue my investigations.

After this initial phase, once I had become more certain of my research focus, I constantly moved between gathering and analysing material. Berner (2007) points out that during fieldwork, the researcher has an opportunity to test various interpretations, search for counterarguments and find further evidence to strengthen claims. In this process, Berner especially encourages the researcher to be open to surprises. Something that especially surprised me during fieldwork was how reflexive the people working in Smart Customer Gotland were about their practices. They expressed doubts, concerns and difficulties when talking about their work to construct a functional smart grid. In the interviews with households, I was also struck by how much those individuals reflected about what kind of project they were participating in and about the role of smart grids in future energy systems.

My analysis also included desktop work as I systematically coded and thematized the material. During this process, I used a computer program called NVivo that enabled me to get an overview of the extensive amounts of material. I imported all the interview transcripts and all official texts produced in the course of writing the Swedish smart grid action plan into this software. However, I did not import the 
documents produced by Smart Customer Gotland, since those texts were not as extensive and I got a better overview from having them in front of me in their printed versions rather than looking at a computer screen. They consisted of a different type of material, such as printed websites, information folders and recruitment materials (e.g. pamphlets and candy cases), which was easier to code and categorize using coloured pens than through NVivo.

Nevertheless, the analytical method for finding codes and themes was not dependent on whether I used a software program or not. In practice, I began my coding process by reading through all the texts, marking sections of special importance and making notes in paragraphs. I then imported the texts into NVivo and searched for reoccurrences that I digitally marked with codes. I then went through the codes again and combined or divided these codes into larger themes with subthemes. However, my analytical process differed depending on what I focused on. When exploring the smart grid future, for example, I searched for the actors' explanations of what smart grids entail, what they argued will change with a smart grid, and descriptions of the users who will inhabit these futures. I also searched for alternative non-smart grid futures, which were especially visible in scenario reports, as a way of exploring experts' and authorities' descriptions of what will happen without smart grids. This process generated themes such as "flexibility", "welfare" and "digital".

This process was similar to coding interviews with households and prosumers, when I also searched for distinct and separable themes. In the interview transcripts, for example, I searched for statements of how the interviewees engaged with smart grid technologies and why they were taking part in the demonstration project; this process generated themes such as "convenience" and "money". However, when analysing how the smart grid emerged within the Smart Customer Gotland project over time, I analysed a continuous process. For example, I searched for statements 
of how interviewees remembered a certain situation or phase, and I coded the material based on a sequence of events. In this case, the themes included "implementing devices in houses", "framing the project as attractive" and "enrolling households".

I want to stress that the process of finding codes, themes and linkages was not linear; rather, it was an interchanging activity that moved between writing texts, thinking and reading through my material. Sometimes I found codes and themes while writing, while at other times I found them when going through the documents; some were given to me by my informants, but most developed over time as my understanding of the material deepened. My way of coding also changed as my thesis developed: I was able to see new patterns as I gained more knowledge about my research field, as my research questions were refined and as my informants learned more about the project and about smart grids. As a result, I was able to go back and forth between NVivo and the written text, and rearrange my themes after I had started writing. I repeatedly went back to the codes and read through original interview transcripts or documents in their printed version. This process enabled me to find new codes or connections that I had not noticed previously or had dismissed as irrelevant. Coding was a way for me to break the material apart, analytically rearrange it and then bring fragments together into new themes; they were "tools to think with" (Coffey \& Atkinson, 1996:32). I therefore want to stress that my themes were not clearly visible in the analysed material; rather, I defined them in the process of structuring reoccurring patterns. In my analysis, I nevertheless strove to achieve credibility, which Baxter and Eyles (1997) define as the notion that those who have experienced what the study claims to describe can easily recognize their experiences.

One strategy I used to achieve credibility was striving to base my analysis on respect for my respondents. This resonates with Alvesson's (2011) recommendation that the 
researcher should base interpretations on empathy for those who are studied. Since I spent time with people working with Smart Customer Gotland and since households invited me to their homes, this form of compassion came naturally. I tried not to interpret their opinions with my own judgements of "right" and "wrong" but rather tried to emphasize the interviewees' own stories. I have therefore based my narrative on several direct quotes from different interviewees, following Baxter and Eyles (1997) claim that meanings are revealed through the respondents' own words rather than through the words used by the researcher. Another strategy I used to increase the credibility of my analysis, was to attend Smart Grid Gotland's final seminar when actors behind the project explained the set up and results for a wider audience. In this way, I got the opportunity to listen to how they described the project with their own words. I also a send the chapters based on material about the demonstration project to my main contact people within Smart Customer Gotland. These people were given the opportunity to comment on whether I had misunderstood any crucial aspects, and when I found their responses to be reasonable, I made changes accordingly. However, this procedure did not result in any changes in my analysis of the events. I did not send any manuscripts to households or prosumers, mostly because in those cases, I did not have a contact person who could speak on behalf of the rest. I made the judgement that sending a copy to each and every respondent was too lengthy and cumbersome procedure.

A final comment on my analytical process is that it resulted in the arrangements of empirical chapters changing several times. At first, I had the idea of structuring the chapters based on themes that reoccurred in the material. As my process continued, however, I found that my analysis could be deepened if I used the current structure, in which I divide the chapters based on different actors, and follow their negations, undertakings and struggles in depth. In the first empirical Chapter 4, titled 'Smart Grid Gotland: Shaping the future of Swedish smart grids', I describe the actors who were part of this demonstration project and how it was set up. 


\section{Smart Grid Gotland: shaping the future of Swedish smart grids}

In this chapter, I introduce the demonstration project that this thesis is based on, this chapter serves as an introduction to the upcoming analysis, in which I discuss how a smart grid was put in place within this particular demonstration project. Here, I introduce Smart Customer Gotland and the framing under which a smart grid evolved within this project. This discussion builds on previous studies that have shown that pre-existing social and technological realities shape what a smart grid becomes in a particular demonstration project (Skjølsvold \& Ryghaug, 2015), and that the interest of the actors involved in a demonstration project influence how the project is set up (Nyborg \& Røpke, 2013). This chapter describes the local conditions that directed the kind of smart grid that could be constructed within this demonstration project.

\subsection{Introducing Smart Grid Gotland}

As previously mentioned, demonstration projects are given a key role by influential actors in the development of smart grids; this is recognized both in an international 
and a Swedish context (Giordano et al., 2011:10; Swedish Coordination Council for Smart Grid, 2014a). There are three major smart grid demonstration projects in Sweden: one in the capital, Stockholm; one in Sweden's third largest city, Malmö; and one on the island of Gotland. Although the former two projects have the objective of constructing a functional smart grid in a newly built city district, the latter was aimed at upgrading an existing grid on a remote Swedish island. Smart Grid Gotland was the first of the three projects to finish; conducted as a four-year demonstration project, it took off in 2012 and continued until the end of 2016.

The project was anchored in the European 20/20/20 targets, and its starting point was the argument that the future energy system will most likely contain large amounts of electricity production from intermittent energy sources such as wind turbines and solar cells (GEAB et al., 2011; Swedish Energy Agency, 2012b). Rather than reinforcing the grid to cope with such a situation, the idea was to explore how the current grid could be modernized using improved control and monitoring systems as well as a more active demand side (Swedish Energy Agency, 2012b). The overall ambition with Smart Grid Gotland was to enhance the hosting capacity of a distribution grid at a reasonable cost in order to enable increased amounts of wind power production with a stable power quality and secured electricity supply, and to give users the opportunity to lower their electricity expenses through flexible consumption (Swedish Energy Agency, 2012b).

High ambitions were attributed to Smart Grid Gotland, and its initiators held aspirations of international recognition, describing their project as developing a smart grid that "is likely to become an international model for a long term sustainable electricity power system" (GEAB et al., 2011:13). The project set out to construct "One of the smartest electricity grids in the world" (Smart Grid Gotland, 2016d). As previously discussed, a smart grid is a "fuzzy" object in the making, often being credited with different connotations and presented as a miracle solution 
to various problems (Christensen Haunstrup et al., 2013; Skjølsvold et al., 2015). Such a general and broad conceptualization seems to have guided Smart Grid Gotland's own explanation of what constitutes a smart grid:

A Smart Grid can be seen as the convergence of IT, telecom and the electricity market. It is a platform that enables the functioning of distributed intelligence, communication technologies and automated control systems in order to response to the environmental, political and technical demands on the electricity distribution system. Smart Grid facilitates the desired actions of its users and these may include the deployment of customer participation through distributed generation, demand side management and demand response as an answer to the introduction of dynamic tariffs, energy storage systems and the optimal expansion and management of grid assets. (GEAB et al., 2011: 9)

In this definition, which is taken from the project's pre-study, smart grids are referred to in terms of several different entities: materialities, human actors, market conditions, signals and so forth. These entities are all connected to one another and make up a heterogeneous assemblage. This definition sets no strict boundaries around what is included or excluded from the smart grid. The impression of a smart grid as a loose assemblage is further deepened by the argument that the future smart grid will be developed over time in a process that Smart Grid Gotland refers to as the "Smart Grid evolution"(GEAB et al., 2011:11). The term evolution generates various associations; to begin with, it implies that the smart grid will take form in a slow process in which the most suitable socio-material configuration evolves over time. The term evolution also aligns this process with nature: rather than a harsh and intrusive technology, the term signals a balanced and harmless process that is as natural as nature itself. Moreover, evolution is a future-looking term: it implies that even though the smart grid may not appear to be realistic or comprehensible today, it will make sense in the future. It may even imply that the smart grid is an unstoppable process that is bound to happen and is thus pointless 
to resist. The description of a smart grid in terms of evolution also generates similar associations to Smart Grid Gotland, since the project becomes connected to this gradual process of change. The demonstration project was thus meant to assist in this evolution by contributing solutions for how different elements could be designed and implemented - that is, by establishing a functional smart grid that could be developed into a more advanced future version.

\subsubsection{Locating the smart grid project on Gotland}

Gotland is an island in the Baltic Sea that can only be reached by ferry or airplane. The island stretches over $3000 \mathrm{~km}^{2}$ and has nearly 60000 inhabitants (Region Gotland, 2016). As the largest Swedish island, Gotland offers a substantial physically detached test area, which is one of the reasons why Smart Grid Gotland considered it to be a suitable location to conduct a full-scale demonstration project (Smart Grid Gotland, 2016c). Another central argument for its use is that Gotland already hosts large amounts of wind electricity production; the project describes this situation as making Gotland into one of the very few large-scale sites that already reassembles the future energy system (GEAB et al., 2011).

Moreover, the electric grid on Gotland is connected to the mainland through a single high-voltage direct-current link, through which all electricity is transferred to and from the island. On windy days with low consumption, electricity is thus transferred from the island. However, the carrying capacity of this cable is in such a state that it limits the amounts of transferred electricity, making Gotland's grid especially sensitive to mismatches in electricity supply and demand. While waiting for a new cable to be installed, the island's grid owner has limited the number of new wind power plants in order to ensure a sustained electricity supply and power quality. Nevertheless, the demand on the local grid is high, causing more frequent blackouts than on the mainland (Executive for GEAB's electricity grid, 2013; CEO 
of GEAB, 2013). Various material conditions thus make Gotland particularly suitable for a smart grid project, with the intention of decreasing the pressure on the grid. However, social dimensions also influenced the choice of location. Representatives from the project argued that compared with other Swedes, Gotlanders are more familiar with the fact that a large amount of wind power production can cause frequent blackouts (Executive for GEAB's electricity grid, 2013; CEO of GEAB, 2013), and are thus acquainted with the issues associated with smart grids. Furthermore, despite its remote location, Gotland offers the potential for publicity, since once a year, the island hosts the so-called Almedalen Week (GEAB et al., 2011) when it becomes the national epicentre of attention as the elite cadre of Swedish politicians meets under intense media coverage. The final reason why Smart Grid Gotland took place on Gotland is that the project leader's (Vattenfall) subsidiary (GEAB) is the sole owner of the island's local distribution grid (GEAB et al., 2011). In upcoming chapters, I show that locating the project on Gotland came to influence the kind of entities that could be enrolled in the establishment of the smart grid on the island - a process that was also strongly guided by the project's organizational structure and involved actors.

\subsubsection{Introducing actors and subprojects}

Smart Grid Gotland was conducted as a consortium between powerful actors in a Swedish smart grid context: the state-owned energy company Vattenfall; the local energy company and grid owner Gotland Energy AB (GEAB); two technology providers, ABB and Schneider Electric; the transmission system operator Svenska Kraftnät; a university, the KTH Royal Institute of Technology; and the Swedish Energy Agency, which acted as a co-funder (Smart Grid Gotland, 2016g). Smart Grid Gotland was organized into three research and development subprojects along with an overarching research platform that provided these subprojects with technical solutions. These different projects contributed with different pieces in the 
process of assembling the smart grid. The subproject named Wind Power Integration was operated with the objective to improve the existing grid's ability to handle increased amounts of wind power production with as few major investments as possible. Within this subproject, technical solutions related to energy storage and information exchange between different voltage levels were developed and tested (Smart Grid Gotland, 2016b). The second subproject, Power Quality had the objective to show that commercially viable technologies can be used to improve power quality in a rural grid with large quantities of distributed electricity production. The subproject also tested how a grid can handle increased amounts of small-scale electricity production and larger photovoltaic systems (Smart Grid Gotland, 2016a). However, these tests were performed through a temporary installation that was dismantled when the project finished (Smart Grid Gotland, 2016f). The third and final subproject, Smart Customer Gotland ${ }^{5}$, focused on the role of electricity users in the smart grid; this subproject is the focus of this thesis.

\subsubsection{Smart Customer Gotland}

Smart Customer Gotland was conducted between December 2013 and April 2016, and was primarily performed by Vattenfall and GEAB. Vattenfall is one of Europe's largest resellers of heat and electricity; it is the leading energy company in the Nordic countries and the largest grid owner in Sweden. Vattenfall is owned by the Swedish state, and works within the whole electricity chain, from production and distribution to sales. The company has 20000 employees and a yearly turnover of more than 150 o00 MSEK. Vattenfall produces electricity in several European countries using for example nuclear power, hydropower, wind power and coal power (Vattenfall, 2016). The company is thus a powerful player on the European energy market. GEAB, on the other hand, operates locally on Gotland; $75 \%$ of

\footnotetext{
${ }^{5}$ My own translation of the Swedish name Smart Kund Gotland
} 
GEAB is owned by Vattenfall and $25 \%$ is owned by the local municipality ${ }^{6}$. The company works within electricity production, distribution and sales (GEAB, 2016).

The explicit objective of Smart Customer Gotland evolved over time and became more and more concretized as the project developed. In a recent article, the two main project leaders behind Smart Customer Gotland stated that the idea with the project "was to use price signals to incite customers to turn on large electricityconsuming equipment during periods of high loads and low demand" (Svalstedt \& Löf, 2017:1). They intended to decrease the overall pressure on the Gotlandic distribution grid through shifting consumption in time; periods with high loads near the grid's maximum capacity would be fewer and shorter, enabling an increase of intermittent energy production on Gotland (ibid). The focus on flexible consumption rather than on reduced consumption was aligned with the commercial interests of the actors behind the project:

With both a grid owner and an electricity seller in the house, I would say that reduced energy use directly contradicts our goals. We'd rather see that more electricity is used. (Executive for GEAB's electricity grid, 2013)

The Swedish Energy Agency's financing decision also contains ambitions of a commercial nature, as it declared that Smart Customer Gotland should develop products that were considered to be attractive to both commercial actors and households (Swedish Energy Agency, 2012). Behind this commercial focus, the Agency's rationale was that the Swedish export industry would benefit if Swedish companies could develop products suitable for a future energy system (ibid). Smart Customer Gotland therefore had the explicit objective of gathering information on people's interest in such endeavours; this objective was articulated as "achieve[ing] better understanding of customers' behaviour, interest and acceptance of active participation" (Svalstedt \& Löf, 2017:1). This goal was also formulated in terms of

\footnotetext{
${ }^{6}$ Region Gotland
} 
calculable targets specifying that 2000 households and 30 commercial electricity users should participate in Smart Customer Gotland, and that their combined electricity consumption should shift $+/-10 \%$ (Swedish Energy Agency, 2012). This objective was negotiated as the project proceeded, as I will show in later chapters. However, the project set out from an economic perspective on how users might become interested in joining the project - a perspective that is clearly visible in the objective on which the Swedish Energy Agency based their financing:

Provide opportunities for end customers to reduce their costs by actively participating on the electricity market at the same time as the system costs are reduced (Swedish Energy Agency, 2012:6).

These objectives suggested that users are interested in smart grids for economic reasons, and positioned them as customers who engage with the market. The emphasis on economic incentives is aligned with previous studies suggesting that stakeholders regard this to be the main motive for residential end-users to engage with smart grids (Ballo, 2015; Mah et al., 2012; Verbong et al., 2013). In upcoming chapters, I will show how these ideals not only influenced the smart grid that was established within this project, but also became questioned and undermined as the project unfolded.

Vattenfall and GEAB had different interests in this project, as did different parts of these companies. As a grid owner, GEAB's interest stemmed from the need to meet demands by the Swedish Transmission grid operator to uphold electricity quality and security, which were threatened by an increased implementation of intermittent energy sources. As sellers of electricity, on the other hand, both Vattenfall and GEAB considered this project to be an opportunity to enhance their framing as companies assisting in a transition to more sustainable energy production. As an international player, Vattenfall also considered this project to be of interest in terms of its engagements in other European countries - especially in Germany, which has more intermittent energy production than Sweden. Another 
argument in favour of the project was that it would grant Vattenfall the opportunity to produce commercially viable products; in this way, the project would enhance Vattenfall's future role as a provider of technical appliances and services for flexible consumption. The objective with Smart Customer Gotland was thus to construct a functional smart grid that was aligned with various interests and ambitions.

In this chapter I briefly described the local conditions - such as aims, ambitions, materialities, geographic location, main actors and their interests - that directed the kind of smart grid that was possible to construct within Smart Customer Gotland. When explaining the process of materializing a smart grid, the interviewed actors and the pre-study continuously drew on national conditions and on imaginaries of how a smart grid future could look like. This entanglement with national socio-material configurations is thus also important in understanding how the smart grid evolved on Gotland. The next chapter provides an analysis of this national contexts the local actors were drawing on; it attends to the wider Swedish electricity system and to sociotechnical smart grid imaginaries. After setting out these contexts, I will in the proceeding chapter analyse how these imaginaries were selectively mobilized and translated in the making of a smart grid configuration on Gotland. 



\section{Swedish sociotechnical smart grid imaginaries}

Both this chapter and the previous one are part of my analysis of the conditions that influenced what kind of smart grid could be constructed within Smart Customer Gotland. In Chapter 4, I described the local conditions of the specific case; here in Chapter 5, I will examine the imaginaries of a Swedish smart grid future. These imaginaries also influenced the kind of smart grid that could be achieved within this demonstration project. This chapter thus involves a spatial extension, as I move from a local particular setting to a general Swedish perspective. It also involves a transition in time, as I explore the futures that are evoked in national documents about smart grids, and analyse the implicit imaginations of smart grid futures that are contained in these documents. For me, these imaginaries constitute an important part of what Law (2004:27ff) defines as a hinterland: a geography of associations that holds relational webs together and enables certain human and non-human connections above others. Imaginaries of smart grid futures establish a route that influence which realities are more or less likely to be made possible; imaginaries function as a template of associations that legitimize certain configurations and make them thinkable and meaningful; imaginaries thus influenced what kinds of smart grids were achievable within Smart Customer 
Gotland. I draw on Jasanoff and Kims' (2009; 2013) concept of sociotechnical imaginaries in order to unpack notions of smart grid futures. I base this chapter on an analysis of all the official documents that were produced during the course of constructing a Swedish action plan for a smart grid implementation. These texts were produced by influential smart grid advocates and include items such as transcripts from seminar discussions, reports on specific topics, scenario reports of smart grid futures and final reports (for details, see Chapter 3). By engaging in such an analysis, I scrutinize the reasons why these actors stress the significance of a smart grid implementation, why they find this implementation to be important and what expectations they ascribe to the smart grid. The actors' descriptions of smart grid establishments contain traces of what they define as desirable in terms of human and non-human relations, and of what kinds of future societies they find attractive.

The voices heard in these documents represent a distinguished group of actors who were summoned to participate in the creation of the Swedish smart grid action plan. These actors were thus influential enough to be able to guide the smart grid future by transforming their expectations of what a smart grid could enable into requirements that these expectations be fulfilled (cf. van Lente \& Bakker, 2010). In this way, sociotechnical smart grid imaginaries function as a powerful means of persuasion; they define what is considered logical and set future directions.

Sociotechnical imaginaries are directed by current situations and are embedded in a national context (Jasanoff \& Kim, 2009, 2013). They link the future with the past and the present: what is happening now and what has happened before will influence what will happen tomorrow. In other words, "some account of relative embedding, or rootedness, is needed for us to understand both durability and change" (Jasanoff, 2015:21). Therefore, I understand sociotechnical imaginaries and the history and presence of the Swedish energy system as part of the 
"hinterland" within which Smart Customer Gotland operated. Before I engage with notions of smart grid futures, I will provide a brief overview of the current Swedish energy system, which constitutes the foundation for smart grid futures.

\subsection{The current Swedish energy system: an introduction}

The Swedish electricity grid is arranged hierarchically into three different levels: the national transmission grid, the regional distribution grids and the local distribution grids. These grids are connected through substations that convert the voltages to lower levels. The transmission grid constitutes the structure's backbone, transporting electricity over long distances; it then branches off into distribution grids that deliver electricity to end-users. However, this infrastructure is not isolated to national borders; the Swedish electricity system is connected to other Nordic countries through high-capacity lines (Wangel, 2015). Although the transmission grid is solely operated by the state-owned company Svenska Kraftnät, the distribution and local grids are owned and operated by several actors, of these, three large companies hold dominant positions: Vattenfall, EON and Fortum (ibid). This grid structure is built to transfer electricity in one direction: from production units to end-users. However, as I will show in this chapter, sociotechnical smart grid imaginaries propose alternatives to this current configuration.

\subsubsection{Large-scale production and high consumption}

In a per capita comparison, Sweden is the sixth highest electricity-consuming country in the world (Swedenergy, 2014b). The reasons for this position are plentiful. Sweden's geographical position, which entails very cold winters, and its continuous economic growth over extensive periods of time, are two frequently mentioned reasons (Swedenergy, 2014a). Political decisions that were made during the 1970s is another reason, as electric radiators were installed in many Swedish 
homes in order to construct a demand for soon-to-be-installed nuclear power facilities (Summerton, 2004). A final oft-mentioned reason is the second international oil crisis, which encouraged the installation of electric heaters in the early 1980s (Swedenergy, 2014a). The national Swedish trend of increased electricity usage for heating and warm water lasted until 1990 and then decreased, partly due to frequent installations of more energy-efficient solutions such as heat pumps (Swedish Energy Agency, 2015). To this day, heating (including hot water) represents more than half of the energy used in Swedish homes and buildings. In small residential houses, the most common energy source for heat is electricity, while district heating is the most frequently used source in apartment blocks (ibid).

With regards to electricity production, the Swedish energy system differs from those of many other countries. Almost $50 \%$ of Swedish electricity is produced by hydropower and slightly more than $30 \%$ is produced by nuclear power, the remaining amounts come from thermal power, wind power and a very small portion of solar power (Statistics Sweden, 2015). Nuclear power has long been a debated energy source in Sweden, and was the subject for a public referendum in 1980. At that time, Swedish citizens were asked to vote on whether they supported a future energy system with or without nuclear power. In this way, the referendum encouraged people to become informed and to take a stance. As upcoming chapters will show, Swedish nuclear power is still to this day, a topic that evoke various opinions among persons I interviewed for this study.

The alternative choice - of nuclear power being phased out at a pace that allowed for sustained economic wealth - gained the most votes in the public referendum, but various negotiations on how to interpret this outcome have been intensively debated ever since (Anshelm, 2000; Kall, 2011). After the referendum, the Swedish parliament decided that nuclear power should be replaced with renewable energy sources until 2010, a decision which since then has been questioned and 
renegotiated (Kall, 2011:75ff). In 2016, the Swedish parliament came to an agreement that all electricity produced in Sweden should be based on $100 \%$ renewable energy sources by 2040; however, the parliament also decided that the market should decide when and whether it would be appropriate to phase out nuclear power by declaring: "[t]his is a goal, not an end date that prohibits nuclear power and does not mean the closure of nuclear power with political decisions" (Government Office of Sweden, 2016:1). This shift illustratively shows that decisions about the future Swedish energy system have been transferred from the political arena, in which citizens take a position by voting for political parties or in referendums, to the market.

This shift is also visible in Sweden's reliance on a market-based support system as a means of increasing electricity production based on renewable energy sources. This so-called "electricity certificate system" was introduced in 2003 (Swedish Energy Agency, 2017), and is based on the logic that market competition generates the best kinds of solutions, in regards to both economic prosperity and environmental considerations. In the period since this system was introduced, wind power has shown the most intense increase in electricity produced by a renewable energy source in Sweden and now accounts for around 10\% of the country's total electricity production (Swedish Energy Agency, 2016b). However, this does not represent a dramatic change in small-scale production units, as wind power production is dominated by large parks with very good wind conditions (ibid). Solar power, on the other hand, only accounts for $0.04 \%$ of Sweden's total electricity production (Swedish Energy Agency, 2015). Energy production in Sweden is thus characterized by large-scale production units, a configuration in which large energy companies hold dominant positions.

Bladh (2007), a historian of technology, shows that this has not always been the case, the Swedish electricity system used to be characterized by small, decentralized 
units operated by communities or single households. Bladh (2007) argues that in the transition to a centralized system operated by large companies, electricity users lost their direct contact with electricity production; as a result, their technological understanding decreased, changing electricity from something comprehensible into an anonymous entity (Bladh, 2007). As I will show later in this chapter, sociotechnical smart grid imaginaries are based on ideas of active and empowered users who for example produce their own electricity; in a sense, these prospects entail a return to previous configurations.

\subsubsection{The energy system operating on a liberalized market}

As I noted earlier, the Swedish energy system is market-based. It has thus undergone a marketization, a process in which previous monopolies transform into market structures that re-arrange their organization and regulation (Çaliskan \& Callon, 2010). This huge reform took place in 1996, when the previous state monopoly was abandoned in favour of a liberalized electricity market in Sweden. The historians of technology Högselius and Kaijser (2010) show that this reform was not necessarily introduced as a means of handling a dysfunctional system; in fact, they found that the transition was based on ideological grounds rooted in neoliberalism. The reform was primarily designed by energy economists, and apart from a few experts there were not that many who actually understood the dignity of the Swedish liberalization when it took place (Högselius \& Kaijser, 2007:138).

For electricity users, this liberalization created the possibility of choosing between competing utility companies and contracts, whereas the grid did not allow such choices. This reform had a very symbolic meaning, in the sense that users were no longer described as being forced into passivity, but were rather expected to behave as responsible customers empowered with the ability to influence the electricity market (Summerton, 2004). This reform thus meant that people were positioned as 
customers, who express their ideas of what is desirable through the services and goods they buy on the market. In Chapter 7, I will show that there were both households who participated in Smart Customer Gotland and prosumers, who directed critique towards this logic. They argued that the market choices they were given did not give them the possibility to influence anything of importance in relation to the future energy system.

The liberalization of the Swedish electricity sector resulted in a framing in which electricity became an economized good to be bought and sold on the market. Callon, Millo, and Muniesa (2007) suggest that activities on the market would be impossible to conduct without the presence of certain technical tools, which they denote as "market devices"; these devices give people a certain perception of what it means to be economical. The liberalization of the Swedish electricity market was followed by the establishment of various such market devices as well as other reforms, rules and regulations that strengthened the logics of the market in different ways. A crucial component was the Nordic electricity trade market, Nord Pool, which opened in the same year as the market was liberalized. The aforementioned certificate system is another example of an establishment that is aligned with the idea of electricity as a market commodity.

Another central change of the Swedish energy system occurred in 2011, when the Swedish energy market was divided into four bidding areas; in practice, this means that users in areas with low electricity production (i.e. southern Sweden) at times pay a higher price for their electricity than users in areas with high production (i.e. northern Sweden). This arrangement was introduced as a way to stimulate the establishing of new power production units in areas with electricity deficits, and to signal to Svenska Kraftnät where grid enforcements were needed. Also, it functioned to ensure that Sweden did not come in conflict with EU regulations of free mobility for services and goods (Swedish Energy Markets Inspectorate, 2014). 
Wangel (2015) stresses that the establishment of these bidding areas were a means to ensure the flow of electricity between countries thereby contributing to the creation of a unified European electricity market. The establishment of these bidding areas can thus be understood as further strengthening the marketization (Çaliskan \& Callon, 2010) of the Swedish energy system.

Another reform, highly central from a smart grid perspective, that followed similar principles was the reform that facilitated the installation of smart meters in Swedish households. In 2009, a new metering regulation facilitated the introduction of these devices by specifying that grid owners had to measure their customers' electricity consumption on at least a monthly basis. The ministry behind this regulation rationalized this reform as being caused by the underperformance of the liberalized electricity market, and claimed that customers' willingness to influence their electricity consumption by changing electricity provider would increase if they were given access to more precise information (Government Office of Sweden, 2002).

To meet this legal requirement, almost all grid owners decided to install more advanced equipment than was required; as a result, most Swedish households have meters that can register hourly consumption and handle two-way communication, characteristics that qualify these devices as smart meters (Swedish Coordination Council for Smart Grid, 2013a). Since smart meters enable rigours measurements of electricity consumption and transmit signals between market actors, they can be understood as market devices that strengthen the enactment of electricity as a calculative commodity. The widespread use of similar devices has led to intense debates in other countries for reasons such as health concerns, privacy issues and unfair distribution of cost versus benefits (Mah et al., 2012). Such concerns have not been loud in Sweden, however; on the contrary, the installation of smart meters was performed with no substantial public debate. 
In 2012, the Swedish government implemented yet another reform based on market logics and economically driven principles. This reform allowed people to demand that their electricity consumption be measured in even more detail, on an hourly basis. The responsible ministry justified this change by referring to market logics and economic incentives:

Most important, however, is the electricity consumers' increased ability to strengthen their position on the electricity market and reduce their electricity costs.[...] It should to a larger extent than today be possible to affect one's electricity costs by being an active electricity customer. (Government Office of Sweden, 2011:8)

This perspective aligns with Callon's (2007b) argument that market structures are established to facilitate actions that are considered to be economic. Contrary to what many social scientists claim, Callon argues that "homo economicus" really exists, because "He is formatted, framed and equipped with prostheses which help him in his calculations" (Callon, 1998:51). Drawing on these conceptualizations and through a series of reforms, the Swedish electricity user has been encouraged to act as a homo economicus who bases decisions on what is the most economically advantageous. Such a framing of the electricity market is recognized in international research; for example, Aune, Godbolt, and Sørensen (2016) have shown that economists engaged in energy policymaking expect households to act as calculative agents that adjust their consumption according to price signals, make informed choices regarding which supplier is the cheapest and make economically sound decisions regarding energy-efficiency measures in their homes. However, this kind of economic framing has not always played out successfully in a Swedish context. For example, the introduction of hourly measurement was not particularly successful, as very few Swedes changed their electricity contracts to allow for hourly measurements (Nilsson, Leymann, \& Näselius, 2014). Nevertheless, this is the overall framing that Swedish smart grid stakeholders point to as creating the best prerequisites for smart grid implementation; they refer to the metering regulation, 
liberalization and smart meters as creating excellent requirements for a Swedish smart grid implementation (e.g. Swedish Coordination Council for Smart Grid, 2013a).

\subsubsection{Initial steps towards a Swedish smart grid implementation}

The first major step that recognized the potential of a Swedish smart grid occurred in May 2012, when the Swedish government of that time decided to appoint the Swedish Coordination Council for Smart Grid. This council was assigned the objective of developing a national knowledge platform and stimulating cooperation in the field of smart grids; they were also given the task of writing a national action plan for smart grids for the years 2015-2030 (Government Office of Sweden, 2012). In December 2014, the council presented its proposed action plan and recommended that a new forum for smart grids be established when the council dissolved (Swedish Coordination Council for Smart Grid, 2014a). A year later, the Swedish government decided to follow this recommendation and establish the Forum for Swedish Smart Grid, with the primary objective to implement the Swedish smart grid action plan that was established by the previous council (Government Office of Sweden, 2015). The forum is connected to the Swedish Ministry of the Environment and Energy and in August 2017, the Swedish Minister for Energy, Ibrahim Baylan, was appointed as chair (Forum for Swedish Smart grid, 2017); a clear indication of how highly ranked smart grids are on the Swedish political agenda. Besides three large-scale smart grid demonstration projects (see Chapter 4), there are several ongoing initiatives in Sweden with objectives to design, assess and implement various smart grid configurations on a smaller scale. These projects focus on different elements of smart grids (e.g. electrical vehicles, implementation of intermittent energy sources, flexible consumption etc.) and are 
conducted in conglomerates of various constellations consisting of actors such as grid owners, technology developers and universities (Ramböll, 2013). ${ }^{7}$

To sum up, the Swedish electricity system is currently characterized by a hierarchical system in which electricity flows in one direction from large-scale energy production units to high-consuming electricity users. In this system, electricity is primarily produced by hydropower and nuclear power. This system operates within a liberalized electricity market that is based on the ideological basis of people making rational and economic decisions when provided with enhanced access to information. This backdrop constitutes the foundation for a smart grid implementation, which is a prioritized political topic.

\subsection{Outlining smart grid futures}

I will now examine the future, as evoked in official documents that were produced when the Swedish smart grid action plan was formulated - a work that was initiated by the Swedish Coordination Council for Smart Grid. I will present five different notions of smart grid futures that I have traced in these documents: sustainable society, flexible futures, digital dreams, successful Sweden and empowered and active electricity users. These notions are interwoven and overlapping; combined, they make up smart grid futures as evoked in Swedish strategy and planning documents. The notions that I describe here attach associations to the smart grid, and connect the smart grid to ideas of what kind of smart grid futures are desirable, sought-after and worth striving for. They thus evoke smart grid's web of relations (Law, 2009:141f). In this section, I describe each of these five notions in detail and examine the kinds of associations influential smart grid stakeholders attach to smart grids.

\footnotetext{
${ }^{7}$ For an overview of Swedish smart grid initiatives, see the Forum for Swedish Smart grid at: http://swedishsmartgrid.se/smarta-elnat-i-sverige/
} 


\subsubsection{Sustainable society}

Sustainability is one of the most prominent justifications in advocates' arguments for smart grids; they frequently legitimize a Swedish smart grid implementation by pointing out how it can provide a transition into a sustainable society. For example, such expectations are visible in the name of one of the council's smart grid information folders, which is denoted "Smart Grid - For a Sustainable Energy Society" (Swedish Coordination Council for Smart Grid, 2013b). Smart grid advocates frequently comment on how smart grids are well-suited to contribute to the country's climate and energy ambitions. The head of the Swedish Coordination Council for Smart Grid argues that the council's whole existence is motivated by how "we have to meet our ambitious energy and climate goals and contribute to the development of a sustainable energy system" (Khorsand, as cited in Swedish Coordination Council for Smart Grid, 2012).

The council hired the organization North European Power Perspectives to assess the possibility of smart grids enabling such ambitions and in their final report, they concluded "smart grids will contribute to achieve our energy and climate goals!" (North European Power Perspectives, 2014c:4). This statement referred to four overarching goals and directives: first, that Sweden should reduce its greenhouse gases emissions by $40 \%$ by 2020 ; second, that by the same year, $50 \%$ of Swedish energy consumption should be based on renewable energy sources; third, that the European Union's energy usage should have decreased by $20 \%$ by 2020 . Beyond these so-called "2020 goals", North European Power Perspectives expected that smart grids would assist in achieving a fourth goal, that the Swedish transport sector should be free from fossil fuels by 2030 (ibid). However, in another report the organization clearly stated that the future importance of a Swedish smart grid was strongly linked to affairs in other countries, and to how future energy and climate objectives were to be formulated. In particular, that report referred to the 
uncertainties regarding whether intermittent energy sources would become widely spread or not:

How big the expansion of renewable, variable/intermittent electricity generation in Northern Europe will be, is of course of crucial importance to the need to develop smart grids. In the scenarios with the strongest expansion of renewable energy, the proportion of intermittent power capacity should already reach over $50 \%$ in 25-30 years, both in the Nordic region and in Europe as a whole. If such a development becomes reality, it will result in high demand for the development of smart grids. In scenarios with moderate amounts of renewables, the share of intermittent power capacity will be no more than moderate, reaching at most $15-20 \%$ in 2050. The requirement for smart electricity grids will then not be nearly as big. (North European Power Perspectives, 2013b:2f)

According to the prospect prepared by North European Power Perspectives, a future with a fully-fledged smart grid will rely on an energy system in which at least $50 \%$ of the electricity is produced by intermittent energy sources, such as wind or solar. In this way, smart grids are closely associated with intermittent energy sources that often have a distributed character (North European Power Perspectives, 2014d). In contrast to today's grid structure, electricity in a smart grid future is expected to flow in both directions instead of only from centralized production units to end-users. This system further contains production units generating electricity depending on when the sun shines and the wind blows.

\subsubsection{Small-scale or large-scale facilities}

The smart grid future as evoked in the studied documents include small-scale, distributed production units that generate electricity from intermittent energy sources; the smart grid advocates point to a future with an increased use of smallscale wind turbines and solutions based on solar energy (Swedish Coordination Council for Smart Grid, 2014c:18). However, other voices oppose a system that is 
completely based on such energy sources, since they cannot secure a stable electric grid. In the words of the consultant and service provider STRI:

Large power plants are needed, not only to produce electricity, but also to keep the system stable, and to provide sufficient backup power in case an important component of the system fails. Such systems services are generally not delivered by renewable electricity production facilities. (STRI, 2013:11)

This quote shows STRI's doubts regarding whether major changes are possible without challenging the reliability of the energy system. Swedish smart grid stakeholders frequently argue that small-scale facilities cannot replace larger ones. The Swedish Coordination Council for Smart Grid states that a decreased reliance on larger facilities will probably result in power shortages and large price fluctuations, and suggests that the best way to avoid such a scenario is to change the electricity market regulations so that larger facilities still remain profitable (Swedish Coordination Council for Smart Grid, 2014a:226). The council thus argues for a sustainable energy system that is reliant on large-scale facilities. Such a standpoint however raises the question of what is considered sustainable and what is not.

As mentioned earlier, the current Swedish system primarily relies on electricity produced by hydropower and nuclear power. Especially the debate on whether nuclear power should be considered sustainable or not has a long history in Sweden. Advocates argue that nuclear power does not produce carbon dioxide emissions, and is therefore environmentally friendly, while opponents associate nuclear power with the radioactive waste it produces, and argue that it is a highly harmful energy source that cannot be considered sustainable (Anshelm, 2000:15f). Arguments for and against nuclear powers relation to a sustainable society are also highly prevalent in the Swedish smart grid strategy and planning documents. On the one hand, phasing out nuclear power is evoked as part of a sustainable society. 
For example, the council's scenario of a fully-fledged smart grid future links nuclear power with "climate anxiety":

[T] he climate anxiety that appeared in the years around 2010 gained new momentum as the effects of climate change became increasingly more apparent. This led to a declining confidence in both fossil and nuclear solutions, by both politicians and the general public. (Swedish Coordination Council for Smart Grid, 2014c:17)

On the other hand, another report by the council disconnects nuclear power from climate concerns by stating that "[r]egarding the electricity production mix, Sweden has a favourable situation from a climate perspective", and referring to Sweden's reliance on nuclear and hydropower as the main reasons for this situation (Swedish Coordination Council for Smart Grid, 2013a:71). What makes this ambivalence particularly interesting from a smart grid perspective is that if nuclear power continues to hold a prominent position in the Swedish energy system, the need for a fully-fledged smart grid appears to be reduced. The question of how electricity should be produced in a sustainable smart grid future is thus not completely clear. Such uncertainties regarding what is considered sustainable are also prevalent in prospects about future electricity consumption.

\subsubsection{Reduced or increased electricity consumption}

Smart grid advocates express different opinions on whether or not general electricity consumption will decrease in the future. According to some arguments, users in a smart grid future will reduce their consumption for example due to personal efforts and more energy-efficient buildings (North European Power Perspectives, 2014a:7; Swedish Coordination Council for Smart Grid, 2014b). In contrast, other arguments predict that electricity consumption may increase in the future. Such opinions can be based on assumptions of how the transport sector will 
be electrified, how households will use more electrical appliances and how industrial processes will become even more energy-intensive in the future (ibid).

Increased usage of electrical vehicles is an illustrative example of how different ambitions clash. On the one hand, an electrified transport sector is associated with climate-friendly connotations. On the other hand, such a development contradicts the ambition of reduced electricity consumption. The key strategy for handling this dilemma that smart grid advocates suggest is to emphasize efficient consumption over reduced consumption, i.e. the ambition is not necessarily to reduce electricity consumption, but rather to avoid consumption peaks that occur due to similar consumption patterns. The smart grid advocates' overall plan to flatten such peaks is through evened-out consumption; that is to shift consumption in time rather than to necessarily reduce consumption. This plan implies that in a future smart grid society, electricity consumption may well continue at present levels or even higher, as long as consumption peaks are lower. However, smart grid proponents have raised concerns that flexible consumption may be counteracted by EU directives:

Developments within the EU are moving towards more detailed requirements for energy efficiency and it is important that these do not undermine the potential to even out loads and allow flexible use. (Swedish Coordination Council for Smart Grid, 2014a:92)

The council thus presents flexible electricity consumption as preferable to reduced electricity consumption; implying that flexibility, rather than reduction, will pave the way towards a sustainable future.

One of the core ideas of the notion of a sustainable society as evoked in the studied documents, is that sustainability can be achieved without causing any restrictions, discomfort or uneasiness for electricity users; for example formulated as "in general, no short-term reduction of power has a significant impact on comfort" (North European Power Perspectives, 2013c:5). One reason behind this idea, as suggested 
by smart grid advocates, seems to be that the "greening" will coincide with other notions. By making the future more flexible, more digital, more successful for Sweden and inhabited by empowered and active electricity users, smart grid advocates seem to suggest that sustainability can be fulfilled without compromises.

\subsubsection{Flexible futures}

As mentioned earlier, flexibility is a treasured notion in sociotechnical smart grid imaginaries. Smart grid advocates primarily push for flexibility, since a large-scale increase of solar and, in particular, wind power would require alterations in how to balance the electricity system (Swedish Coordination Council for Smart Grid, 2013a). One challenge can be formulated as "[t]imes of day with excess power will shift quickly to times of power deficiency. The system must therefore be designed properly and be prepared to quickly adjust" (North European Power Perspectives, 2013a:25). Another core challenge is to transfer electricity from areas with high production and low consumption to areas with low production and high consumption. In other words, "[t]here is a significant risk that renewable power will be trapped in certain regions" (North European Power Perspectives, 2013a:25). Unlike many other countries, the Swedish energy system includes hydropower facilities that can be relatively easily turned on and off, unlike the alternatives. Thus, they can to an extent handle the challenges caused by inequalities between demand and supply. However, a report authored by North European Power Perspectives states that hydropower alone is insufficient to regulate the variations that come with an increased introduction of wind power (North European Power Perspectives, 2013a). Instead of relying on the traditional way of adjusting power production to meet demand or on a strengthening of the grid to handle these challenges, smart grid proponents urge for the installation of a more intelligent grid: 
Smart grids can be said to contribute to allowing the flexibility of the electricity system to be utilized to a much greater extent and more efficiently; in other words: the ability to manage complexity increases. (Swedish Coordination Council for Smart Grid, 2013a:30)

Smart grid advocates thus describe flexibility as a solution that can handle the increased complexities they anticipate will follow from the large-scale introduction of intermittent energy sources to the energy system. They suggest that the smart grid can offer flexibility in a variety of different ways. For example, smart grid stakeholders propose that batteries can function as flexibility providers; in particular batteries of electric vehicles play an essential role in their sociotechnical smart grid imaginaries. These batteries are expected to be charged when there is excess electricity in the grid and discharged when there are electricity deficits (Swedish Coordination Council for Smart Grid, 2013a). In other words, an electrical vehicle can be described as a "flexible resource" (North European Power Perspectives, 2014d:10).

Smart grid stakeholders furthermore suggest that imbalances between demand and supply can be regulated based on a larger geographic area. They propose that the Swedish energy system will become even more integrated with the Northern European electricity market and grid structures and that electricity produced in Sweden will be exported to other countries to a larger extent (North European Power Perspectives, 2013a). They argue that a smart grid is needed in order for electricity to easily flow over national borders, since, "[i] ncreased European coordination of the electricity market, both physically and regularly, also enforces increased intelligence” (North European Power Perspectives, 2013b:2).

These prospects provide an account of how the future energy system enables flexibility by transforming itself into a flexible unit. The elastic capacity of the future energy system at different scales does not seem to include any strict boundaries 
regarding what should be included in the smart grid and what should not. This flexibility entails non-static assemblages that are in constant flux, concerning not only what kinds of entities are part of the smart grid, but also what kinds of relations they have to one another. Of course, this elasticity contributes to the general impression of smart grids as having a flexible nature, as noted in previous studies (Skjølsvold et al., 2015; Stephens et al., 2015). The primary way to increase flexibility, as proposed by smart grid advocates, is however through introduction of flexible electricity consumption.

\subsubsection{Flexible electricity consumption in flexible smart grid futures}

The idea that electricity usage should match the hours of production is at the core of the sociotechnical smart grid imaginaries. The notion of flexible futures rely on the introduction of so called "flexible consumption", i.e. that electricity consumption will increase during times of electricity excess and decrease during times of electricity deficit (Swedish Coordination Council for Smart Grid, 2013a). A report published by the Swedish Energy Markets Inspectorate illustratively describes what such flexibility entails:

In the future, instead of having producers adapt their production to the consumers' electricity consumption, consumers might have to adjust their consumption based on what the producers are capable of producing in each and every moment. (Bollen, 2010:4)

In this way, the responsibility of ensuring a stable and well-functioning grid is directed away from the production side and towards the consumption side of the electricity grid. However, the prospects of flexible consumption in households depend on what kind of electricity usage should be shifted in time. Since some devices are more common in certain kinds of homes than in others, such prospects also become a question of housing. A dwelling type that is frequently associated with such prospects is the "smart home", in which most electricity consumption of 
the entire home seems to be flexible, as "thermostats and other sensors are connected to the electricity meter and smart appliances can automatically be turned on and off" (Larsson \& Ståhl, 2011:26). Other smart grid advocates offer a much more restricted list of the kind of devices that should be shifted in time, for example a representative from the Swedish electricity companies' $R \& D$ organization, Elforsk, argues that "[i]n apartments, there is not that much flexibility to mention, and who wants to be disturbed by a centrifugal washing machine in the middle of the night?" (Magnus Olofsson, as cited in Swedish Coordination Council for Smart Grid, 2012). Instead, Elforsk's recommendations focus on "villas and not apartments; especially not newly built apartments, as new electrical appliances are very energy efficient with low power consumption" (ibid). This perspective aligns with those of other smart grid proponents, who particularly target electricity-heated villas as having the best potential for flexible consumption (North European Power Perspectives, 2013a). In their final report, the Swedish Coordination Council for Smart Grid argues for flexible consumption to be introduced in three sequences: first, in companies; second, in households with large electricity consumption; and finally, in all remaining households (Swedish Coordination Council for Smart Grid, 2013a). As mentioned in Chapter 4, Smart Customer Gotland did not take place in a newly built city district and, as such, it differs from other large-scale Swedish smart grid demonstration projects. This demonstration project resonated with the suggestion proposed in Swedish strategy and planning documents as it initially set out to include both companies and detached villas. In Chapter 6, I will however show that the task of enrolling households and companies to engage with flexible consumption, was more challenging than the sociotechnical smart grid imaginaries suggest. 


\title{
5.2.2.3 Fluctuating electricity prices as a way of encouraging flexibility
}

Swedish smart grid advocates emphasize economic gains as the main motivator for flexible consumption in a way that aligns with previous research findings (Ballo, 2015; Mah et al., 2012; Verbong et al., 2013). This kind of logic rests on the assumption that prices will fluctuate more in the smart grid future, and that the market subsumes to theories of supply and demand, such that a fluctuating electricity supply inevitably results in a fluctuating electricity demand:

\begin{abstract}
An increased amount of intermittent renewable production results in rapid price changes, and increases the electricity users' interest to adjust their energy use to times when prices are low, and thus to reduce their costs. (Swedish Coordination Council for Smart Grid, 2014b.31)
\end{abstract}

However, smart grid advocates push for a number of changes to be implemented in order for electricity users to be persuaded to adjust their consumption to fluctuating electricity prices. For example, the council states that "as long as the customer is charged on a standard profile curve, there is no economic incentive for consumer flexibility" (Swedish Coordination Council for Smart Grid, 2013a:135). Instead, the council argues for new price models that "give customers economic incentives for load shifts" (Swedish Coordination Council for Smart Grid, 2013a:48). In a report by North European Power Perspectives this is also formulated in terms of empowerments: "Flexible consumption can give customers real influence over their costs if electricity usage is steered by price signals by means of hourly measurement and debiting" (North European Power Perspectives, 2013c:4). The council even suggests that the concept of economically driven flexible consumption can be further encouraged through the installation of devices that are directly connected to the Nordic power markets' epicentre, the Nord Pool Spot. In this way, electricity users are suggested to "utilize equipment that bases the automatic control of electricity usage on the electricity price" (Swedish Coordination Council for Smart Grid, 2014:119). They thus seem to suggest that electricity prices should 
automatically determine when devices should be turned on or off; a suggestion that illustrates the smart grid advocates' trust in economy as a main incentive to encourage flexible consumption.

Two different alternatives of flexible consumption are evoked in the studied documents: either electricity users adapt their consumption to fluctuating electricity prices themselves, or automatic solutions manage flexible consumption based on signals (primarily price signals). Smart grid stakeholders further suggest that the automatic solutions can be remotely controlled by someone outside of the household; simply, "[t]o control or to be controlled, that's the question" (North European Power Perspectives, 2014b:20). The question of who should steer the electricity consumption; utility companies or users themselves is also recognized in previous smart grid studies that present this as one of the core issues when it comes to flexible consumption (Christensen Haunstrup et al., 2013; Nyborg \& Røpke, 2011).

The notion of a flexible smart grid future thus relies on entangled relations between devices, tariffs, electricity users, utility companies and the electricity market; relations that primarily have an economic nature. In Chapter 6, I will show the tensions, doubts and contradictions that arise as persons working in Smart Customer Gotland struggle to establish a smart grid within such an economic framing. In Chapter 7, I will show that users that participated in the demonstration project and prosumers direct severe critic towards this framing. For now, I will continue to explore the smart grid future as evoked in Swedish smart grid strategy and planning documents and move on to show that achieving flexibility seem to depend on another core notion of the smart grid future: digitalization. 


\subsubsection{Digital dreams}

Smart grid advocates suggest that flexibility will be achieved through digital solutions, and argue that smart grids can handle large volumes of data by making use of new forms of advanced calculating technology and software (Swedish Coordination Council for Smart Grid, 2013a). As I described in the introduction to this thesis, a smart grid can generally be understood as a digitalized electricity grid. Previous research has shown that information communication technologies (ICTs) are expected to add intelligence to the grid and thus transform the "dumb" grid into a "smart" version (Nyborg \& Røpke, 2013; Verbong et al., 2013; Wissner, 2011). Such notions are also prevalent among Swedish smart grid advocates; for example, the council argues that digitalization will enable huge volumes of information to travel back and forth constantly. To the council, this constitutes the essential difference between a traditional grid and a smart grid: while the former can only transmit information in one direction, the "Smart Grid, similar to the Internet, opens up the possibility of information traveling in two directions" (Swedish Coordination Council for Smart Grid, 2013b). The key device in smart grid digitalization is the smart meter; today, these meters allow the real-time measuring of electricity consumption, and can receive remote control signals that turn electrical devices off and on (Swedish Coordination Council for Smart Grid, 2013a). Although these meters are now connected to houses, the council suggests that "tomorrow they might consist of different virtual components for the home and the car, but perhaps also of embedded features that enable the user to be connected to all their consumer electronics" (Swedish Coordination Council for Smart Grid, 2013a:47). Incorporated into a large and ubiquitous infrastructure that will encompass many, if not all, aspects of social life in the future, these meters seem to as play an essential part in the future as evoked in the studied smart grid documents. In this future, people will encounter interconnected devices everywhere 
in society, providing them with constant access to information - a feature that is highly prevalent in the council's scenario of a fully-fledged smart grid future:

Both at work and at home, all appliances that fulfil the everyday lives of people are in principle digitally connected today. Most of them provide automated, advice-based services to facilitate middleclass lives regardless of where we look in the world. For example, solutions that surveil, optimize and steer energy consumption are in high demand within real estate, thanks to the overwhelming majority of people and private companies that affirm digitally based services. (Swedish Coordination Council for Smart Grid, 2014c:18)

According to imaginaries such as these, instantaneous data transfers will permeate every aspect of social life, as almost nothing will escape this digital force. In the digital tomorrow, increased amounts of information will also characterize the grid itself.

\subsubsection{Increased monitoring}

The council argues that current monitoring and control systems are few in the local grids, and electricity users are usually the first to notice if there is a failure somewhere. However, they anticipate that "[i]n the future, errors are automatically detected [...] since the smart grid operators will have a comprehensive overview of the entire distribution system [...] and completely new ways of steering and surveilling the grid” (Swedish Coordination Council for Smart Grid, 2013a:44). Smart grid advocates argue that these capabilities are essential in a future with intermittent energy production, since electricity will then travel in both directions and be difficult to steer. In a sense, the smart grid future does not seem to tolerate the existence of black-outs and other disturbances. Instead, all perceived weaknesses seemed to be solved in a regimented manner by improved information and monitoring capacities. Smart grid advocates thus describe the digital tomorrow as enabling a resilient society that operates with sustained functionality even when 
challenged by unexpected events. However, the technology provider Siemens expands on this perspective and states that while smart grids will provide resilience, they will also introduce a double nature to such solutions:

Society today is more connected and paired, and characterized by a greater complexity involving more actors than ever before, which is something that can help increase societal resilience, but at the same time make society more sensitive and thus also less resilient than before. (Tina Karlberg, as cited in North European Power Perspectives, 2014a:14)

The smart grid future seems to rely on a dual mechanism. On the one hand, society will thrive on control functions; on the other hand, this implies a more sensitive society that malfunctions when introduced to unexpected situations. A recurring line of argument among smart grid advocates is that the threats leading to malfunctions in the smart grid future will all be associated with ICT. For example, the consultancy firm 4C Strategies states that ICT is a key issue in smart gridrelated hazards (4C Strategies, 2013:14). This can also be formulated as "when problems then start to reappear, there is a clear risk that we have to shut down parts of the smartness again" (Malmgren \& Johansson, 2014:41); that is, although ICT makes the grid smart, this smartness can backfire. Simultaneously serving as a saviour and a hazard, the highly digitalized smart grid can thus be characterized as a 'two-faced Janus'. However, smart grid advocates seem to promote digital services and devices; and one reason for this is that they propose that such solutions will generate prosperity for the companies behind them; advocates thus connect digitalization with welfare and success, which is another notion of sociotechnical smart grid imaginaries.

\subsubsection{Successful Sweden}

The notion of Sweden as a successful country is another highly prevalent notion that is visible in the analysed documents. Smart grids are frequently expressed as a 
necessity in order to sustain prosperity; for example, this argument is used by the CEO of a smaller energy company:

Making the networks smarter is the only option we have, if we want to maintain our standard in the future. (Brühl Hjort, 2016)

The arguments for a Swedish smart grid implementation carry the baseline assumption that the security and quality of the electricity supply will be jeopardized or even threatened when intermittent energy sources are introduced into the electricity system. One possible solution to such challenges is to enforce the grid so that it can operate even under these changed circumstances; however, smart grid advocates repeatedly describe this option as unnecessarily costly. Instead, the council argues that such investments "to a certain extent can be suppressed or postponed using smart grid technologies" (Swedish Coordination Council for Smart Grid, 2014a:62). In this way, advocates legitimize smart grids as a way of handling upcoming challenges more economically than to replace the entire grid. Such arguments appear most strongly when the council describes a future with a great deal of intermittent electricity production, but without widespread smart grid solutions:

The cost of electric grid maintenance has risen sharply due to all investment needs. As a yearly average, the price of electricity is relatively low, but the variations are large and sometimes extreme, entailing high costs of sustaining a balanced grid. This has meant that the major part of the electricity cost for customers is the expenses paid for using the grid. (Swedish Coordination Council for Smart Grid, 2014c:26)

Such an argument suggests that smart grids are necessary in order to avoid future expenses. Smart grid advocates repeatedly legitimize smart grids by pointing out that they facilitate the combination of a greener society with economic welfare; they thus use arguments that are characteristic of ecological modernization, and promises that are based on environmentally friendly technologies. Just as Lidskog 
and Elander (2012) argue that the Swedish environmental policy has been guided by ecological modernization since the mid-1990s, smart grid advocates suggest that environmental issues can be solved within current institutions, without contesting the current economic growth paradigm.

\subsubsection{Sweden as an international forerunner within a growth industry}

The advocates further deepen the connection to economic growth when they describe smart grids as an emerging market. For example, the Swedish Coordination Council for Smart Grid states that Sweden has excellent preconditions "for smart grids to become a successful growth business" (Swedish Coordination Council for Smart Grid, 2014a:204). Business Sweden, the Swedish trade and investment council, further expands on such a perspective, and claims that smart grids have the potential to "contribute to growth, employment and export revenues to a significant extent" (Business Sweden, 2013:3). The head of the council is aligned with such prospects, as she proposes that smart grids enable "new business opportunities and new ways of doing business and making money" (Khorsand, 2016). Overall, these associations are based on a nationalistic perspective on how welfare is achieved; they emphasize the ways in which Sweden should strive to become a potent competitor in smart grid technologies and services on international markets. From a wide range of motives, smart grid advocates recurrently position Sweden favourably in relation to other countries:

Sweden has the potential to become a pioneer in the use of Smart Grid. We have a deregulated, well-developed electricity market with environmentally aware customers. We have great know-how and a well-developed IT infrastructure. Virtually all Swedish households already have smart electricity meters, meaning meters with advanced features such as remote reading and control. That is far more than in most other EU countries. (Swedish Coordination Council for Smart Grid, 2013b) 
Arguments such as these suggest that smart grids will profit all of Sweden; they also suggest that Sweden "is at the forefront" (Swedish Coordination Council for Smart Grid, 2014a:31) compared with other countries. Furthermore, smart grid advocates propose that Sweden can disseminate products and services internationally, and can thereby become a global source of inspiration for smart grid implementations. In the words of the council: "Sweden can thereby also show the rest of the world" (Swedish Coordination Council for Smart Grid, 2014a:286) how smart grids should be built. However, Ballo (2015) has shown that such self-promoting descriptions are also prevalent in Norwegian sociotechnical smart grid imaginaries. Therefore, there seems to be some merit in Swedish smart grid advocates' claims that smart grids are a very competitive arena in which several countries have the ambition to position themselves highly. Even though Sweden is described as having excellent requirements for such an arena, the dominant argument is that Sweden might lose its prominent position if it is not actively cultivated; Sweden might be "outrun" (Swedish Coordination Council for Smart Grid, 2014a:198) by other competitors. To sustain prosperity, smart grid advocates urgently argue that Sweden should make smart grid investments in order to not miss out on economic opportunities. The council argues that Sweden should focus on smart grid areas "in which we have already established excellence and to some extent also international references" (Swedish Coordination Council for Smart Grid, 2014a:206); the council finds other areas less attractive for example because "we do not have a comparative advantage in this segment today, making it a challenge to take export market shares" (ibid). In this way, the council suggests that the entities that will form the smart grid configuration of tomorrow should be evaluated based on the likelihood of their enabling future economic welfare for Sweden. Placing prosperity enhancement as a core feature of smart grids creates a hierarchy in which other attributes are positioned as less important: 
Today, the needs for smart grids are smaller in Sweden in comparison to other countries, whose energy mix is less based on nuclear and hydropower. Because of this, Sweden has to choose between actions that primarily benefit the development in Sweden, and those that provide international growth. (Swedish Coordination Council for Smart Grid, 2014a:204)

This line of argument does not treat the future Swedish nuclear power with the same ambivalence as I described earlier, when discussing the notion of a sustainable society. Rather, nuclear power is situated in a safe and central position, and can help determine the need for smart grids in Sweden. This quotation also raises questions regarding why Sweden should focus on smart grids at all. It is notable that this argument does not rest on the notion of greening Swedish electricity production; rather, it focuses on the export opportunities that will occur if Sweden invests in smart grids. In this way, the council primarily legitimizes the smart grid by pointing out its possible economic rewards, rather than by indicating the opportunities it provides to change the Swedish energy system. As I noted in Chapter 4, the opportunity to deliver appliances to larger markets was also one of the objectives for Smart Customer Gotland.

\subsubsection{Empowered and active electricity users}

The fifth and final notion of the smart grid future entails empowered and active electricity users. As proposed by previous research, smart grid advocates imagine that users transform, leaving their current passivity behind to take on a more active role in the future energy system (Geelen et al., 2013; Goulden et al., 2014; Verbong et al., 2013; Vesnic-Alujevic et al., 2016). Similar undertones are prevalent among Swedish smart grid advocates; for example, they appear in a report published by the Swedish governmental agency for innovation, Vinnova:

For many decades, electricity customers have been forced into passivity, but for Smart Grids, a passive customer base is a direct 
hindrance to development. All consumers need to be active participants in the energy system [...]. (Larsson \& Ståhl, 2011:16)

It is notable that in this declaration, electricity users are presented as ignorant obstructers who need to align with the smart grid; they are described as hampering a necessary development. However, the council argues that the smart grid does not require anything from anyone - rather, the smart grid is presented as an opportunity. According to the council, the smart grid simply "enables the customer to take a more active role based on their own interests and needs, which is a cornerstone of the smart grid" (Swedish Coordination Council for Smart Grid, 2014a:29). Instead of formulating activeness as a request, the council thus describes activeness as being based on the users' needs: "Customers want to be active participants" (Swedish Coordination Council for Smart Grid, 2013a:36). Those in favour of smart grids seem to praise this ideal of activeness; it appears as if the concept of "activeness" lives within the very foundation of a smart grid, and is an intrinsic ideal and main feature of the smart grid that differentiate it from the current grid arrangement. Previous studies have however shown that the main concern among smart grid experts is that without the active participation of users, the smart grid potentials might not be realized (Gangale et al., 2013; Schick \& Gad, 2015; Skjølsvold \& Ryghaug, 2015). Thus, the idea of activeness carries ambiguities: is it a possibility or a request? Is it aligned with users' interests? Such questions are recurrent in sociotechnical smart grid imaginaries, and similar tensions show up frequently in the descriptions by the actors involved in the smart grid demonstration project (see Chapter 6). Activeness is highly entangled with empowerment in the Swedish smart grid planning and strategy documents. I traced three different ways in which the active smart grid user is associated with empowerment - through market engagement, through increased access to information and as a prosumer. 


\subsubsection{Empowerment through market engagement}

Swedish smart grid proponents primarily use the term "customers" to denote smart grid users. In this way, they establish a connection between smart grid users and market engagement. Similarly, they associate empowerment with market choices:

A central starting point for the council's action plan is that smart grids can increase electricity customers' influence by providing them with more market choices and stimulate the development of new products and services. (Swedish Coordination Council for Smart Grid, 2014a:12)

This argument, as formulated by the council, carries a neoliberal understanding of empowerment, in which users "perform influence" through the choices they make on the market. The council formulates this market-focused form of empowerment as follows: "Electricity consumers will ultimately gain influence through their responses to new products and services" (Swedish Coordination Council for Smart Grid, 2014b:51). In this way, the smart grid user comes across as an enhanced version of the active electricity customer that the liberalization of the Swedish electricity market once set out to create. The governmental directive guiding the council's work explicitly states that the action plan should continue along the path of a sustained liberalized electricity market (Government Office of Sweden, 2012). In the smart grid council's description of a fully-fledged smart grid future, liberalization is not only sustained, but is further extended: smart grid users are given an abundance of different alternatives to choose from on the market:

This whole situation has created a whole new ecosystem of services and solutions around everyone who delivers services to both households and companies. Customers therefore experience getting real help today from the provider they have chosen as the main supplier for the various basic needs in life. (Swedish Coordination Council for Smart Grid, 2014c:19)

Smart grid users are ascribed with the role of engaging in active treasure hunts in search for the perfect supplier, who not only provides them with electricity, but also 
provides them with all their everyday necessities and needs, turning the selection of the right supplier into a very important decision. However, other voices oppose this dominant argument; according to the head of the Swedish Consumer Energy Markets Bureau: "customers tend not to have time to be 'niched' in more than one market. [...] This is a fact that speaks for simplicity" (Hesselgren, 2016). This tension between empowerment and easiness recurs among smart grid advocates: on the one hand, electricity users are described as being informed and able to make their own decisions; on the other hand, users are described as not really having the necessary time or engagement to make such decisions.

\subsubsection{Empowerment through increased access to information}

Another line of argument presents empowerment as being closely connected to enhanced information; through various kinds of appliances, the smart grid users of the future seem to receive detailed information about their consumption, and follow it in real time. Smart grid advocates stress that this is a core notion behind the concept of user activeness; in the words of the council, "electricity users need data with higher resolutions as a basis for active choices about their electricity use" (Swedish Coordination Council for Smart Grid, 2014:112f). Based on this judgement, the council formulates its only proposal of a regulatory change: that electricity users should be provided with access to information about their electricity consumption on an hourly basis, in an easier fashion and without fees (Swedish Coordination Council for Smart Grid, 2014:14). According to the council, enhanced information "gives the customers greater control possibilities" (Swedish Coordination Council for Smart Grid, 2014a:116), which enables them to "make informed decisions about their usage" (ibid:42). These kinds of solutions are inscribed with ideas of users who are aware of every single appliance in their home as an energy-consuming and cost-generating device. In this notion, users are encouraged to continuously make informed decisions and to micromanage their 
electricity consumption; an example of such a user is formulated by the small-sized energy company Falbygdens Energi:

Customers become energy citizens and are positioned in the driver's seat with access to all relevant information about their energy use, costs, the grids' status and balance, history and upcoming changes everything in real time. Information provides knowledge and knowledge makes the energy citizens more involved and active. (Lars Ohlson, as cited in Swedish Coordination Council for Smart Grid, 2012:6)

According to this prospect, these smart grid users will engage with information they might previously not have even known existed; granted access to the "grids' status and balance, history and upcoming changes", these users will not only be interested in the functional matters of the electricity market and in their private electricity consumption, but will also be interested in the electricity grid at large. This imagined smart grid user is very similar to the "Resource Man" described by Strengers (2013:36): "the gendered, technologically minded, information-oriented and economically rational consumer of the Smart Utopia”. Strengers describes this individual as a person who is interested in monitoring and assessing his energy consumption, and who is knowledgeable enough to interpret and use this information in order to change his behaviours.

However, some Swedish smart grid advocates express concerns about the risks that are connected to enormous transfers of information; these concerns primarily involve matters of compromised personal integrity, "Customers perceive it as if they get a better insight into their own consumption, while in fact it is detrimental to them and instead is to the supplier's advantage (Malmgren \& Johansson, 2014:45f). In several lines of argument, increased access to information is associated with some kind of Trojan horse, in the sense that users may think beforehand that they will benefit from increased access, but will eventually be the losers. Smart grid advocates express different opinions on how such issues should be tackled, and on 
whether there is a need for concern or not. The dominant opinion seems to be that solutions will be found in future to the potential side-effects; for example, according to the head of the council's reference group on security issues, "[e]ach new sector that is digitalized has to wrestle with questions of security. They have to be resolved and that includes questions about privacy as well" (Ann-Marie Fransson, as cited in Malmgren \& Johansson, 2014:4). According to this reasoning, the potential benefits of increased information access are greater than the potential integrity threats; the latter are therefore not described as something that should stop a smart grid implementation.

\subsubsection{Empowerment through being a prosumer}

The final way in which smart grid advocates establish connections between smart grids and empowerment is through descriptions of a smart grid future in which households produce their own electricity. Advocates propose a future in which households produce electricity at small-scale sites, using energy sources such as wind or solar. They refer to these actors as prosumers (4C Strategies, 2013; Malmgren \& Johansson, 2014). Here, the praised "activeness" translates into concrete action to change how electricity is produced. From this perspective, the smart grid is described as empowering households, not only by positioning them as users or customers, but also by positioning them as prosumers. Households are described as empowered as they become in charge of the production units (i.e. distributed and intermittent energy sources) that are the primary reason behind smart grids. Prosumers can in this way be understood as one of the elements that challenges the reliability of the grid, arguments that also are raised by actors involved in the smart grid demonstration project (see Chapter 6).

Smart grid advocates primarily express prosumers' empowerment in terms of independence; for example, the council describes a smart grid future in which "the autonomous prosumer has been created, a paradigm shift has occurred" (Swedish 
Coordination Council for Smart Grid, 2014c:12). In this sense, empowerment is described as something that is achieved as prosumers are no longer dependent on a utility company for a secured electricity supply. This in turn creates the possibility of independence from the electric grid - a possibility that the council portrays in their description of the fully-fledged smart grid future:

The ongoing trend has also spurred the interest to such an extent that there is now an increased amount of people who demand that they be allowed to build their own grids with their own concessions and without having to become a part of the national grid. The government opposed this development for a long time, but after huge public pressure, they gave in and allowed pilot schemes in ten smaller regions and communities around the country. There a number of wind and solar communities operating smaller plants that are essentially self-sufficient in electricity. (Swedish Coordination Council for Smart Grid, 2014c:19)

Here, the council presents prosumers as actors who can influence public opinion; they even appear as troublemakers, who may challenge the current establishment a bit too much. The council seems to ascribe prosumers with attributes similar to those of an enfant terrible; the prosumer is presented somewhat like an unorthodox, rebellious genius, who can sometimes be perceived as offensive. In this way, prosumers are associated with a future that the council does not seem to support fully. This ambiguous attitude towards prosumers may have affected how the council treats them; even though smart grid advocates argue that prosumers will play an important role in the future, the council does not suggest any concrete changes in its final report to increase the number of prosumers. Rather, it states that the action plan does not contain "any concrete proposals on the design of current or future support system for renewable electricity production, since this lies outside of the council's mandate" (Swedish Coordination Council for Smart Grid, 2014:44). As I will show in Chapter 6, prosumers were not included in the smart grid assembled within the demonstration project. In Chapter 7, I will examine how 
representatives from this ambiguously treated actor group describe the future they consider to be sought-after; their descriptions evoke a different kind of smart grid configuration than the one established by the demonstration project.

\subsection{Summarizing discussion}

In this chapter, I examined the Swedish energy system; I described the arrangement of the current system and analysed smart grid planning and strategy documents in order to trace different notions of smart grid futures that are implicitly conveyed by these documents. I understand these national conditions to be part of the hinterland influencing what was possible to achieve within Smart Customer Gotland. Sociotechnical smart grid imaginaries entail "collectively imagined forms of social life and social order reflected in the design and fulfilment of nation-specific scientific and/or technological projects" (Jasanoff \& Kim, 2009:120). Swedish sociotechnical smart grid imaginaries are embedded in a context of national identity and specific energy system characteristics. In some ways, smart grid futures entails reconfigurations of current human and non-human relations; in other ways, current structures are portrayed as somewhat cemented in place.

Like any infrastructure, smart grids have societal implications and are deeply political (Winner, 1980). The political dimension of sociotechnical imaginaries is also enacted as they "project visions of what is good, desirable, and worth attaining for a political community; they articulate feasible futures" (Jasanoff \& Kim, 2009:123). Moreover, prospects about the future contain scripts - that is, descriptions of future relations between humans and technologies (Van Lente \& Rip, 1998). Thus, sociotechnical imaginaries are not ineffective; rather, they do something, and have the potential to influence the future. Sociotechnical smart grid 
imaginaries function as normative agendas of what the future should look like and are highly performative.

As I analysed what these performative sociotechnical smart grids imaginaries look like, I found five recurring notions of the smart grid future: sustainable society, flexible futures, digital dreams, successful Sweden and empowered and active electricity users. Through these notions, I trace how smart grid advocates attach different connotations to smart grids, connotations that they present as attractive and sought-after. To begin with, in the smart grid futures evoked in these documents, set climate and energy ambitions are fulfilled. However, the meaning of this is uncertain, as the notion of sustainable society that appears in these texts is very heterogeneous; imaginaries about sustaining nuclear power and about transitioning to renewable energy sources are both linked to smart grid futures. These imaginaries are thus flexible and ambiguous enough to enrol different types of interest. However, sociotechnical smart grid imaginaries carry the certainty that the "greening" of the energy system, whatever this may entail, should not compromise electricity supply or quality, negatively affect national welfare or impact people's comfort and convenience. To achieve this sustainable society, smart grid advocates propose various measures that simultaneously entail notions of future smart grid societies.

Digitalization is a core notion in this future, suggesting reconfigurations that encompass many aspects of social life. Furthermore, advocates support a future smart grid society in which human and non-human actors are entangled in an energy system that is characterized by flexibility. Moreover, in this future, Sweden is a prosperous country due to its investments in smart grids; Swedish companies are successful in the international arena and generate economic prosperity. Finally, this future is inhabited by empowered and active electricity users. These notions are all 
guided by market logics and economic incentives that have constituted the guiding principle for the Swedish energy system ever since its deregulation in 1996.

In these sociotechnical imaginaries, smart grids are framed as providing countless benefits, while potential risks are primarily described as manageable and limited (cf. Jasanoff \& Kim, 2013). Actors describing smart grid futures do express some concerns about the risks of the smart grid; for example, digitalization generates doubts regarding integrity and resilience issues. However, in relation to the described benefits that are generated by a smart grid implementation, these risks are framed as controllable trivialities. However, there are inconsistencies in how a smart grid implementation is expected to provide all these portrayed benefits. For example, the notion of a successful Sweden is based on a highly nationalist view of how welfare is achieved, and is grounded on the assumption that a company's economic gains will be evenly distributed among the citizens of the country in which this company is located. It is necessary to ask: for whom does a smart grid generate prosperity? How do ideas about empowerment and activeness turn into practical implementations? Furthermore, there is a clear risk of other ambitions superseding the notion of a sustainable smart grid future. Simply put, a digital, flexible and successful smart grid future inhabited by empowered and active electricity users may require deviations from sustainability. This concern has been raised by other scholars as well; a smart grid future that is reliant on various appliances may not necessarily be sustainable, since the production of such devices demands large amounts of energy and resources (Strengers, 2013).

An important premise for this chapter is that the people who present imaginaries also have ambitions to fulfil them. For example, this premise appears in smart grid advocates' suggestions of how their ideas could be inscribed into devices that will script people in accordance with the advocates' images. Through a sequence of different reforms, electricity users in the Swedish context are encouraged to engage 
in flexible consumption based on price fluctuations. These regulations and resulting tariff structures are inscribed with ideas of smart grid users as economically interested individuals who adjust their electricity use to a shifting electricity price. In this way, economic incentives become performative: the smart grid users who are most likely to succeed in the future are those who can take advantage of these structures (cf. Callon, 1998).

Thus far, I have introduced the hinterland that constitutes the geography of possibilities within which Smart Customer Gotland operated. I have mapped out the associations that influential smart grid advocates connect to a national smart grid implementation. I conceptualize these sociotechnical smart grid imaginaries as setting a normative frame for further smart grid development. In the next chapter, I will examine how the actors in Smart Customer Gotland selectively draw on these imaginaries, and appropriate them to fit the local context and their interests; I will explore the process of assembling a functional smart grid on Gotland. 



\section{Making smart grids work: a process of exclusions and inclusions}

In the previous chapters, I outlined the "hinterland" in which Smart Customer Gotland operated. I explored the sociotechnical imaginaries and local conditions that influenced what kind of smart grid was plausible within this demonstration project. The smart grid that took shape within the project did not emerge in a vacuum; rather, it was necessary for it to resonate with the sociotechnical imaginaries that legitimized a Swedish smart grid project. At the same time, the smart grid that evolved on Gotland had to comply with the local conditions: the goals that had been set out, the timeframe, the geographic location and so forth. Against this backdrop, I conceptualize this demonstration project as a venture that was intended to establish a smart grid that made sense in this particular local context and that aligned with the sociotechnical smart grid imaginaries. In this chapter, I follow the process by which a smart grid evolved within Smart Customer Gotland. I base this chapter on interviews with persons who worked with the project on a daily basis, or who held leading positions and had deep insight into the project's undertakings. I have given these individuals names that start with the letter E, for "Employees". Furthermore, I have analysed written material that was 
produced throughout the course of the project, and have conducted participant observation at specific project events (for details, see Chapter 3).

My analysis focuses on how the smart grid configuration evolved, on what kinds of interest guided this process and on the various tensions that appeared as the project unfolded. I conceptualize the process by which the smart grid took shape as a translation, as defined by Callon (1986), and I analyse how the concept of smart grids was filled with content in this local setting. Therefore, I examine how seemingly unrelated entities were drawn into coexistence in order to create a functional smart grid, along with the struggles, doubts and contradictions that arose in this process.

As I follow how the smart grid evolved in Smart Customer Gotland, I structure my analysis around three processes. First, I examine how elements were merged together and given meaning within this smart grid project. Second, I follow the process through which people working within the project legitimized the established configuration by aligning it with sociotechnical smart grid imaginaries. In particular, I examine their legitimization of why this smart grid version enabled active electricity users. Third, I analyse how the project was framed in a way that was attractive to households as potential participators of Smart Customer Gotland. Even though I understand these processes to be both entangled and parallel, I will present them separately for the purpose of clarity. First, I will describe how the persons working within the project reasoned about their assignment to assemble a functional smart grid.

\subsection{Taking control of a fuzzy object in the making}

The persons who worked within Smart Customer Gotland frequently commented that the term "smart grid" has an unclear meaning, and this is because there are "a countless number of definitions of so-called smart grids" (Emil). This argument 
confirms previous conceptualizations of smart grids as ambiguous objects in the making that are associated with various expectations and interpretations, and that have an unclear ontological status (Christensen Haunstrup et al., 2013; Schick \& Winthereik, 2013; Skjølsvold et al., 2015). On Gotland, having an unclear definition for smart grid created uncertainties in the project's initial phases; several of those who worked with the project struggled when trying to describe smart grids, and argued that it is not easy to get the concept straight. The word "buzzword" was frequently used to describe the concept; Emil commented, "[smart grids] is a fashionable word, it is now very hip with smart grids", implying that the demonstration project was riding a wave of popularity. However, others considered that the popularity of "smart" items did not only have positive implications, as the meaning of the concept dissolves when "Everything is smart [...] even parking lots" (Edvin).

Furthermore, some argued that the unclear essence of smart grids resulted in the concept becoming a solution to a manifold of problems, leading to unrealistic anticipations; as if a smart grid implementation is "like a hallelujah moment, but it is not" (Ester), or as if a smart grid comes across as "a magic formula of some kind" (Elin). In other words, combining the popularity of smart grids with their unclear essence can turn the concept into an obstacle, since smart grids "sound cooler than they are" (Erik). Although the sociotechnical smart grid imaginaries and the demonstration project's pre-study that laid the ground for its funding approval (see Chapter 4) ascribe smart grids with a high degree of anticipation, the actors who were assigned with the task of concretizing and materializing smart grids gave the impression that they were not completely at ease with delivering a configuration that would live up to this anticipation. Although the popularity of smart grids helped to legitimize the project's existence, and provided publicity as well as funding, it also created tensions for those who were required to fulfil these expectations. 
However, the lack of clarity regarding smart grids simultaneously provided the project with the opportunity to shape what smart grids could become. For example, this was recognized by Erik, as he argued that "taking control of the concept smart grid has been going on for quite some time. Defining what the smart grid is, is a bit of a fight among several actors." Erik argued that such discussions arise because different organizations have different backgrounds and operate within different sectors, all of which want smart grids to align with their interests. As I will show, the interests of the organizations behind this demonstration project did in fact guide the kind of smart grid that evolved within Smart Customer Gotland.

\subsection{Defining the problem to solve}

As a first step in the process of assembling a smart grid, the project had to define what kind of problem its smart grid should solve. As I described in Chapter 4, Smart Grid Gotland was anchored in the European 20/20/20 targets and in their dependence on an increased amount of electricity from renewable energy sources. The actors behind the project justified the demonstration project by pointing out the challenges that such a transition poses to the current electricity system and market structures - challenges that, they argued, could be handled by the establishment of a smart grid (GEAB et al., 2011). However, the project translated these problems, which are part of the national sociotechnical smart grid imaginaries, into a local context. The demonstration project was located on Gotland partly because the island already hosts a large number of wind power stations; however, new power stations were not allowed because the transmission capacity of the Gotlandic grid was already approaching its limit (see Chapter 4). When Smart Grid Gotland started, the grid owner had estimated that the current grid tolerated an installed power of $195 \mathrm{MW}$ - a limit that would be reached within a few years if the planned power stations were realized (Swedish Energy Agency, 2012). While 
waiting for a new high-voltage link that could decrease the pressure on the grid, actors behind the project suggested that vulnerable periods could be shortened by evening out electricity consumption. Situated within this local context, the project thus set out to materialize a smart grid that could handle these Gotlandic challenges; in an alignment with the notion of flexible futures (see Chapter 5), the project leaders suggested that the demands on the Gotlandic grid could be decreased through flexible consumption.

In articles written by leading actors within Smart Customer Gotland, the concrete objective of the project was to decrease the number and length of vulnerable periods by constructing a smart grid configuration that motivated electricity users to move their consumption from periods of high demand to periods of low demand (Svalstedt \& Löf, 2014, 2017). In this way, the demonstration project drew on sociotechnical smart grid imaginaries as they positioned electricity users in a pivotal role to achieve a more sustainable and reliable energy system. The project set out to explore how flexible consumption could be encouraged; or, in the words of Smart Customer Gotland's project leader:

The whole idea with the project is to try to understand what may trigger customers to change their consumption, and consume more when the price is low and consume less when the price is high. (Project leader, Smart Customer Gotland, 2013)

This objective shows that the project was intended to steer consumption based on fluctuating electricity prices, and that the project set out from the idea that users are motivated by economic rewards to engage with flexible consumption. The same idea was illustrated in the financing directive from the Swedish Energy Agency, which justified its funding by pointing out that "Participating customers get the chance to lower their electricity expenses" (Swedish Energy Agency, 2012:3). These assumptions resonate with findings from previous studies that show that visions formulated by smart grid stakeholders are informed by a techno-economic 
approach suggesting that as long as the right technologies are implemented, they will enable economic savings for users (Mah et al., 2012; Verbong et al., 2013).

In addition to using fluctuating prices, Smart Customer Gotland set out to encourage flexible consumption by developing and implementing commercially viable products. This ambition was explicitly declared in the Swedish Energy Agency's financing directive, which argued that a demonstration project in an early phase of global smart grid development held the potential to deliver commercial products that could enhance Swedish export opportunities (Swedish Energy Agency, 2012). Hence, the project had the objective of delivering technical appliances that were intended for a larger market and that were expected to position Sweden in relation to other countries; this ambition aligned the project with the notion of a successful Sweden, as described in Chapter 5.

Thus far, the project had translated the initial issue of integrating intermittent energy sources into the electricity system into a problem of how flexible consumption could be encouraged using electricity prices and commercial products. In other words, the project set out to find out: through which commercially viable products and fluctuating prices could flexible consumption be encouraged? This problem definition guided the kind of smart grid that could be assembled within this particular demonstration project. Since Vattenfall and GEAB intended to provide the commercial appliances and fluctuating prices these companies established themselves in a central position. Using the vocabulary of translation processes, they established themselves as the project's obligatory passage point.

The process of identifying problematic issues is also a process of identifying which actors should be part of the solution (Callon, 1986). In this case, electricity tariffs and commercial appliances were identified as actors that should stimulate flexible consumption; in the next step, the project defined which actors should provide 
flexible consumption. In other words, the project moved on to define what kinds of electricity consumption could be shifted in time.

\subsection{Defining flexibility providers}

The initial objective of Smart Customer Gotland was to include various kinds of electricity users. To care for these variations, the project was initially divided into two separate parts: one focused on households and farmers, and the other focused on commercial actors and industries (GEAB et al., 2011). These focuses were also reflected in the Swedish Energy Agency's financing decision, that declared that the project should include both private and commercial actors (Swedish Energy Agency, 2012).

The initial requirements for households to join were that they should be GEAB customers (both distribution grid and electricity supply), have some kind of electric heating (waterborne or direct) and have a yearly electricity use of more than 8 MWh. In addition to altering the electricity consumption in their homes, farmers were primarily expected to alter the electricity usage in their grain mills. The section of the project intended to focus on commercial actors was partly directed towards companies that used more than $200 \mathrm{MWh} /$ year and that were located within a specific geographic area, and partly directed towards a few larger process industries scattered across the island. One Gotlandic company was particularly targeted: a cement factory that was by far the biggest electricity user on Gotland, which was described in the pre-study as having the island's biggest potential for load shifting (GEAB et al., 2011). The initial ambition was to enrol 2300 households, 200 farmers and 30 companies in Smart Customer Gotland (ibid). As will be shown, in the end, these ambitions did not even come close to being fulfilled, whether in terms of the variation or in the number of involved actors. 
As Smart Customer Gotland proceeded, the commercial actors and farmers were completely excluded from the project, which ended up focusing on households alone. Instead of the initial ambition of constructing a smart grid that included a variety of different electricity users, the smart grid that was assembled within the project came to entail a much narrower configuration.

\subsubsection{Justifying exclusions and inclusions}

One reason why all commercial actors were excluded from the project was that they, unlike the households, were expected to finance the technical installations themselves; in addition, the project was initially set up with goals that stated that these investments had to be repaid within a year. However, Smart Customer Gotland did not find any companies that could meet this ambitious goal. They did find companies that could turn the investments into a profit within 3-5 years; however, since these companies could not meet the project's aim, they were excluded. This decision gives the impression that a short-sighted perspective on returns on investment prevented companies from participating in the project - a situation that contradicts the framing of smart grids as an investment for the future. The objective that investments should be repaid within a year was translated into a requirement that excluded companies from taking part in the socio-material configuration taking form on Gotland.

Another reason behind this exclusion process was that several of the larger electricity-consuming companies on the island had already implemented many of the changes the project set out to evaluate. Or, as formulated by a project employee, "we have nothing to teach them; they have something to teach us" (Einar). For example, the project found that the company that was initially targeted as having the biggest potential for load shifting on Gotland had already adjusted its production to the Nordic spot prices. The project's ambition to be in the frontline of 
innovation was thus not applicable in this case. A third reason for not including companies was that altering companies' processes was found to be more difficult than expected:

Larger electricity-intensive companies cannot shift their consumption. They have processes that must run in a certain way, at certain times. They cannot shift. They need a constant supply of cheap energy. They cannot shift on an hourly basis, in the way they would need to do in this project. (Emil)

A further explanation that resonated with this difficulty was the assumption that many companies had customers who could not be told, "sorry, sorry, you will not get the delivery today because the electricity price was too high" (Einar). Persons working within the project argued that such dilemmas were the result of many companies having streamlined their processes for efficiency to such an extent that they could not allow the degree of flexibility required by the project's configuration. One condition that was mentioned as particularly discouraging flexibility was the lack of warehouses to store materials and ready-made products; in other words, "if you do not have warehouses, you cannot steer your production" (Ellinor). In this sense, a logic that was grounded on lean production excluded these companies from being part of the smart grid.

The final reason why companies were excluded also illustrates the difficulty of translating the notion of flexible futures (see Chapter 5) into practice. The project discovered that many large companies on Gotland preferred to base their budgets on known electricity expenses rather than handling the unpredictability that is built into a fluctuating tariff: "they want a fixed price, preferably over a longer period, so they can easily budget their expenses" (Elias). These priorities challenged the sociotechnical smart grid imaginary of flexible futures, as Smart Customer Gotland could not translate the smart grid into a functional configuration for companies. 
In this way, a series of reasons caused the entire company part of the project to be shut down. This decision caused some of the people working in the project to mistrust companies' ability to provide flexibility in a smart grid future; others referred to the exclusions as a direct consequence of the conditions that were set within this particular demonstration project, and did not consider them to be something that could be used to generalize future smart grid projects. Smart Customer Gotland thus ended up with a configuration in which households were the sole providers of flexibility; however, the inclusion and exclusion process still continued within this group.

\subsubsection{Narrowing down flexibility providers}

The project initially targeted all households on Gotland that had GEAB as a distribution and electricity provider, lived in a private detached house with a yearly electricity consumption of more than $8 \mathrm{MWh}$ and had direct or waterborne electric heating (GEAB et al., 2011). As the project proceeded, other items such as electric floor heating, hot water boilers and heat pumps were targeted as suitable devices, simply because they also consumed large amounts of electricity that could be steered in time without affecting the comfort of the people using them (field notes 2013, 2014; Project leader, Smart Customer Gotland, 2014).

However, this setup meant that all households that did not meet these requirements were left out of the project. In practice, this meant that all apartments, all houses using a lower electricity consumption than the set limit and all those who were not GEAB's customers were excluded from the project's smart grid. This decision illustrates how the project selected very particular households that suited its intent to succeed as a demonstration project and to show that flexible consumption could be successfully implemented. The project assembled the smart grid in a particular way that enhanced its chances of success; by targeting these 
households, the project enhanced its chance of demonstrating a functional smart grid on the island.

Furthermore, the commercial interests of the actors behind the project guided the inclusion and exclusion process regarding which actors would provide flexibility in the smart grid that evolved within the project. This was particularly shown in the exclusion of households that contributed to flexible consumption by making use of self-produced electricity; these so-called "prosumers" were not included in the project's smart grid. In the sociotechnical smart grid imaginaries, however, prosumers have a central role (see Chapter 5). This was recognized by Smart Grid Gotland, as the pre-study associated prosumers with enhanced "end-user empowerment” (GEAB et al., 2011:10). In the early phases of Smart Customer Gotland, those in charge of the project discussed whether to include these actors or not; in the end, however, these ideas were not put into practice.

One reason for this turn of events was formulated in the project's pre-study, which declared that Gotland did not have enough prosumers to justify studies on these households (GEAB et al., 2011). Some of those who worked within the project argued that the project needed larger, fairly homogeneous test groups in order to make trustworthy evaluations of the project's result, and that this was not possible with prosumers (Project leader, Technologies Smart Customer Gotland, 2014). Another reason, as explained by the project leader for Smart Customer Gotland, was that studies on prosumers were out of the project's scope because the project had not received adequate funding for such research:

We had preliminary discussions on whether the project was to sell solar cells to customers, but we had to revise that since then we would have subsidized them. (Project leader, Smart Customer Gotland, 2013)

It also seems that the exclusion of prosumers was driven by commercial reasons. The project leader of Smart Grid Gotland pointed to the interests of those in charge 
of the project as a reason to exclude prosumers, and claimed that this project was "a grid owner project" (Project leader, Smart Grid Gotland, 2013). This comment implied that the project was primarily set up in accordance with the interests of the grid owner. He argued the project had the objective "to handle the boom [of solar panels] expected to happen in the near future" rather than the objective to steer development in such a direction (Project leader, Smart Grid Gotland, 2013).

The project was hence set up without any formalized ambition to enhance the role of prosumers. On the contrary, the project leader for Smart Grid Gotland described prosumers as a complicated actor in the energy system, since their widespread inclusion would complicate the overview and governance of the grid: "If Kamprad [the owner of IKEA] started selling solar cells, then [...] we would lose all control" (Project leader, Smart Grid Gotland, 2013). The delicate situation of the island's electricity grid, which was already experiencing high demand, may explain the grid owner's cautious attitude towards prosumers, to some extent. It is also possible that this reluctance was influenced by the fact that prosumers, as electricity producers, are less dependent on utility companies; prosumers even endanger the future status and role of utility companies in the energy system.

However, it is important to recognize that the project was conducted as a conglomerate between different sectors; those parts of the companies who sell commercial appliances might benefit from prosumers, while those who sell electricity might not be as enthusiastic to spur on the spread of prosumers neither would the grid owner as prosumers challenge their responsibility to secure electricity supply and quality. Thus, what is in the interest of some project actors might not be in the interest of others; nevertheless prosumers were excluded from the smart grid that evolved on Gotland.

Some who worked within the project justified the decision to exclude prosumers by questioning the pivotal position of prosumers in the smart grid future. For example, 
the CEO of GEAB argued that "all of us are not mini versions of Gyro Gearloose or even technically savvy", and commented that she doubted every single household would turn into a prosumer. She claimed that such a system would "require thousands of people who operate and maintain all that”, and questioned whether this was practicably manageable or even worth striving for. Her doubts regarding a future with prosumers held an environmental side as well; she claimed that although prosumers are framed as sustainable, the question of whether this is true or not depends on what kind of energy sources prosumers replace, and questioned the environmental benefits of for example replacing district heating (CEO of GEAB, 2013). In this way, the CEO of GEAB was reluctant to include small-scale solar panels or wind power stations in her idea of a future energy system; rather, she seemed to support more large-scale configurations. This opinion resonates with the tensions I described within the notion of a sustainable society in Chapter 5: smallscale solutions based on intermittent energy sources were questioned regarding their ability to secure a reliable electricity supply.

The notion of empowered and active electricity users in the form of prosumers (Chapter 5) was thus not realized within this project. The final configuration of Smart Customer Gotland illustrates how despite the project's ambition to construct a role model for the future sustainable energy system, changes that could alter power relations within the energy system were not put into practice. In the process of putting a smart grid together, commercial interests, local conditions, funding approval and the visions of those in charge guided the assembling process. As a result, the demonstration project constructed a smart grid that did not threaten the role of already-powerful actors within the energy system; in this regard, they assembled a smart grid that stayed within the current paradigm of the traditional energy system. 
Other actors that could provide flexibility, according to the notion of flexible futures, are electrical vehicles; these can be used as batteries connected to the grid, and can provide flexibility by being charged during periods of electricity excess and discharged during periods with a high demand for electricity. The project's prestudy tied into these imaginaries by declaring that one way to provide flexibility was by using batteries in electrical vehicles (GEAB et al., 2011). Such prospects were also recognized by several of the project employees, who referred to electrical vehicles when discussing how they envisioned the future energy system. For example, Emil commented: "you get a really good system if electric cars are charged when there is good access [to electricity]".

However, as Smart Customer Gotland unfolded, electric cars were not included in their smart grid configuration. One reason was a lack of commercial interest, as "none of the companies involved in this project have electric cars, or even sell electric cars" (Project leader, Smart Grid Gotland, 2013). Not many electric vehicles were present on the island when the project took off; therefore, the project leader for Smart Grid Gotland argued: "We can build charging stations on Gotland, but if no one puts in a cord, it is pretty pointless" (Project leader, Smart Grid Gotland, 2013). This situation shows again how the ambition to be in the forefront of innovation was difficult to put into practice; both prosumers and electrical vehicles were partly excluded because they were considered to be too few in number to include in the smart grid demonstration project. This decision illustrates how the project could not be too ground-breaking if it were to succeed in constructing a functional large-scale smart grid; it had to deal with the given preconditions on Gotland.

Thus far, Smart Customer Gotland set out to construct a configuration that encouraged flexible consumption based on fluctuating prices. They decided that the actors providing flexibility were electric heating devices (waterborne or direct), 
electric floor heating, hot water boilers and heat pumps. These actors would be found in detached houses whose owners were GEAB customers (distribution grid and electricity supply). In this way, the project established a problem definition, drew inclusion and exclusion boundaries, and defined some of the actors that would be part of the smart grid on Gotland. In the next step, the project needed to decide how flexible consumption could be achieved - or, in other words, to determine how different elements could be coupled in order to enable electricity consumption to be shifted in time.

\subsection{Coupling elements: creating relations}

In its ambition to assemble a functional smart grid, Smart Customer Gotland tried to establish connections between human and non-human actors that did not necessarily exist beforehand; the project thus tried to bring various elements into coexistence. This process was guided by the project employees' ideas of the preferences, interest and behaviours of future users - ideas that were then inscribed into technical devices. In the following sections, I analyse this process in depth and examine the various tensions it generated.

\subsubsection{Fluctuating electricity tariffs as a predetermined actor}

Based on the established objective, Smart Customer Gotland intended to assess whether fluctuating electricity prices could encourage flexible consumption. The project leader in charge of the project's technical solutions explained that the initial idea was simply to use electricity prices that fluctuated on an hourly basis rather than using traditionally fixed prices; however, such a solution "was already on the market before we got started with the project" (Project leader, Technologies Smart Customer Gotland, 2014) and was hence no longer considered ground-breaking. Smart Customer Gotland therefore decided to design a price tariff especially for this 
project - a tariff they considered to be more suitable for a project with ambitions to be in the forefront of innovation. An article by actors in charge of Smart Customer Gotland declared that the purpose of this tariff was to simulate a future in which a large introduction of intermittent energy sources resulted in a more fluctuating electricity price (Svalstedt \& Löf, 2017). This retail price was denoted the "Smart Customer Price" ${ }^{\prime 8}$, and consisted of three variables: a grid tariff, an electricity tariff and an occasional price reduction.

The grid tariff was GEAB's current time tariff, meaning that the price depended on the demand of the grid and was the highest during the daytime on weekdays from November to March; during all the remaining hours, GEAB offered a lower price due to lower demand (Smart Customer Gotland, 2014b). The electricity price was based on spot prices from the Nordic electricity market exchange for electric power, Nord Pool Spot; however, the daytime price peaks were enhanced by $50 \%$, making the fluctuations between the low and high electricity prices even larger, even though the median was kept the same (Smart Customer Gotland, 2014b; Svalstedt \& Löf, 2017).

The final component in the Smart Customer Price was an occasional price reduction, denoted as "wind compensation". Households were notified that the following day was expected to be windy on Gotland, and then received a price reduction of 15 öre/kWh (Smart Customer Gotland, 2014b). The discrepancies between the actual price and the price based on the wind compensation were paid by the project, which may explain why the compensation was restricted to a limited number of days and was not based on actual wind conditions. Eskil formulated a way of understanding the intention behind this wind compensation:

They see when the wind power stations spin faster and [draw the conclusion], well, now it's cheap electricity, and then when they are

\footnotetext{
${ }^{8}$ My translation of Smart Kund Pris
} 
standing still [they draw the conclusion], well, now electricity is expensive so it is much more concrete [...] than here [in Stockholm], where we need to see if there is any smoke from the chimneys in Värta hamnen. (Eskil)

Eskil thus suggested that the intention was to establish a connection between locally produced electricity and electricity prices. However, the person in charge of designing the price tariffs explained that such a connection does not really exist. Rather, electricity prices are grounded on much more complicated calculations based on longer periods of access to electricity, so "when the wind blows per hour is not connected to the price per hour" (Responsible for price tariffs, Smart Customer Gotland, 2013). He mentioned another structure that prevents prices from actually being based on how the wind blows on Gotland: all of Sweden is divided into four different price areas that set the electricity prices.

If you are going to operate on the spot market, you operate on the whole SE3, which is the third price area in Sweden. Those are the prices the Gotlanders receive, the same way we do in Stockholm, or if you live in that whole price area, so there is not a local pricing onthe-spot price on Gotland. (Responsible for price tariffs, Smart Customer Gotland, 2013)

Smart Customer Gotland thus framed their wind compensation concept as having a local connection that did not align with the much more complicated structures of how electricity prices are calculated. This implies that Smart Customer Gotland intended to establish a connection between local electricity production and prices that was not completely aligned with current market structures. The ambition to create an innovative price structure as a demonstration project resulted in a configuration that did not reflect the current electricity market's functionalities.

Fluctuating prices became the primary script used to encourage people to engage with their electricity consumption. However, as I will show later in this chapter, this economic script resulted in various doubts and tensions when it was put into 
practice within the project. For now, I will continue with my analysis of how different actors were put into place and how the smart grid emerged within Smart Customer Gotland. A key decision in this process concerned how fluctuating prices should encourage flexible consumption - in other words, how prices should influence when devices should be turned off and on.

\subsubsection{Deciding on remote or manual control}

In the early stages of the project, Smart Customer Gotland chose between two alternatives: either households should be in charge of adjusting their own consumption in accordance with fluctuating prices, or the project should handle consumption adjustments through remote control. The question of whether utility companies or users themselves should steer consumption is also reflected in previous smart grid studies that present this as one of the core issues when it comes to flexible consumption (Christensen Haunstrup et al., 2013; Nyborg \& Røpke, 2011); alternatives that result in tensions of who is actually in control (see flexible futures Chapter 5).

People working within Smart Customer Gotland had initial discussions on dividing the households into two different groups, with a group representing each of these two alternatives. However, when the first household installations were made, the configuration was solely based on remote-controlled devices. This decision was revised as the project proceeded. I will return to this turn of events later on in this chapter; first, I will explain the motives behind the initial configuration.

The people who worked with Smart Customer Gotland primarily referred to the needs, interest and behaviours of the future users when they promoted remote control. For example, they argued that it was necessary to "make things easy" (Elisabet) for these individuals, since they are "not interested in managing their own devices" (Ellinor); or, they commented that "people actually have other things 
to do" (Elin) than to manually turn these devices on and off. In this way, the actors involved in the project justified remote control by pointing out that the alternative would be too cumbersome for the users. They also opposed the likelihood of a future in which people adjust their own electricity consumption in accordance with price fluctuations; as Ernst ironically commented: "well, now is the highest price, so I'll run downstairs and put on a fire instead". However, these assumptions undermined the power of the economic script, as the actors involved in the project did not think that users would adapt their lives to these prices:

We have increasingly moved away from that, because we realize that at least people who work cannot spend time turning up and down their own heat. [...] We thought that we would have some customers who would govern themselves and some customers that we would govern. But after we had worked with this for a while, we thought that customers that would govern themselves based on a price signal, how will this be done? "Well now, it is expensive in the morning, so I turn down my heat, then it's cheap at lunchtime, so I have to go home at lunch and turn up my heat, and then it will be expensive again in the afternoon, so I have to go home during coffee breaks and turn down my heat." Can we believe that it will work like this in any kind of future? No. We do not believe in it, it becomes too complicated for the customer, it gets too difficult, and they will not want to continue. (Project leader, Smart Customer Gotland, 2014)

A similar line of argument that justified remote control was that it was difficult to motivate people to engage in something they were not especially intrigued by. Some argued that households might initially find it attractive to learn more about how much electricity their devices use, "but then when you know that, when you cannot influence it anymore, what do you do then? Well then it is our control that comes in and helps you" (Einar). The remote-controlled configuration was thus based on the logic that in order to convince people, "you have to make it so easy for them so they do not have to bother at all" (Project leader, Smart Customer Gotland, 2013). In this 
way, the project employees described remote control as a tool to help people who lacked an interest in electricity; they argued that remote control enabled a comfortable life for users, and unburdened them from duties they would otherwise have been forced to do themselves.

Smart Customer Gotland initially intended to establish a smart grid in which the project remotely controlled certain devices within participating households, based on fluctuating prices. This configuration imposed specific relations between the actors of the socio-material configuration taking shape within Smart Customer Gotland: it placed Vattenfall and GEAB in charge of these devices, rather than the people who lived in the homes where the devices were located. However, as the project proceeded, Smart Customer Gotland encountered problems in enrolling remote-controlled devices into its smart grid.

\subsubsection{Enrolling remotely controlled devices}

The technical solution for remotely controlling flexibility-providing devices changed during the course of the project. The initial idea was simply to cut the cord that connected the device to the fuse box, and to install a plug, in between; by remotely controlling the plug, the devices attached to the plug were expected to be controlled as well (field notes, 2013).

However, as the project proceeded, this configuration was more difficult to make functional than Smart Customer Gotland expected. The project leader for the technical products explained that the devices they wanted to remotely control were more advanced than they had initially thought. She commented that they might have been naive in the beginning, as they had expected that every household had similar solutions; however, they came to realize that "there is an infinite variety of what people have" (Project leader, Technologies Smart Customer Gotland, 2014). She noted that when they arrived at a household, in many cases, they could not go 
through with the installations due to technical reasons. For example, it was sometimes impossible to simply cut the electricity to the device that was targeted for remote control, because other appliances might be connected to the same circuit and would then also be influenced by the on/off signal. She further explained that working in people's homes becomes "very personal for the customer"; for example, some individuals refused the installations for aesthetic reasons and proclaimed: "No, no, I do not want this at home, it cannot be visible" (Project leader, Technologies Smart Customer Gotland, 2014).

Smart Customer Gotland also came to realize that turning the devices on and off in accordance with the initial idea was actually harmful to the functionality of the devices, and that the devices' guarantee might not be valid for damages caused by such reasons (Technical specialist, Smart Customer Gotland 2014). In order to handle these technical difficulties, Smart Customer Gotland decided to develop a complementing product for the remote control of devices that were not suitable for the original solution. Instead of cutting the electricity, this product was integrated with the devices' existing functionality; for example, it could simulate an outdoor temperature and thereby fool a heat pump into sensing that it was colder than it actually was, causing the pump to turn up the heat (Technical specialist, Smart Customer Gotland 2014). One of the project's technical specialists explained that this solution allowed them to "in principle, steer everything" that was of interest (Technical specialist, Smart Customer Gotland 2014). However, installing these products in individual houses demanded a substantial amount of time and was therefore considered an expensive solution. This situation caused several of the people working within Smart Customer Gotland to doubt whether such devices could be a solution for the future:

Initially, we thought we would create a standard product that we'll install in the households. It was shown that this does not work at all. Every single house is individual and requires individual 
solutions. That is the great lesson that we have learned: it is not possible to implement a standard solution. Rather, it is individual solutions in every single place; this will require engineering hours and installation work. I think that this is our really big lesson from the project. (GEAB's representative on the board of Smart Grid Gotland, 2014)

The project's difficulties in enrolling devices for remote control resulted in various tensions. Some of the project employees supported the idea of flexible consumption in households but argued that the setup within the project might not be ideal for future configurations. For example, some said that it was problematic for utility companies to provide the technical solutions: if users wanted to change their supplier, "some new installer must come to your home and change your control module" (Project leader, Technologies Smart Customer Gotland, 2014). People who worked within the project expressed doubts regarding the utility companies' role as an obligatory passage point in a smart grid future.

Some suggested configurations in which new devices had a remote control functionality already built into them when purchased, instead of altering current devices. On the other hand, as a project leader pointed out, "you do not change a boiler or a geothermal heat pump that often; we're talking maybe every 30 years. What you buy today will sit there for a good long time. [...] So it will not happen overnight that new products revolutionize the world" (Project leader, Technologies Smart Customer Gotland, 2014). On the other hand, Emil argued that because newer devices are so energy efficient, they cannot offer as much consumption to be shifted as older devices. He stated that since the project had shown the difficulties of adding remote control to already existing devices, he questioned the likelihood of a future with widespread solutions for flexible consumption, simply because it "costs more than you gain from it".

Smart Customer Gotland's problem in enrolling devices for remote control illustrates a core dilemma of flexible consumption: older versions, which are more 
difficult to enrol into such configurations, are usually the ones that have the most electricity to shift. This dilemma shows the difficulty of assembling a smart grid outside a newly developed district area (in contrast to the other two large-scale Swedish smart grid demonstration projects), but that relies on current devices in already existing households. This dilemma also raises doubts regarding the likelihood of a widespread roll-out of remotely controlled devices in the near future, as most Swedes do not live in smart-grid-prepared homes. This turn of events within the demonstration project shows that materiality can "fight back". By this, I mean that already existing devices in households were not easily enrolled into the smart grid; rather, they challenged the notion of a flexible future and the assumptions that Smart Customer Gotland rested upon.

\subsubsection{Controlling the control}

After a few delays and a more expensive solution than was initially planned, Smart Customer Gotland was eventually able to enrol remotely control devices into the smart grid. The remote control functioned by means of algorithms that decided when the devices should be turned off and on. The main influence on the remote control was the fluctuating price; however, other aspects, such as what kind of device was being managed and the outdoor temperature, also influenced the steering (field notes 2013, 2014; Smart Customer Gotland, 2016).

This setup enacted several different delegations: households with electricityconsuming devices delegated control to Vattenfall and GEAB, who in turn delegated this control to algorithms, which became a powerful actor in the smart grid configuration that was established on Gotland. Project employees inscribed ideas of users' attributes, desires, needs and interests into a set of rules that controlled devices within users' homes. 
Enrolled users could choose between four different combinations of rules that turned their devices on and off with a varied intensity: normal, comfort, economy and economy plus (Smart Customer Gotland, 2016). These names illustrate Smart Customer Gotland's expectations about the people who took part in the smart grid by suggesting that these individuals choose between identifying themselves as normal, as striving for a convenient life, as desiring to save money or as desiring to save a large amount of money. The possibility of choosing between various steering schedules gave users some degree of choice. This intention appeared in Smart Customer Gotland's description of the motivation behind these schedules: "Depending on how we live, we all have different patterns of life. This affects the demands we have for comfort in our residences" (Smart Customer Gotland, 2015c). These assumptions of peoples' desires resonate with the assumptions that are prevalent in the notion of empowered and active electricity users, in which people are described as becoming empowered by being given more choices, and which presents the possibility of finding solutions that are ideal for the individual.

Smart Customer Gotland's configuration suggested that users should not experience any restrictions; rather, the remote control should be altered to suit the individual, meaning that the technology should yield to the individual's preferences rather than vice versa. To ensure that users did not experience any comfort issues, the project enrolled a device to measure the indoor temperature in the homes. If the temperature decreased below a certain limit, the steering schedules were signalled to not turn off heating devices (Smart Customer Gotland, 2015a). This "comfort ideal" was also inscribed in the technology, in the sense that steering schedules could be manually altered by the users, a possibility that was achieved through an app for mobile phones and tablets. The app allowed users to both see and alter the steering schedules. The steering display emphasized the electricity prices' influence, as it indicated which hours had the lowest and the highest prices. This design 
illustrates the economic script in this configuration. Figure 1 shows the interface of this app.

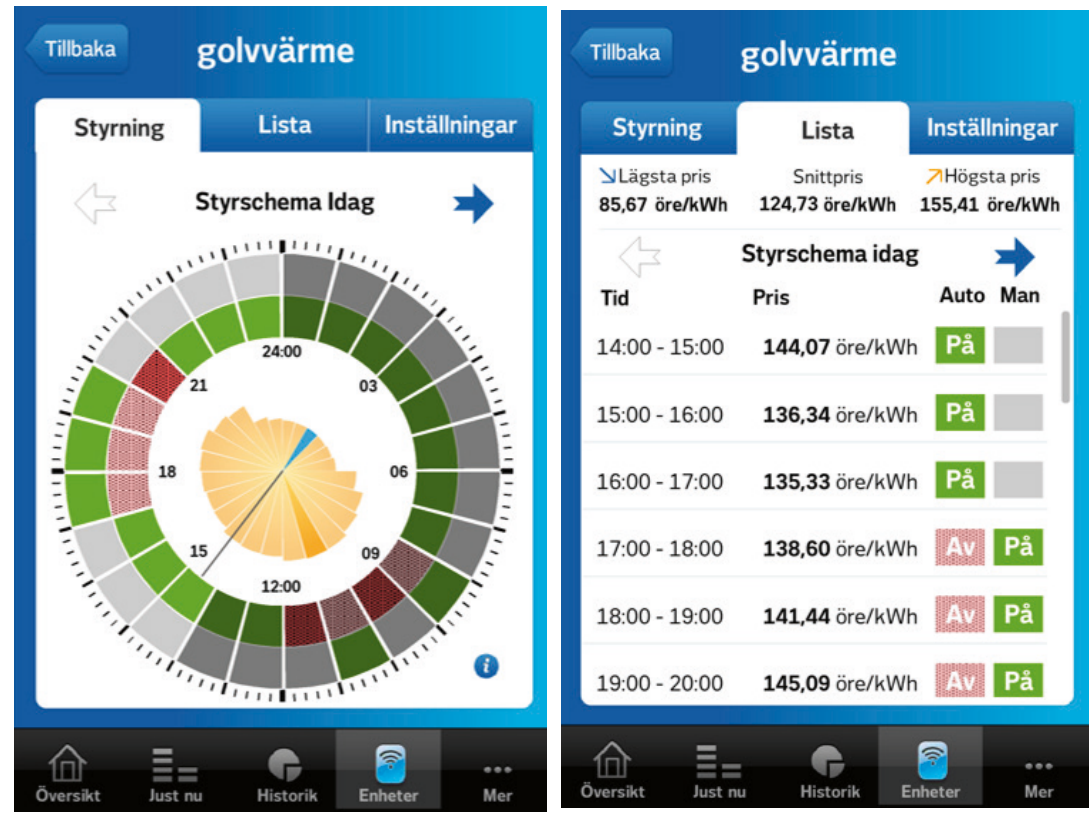

Figure 1. Steering schedules in the app (Smart Customer Gotland, 2017a)

Even though users could manually alter the steering schedules this option was obstructed by another design choice: the steering schedules that managed the remote control were updated every day, erasing all previous manual alterations (field notes, 2014). In this way, users were informed that manual alterations were intended for special occasions only. This logic was illustrated by the way in which project employees internally referred to manual alterations of the steering schedules as using the "mother-in-law button" (Project leader, Smart Customer Gotland, 2014). This wording implies that manual steering was an out-of-the- 
ordinary possibility that should only be used in special occasions, such as when a mother-in-law in need of special treatment was visiting.

In fact, the steering was designed to pass by the users unnoticed; as Eskil explained, "We basically shall not go in and influence their lives; we shall operate without being noticed". This logic seems to have guided the design behind the remote control: the configuration was not intended to interfere with people's lives in any way; the assumption was that people should be able to continue just as before, while simultaneously contributing to the benefits of the smart grid. The persons working within Smart Customer Gotland frequently proclaimed their support for a solution in which "the customer does not receive any degradation in comfort or anything that causes disorders" (Ernst). The project leader for the technical solutions argued that they managed to develop this kind of solution:

The customer does not need to go in and think "oh, at that hour I will steer away [from electricity use], because then it's expensive, but I cannot steer away the next hour, because then it will be too cold". The system does this for them. We believe the system can usually figure out a steering model that fits the individual needs of each customer. (Project leader, Technologies Smart Customer Gotland, 2014)

In that sense, the script that was built into the remote control told users that they did not need to bother about when devices in their homes used electricity, or how much was used; they could leave this matter for the technology to handle. The logic of not bothering people with electricity consumption seems to have guided the design of the remote control; however, this logic contrasted with that of other entities that were part of the smart grid established within the project. These entities encouraged people to enhance their engagement in electricity consumption. 


\subsubsection{Collecting, compiling and presenting information}

The smart grid established within Smart Customer Gotland did not only have a configuration for remote control; it also assigned actors with the task of collecting, compiling and presenting information about the households' electricity consumption. These technical appliances were inscribed with certain ideas about the users, and were designed to inspire specific behaviours; in particular, they were designed to encourage efficient electricity consumption and to shift the timing of consumption. Unlike the remote control configuration, this configuration did not focus on specific electricity-consuming devices; rather, it assembled information about all electricity-consuming devices in participating households.

Smart Customer Gotland based this configuration around an already existing commercial product from Vattenfall, this solution entailed a "measurement sensor" that was attached to the pre-existing smart meters of the participating households. The sensor read the frequency that was emitted from the meter's diode; since different devices emit different frequencies, the sensor was thus able to distinguish different devices (field notes 2013, 2014; GEAB, n.d.-b). A software program then translated this information into graphs and numbers, which were transmitted to the app on mobile phones and tablets. Users were then presented with an overview of how much electricity the devices in their homes used, when they used it and on what, as shown in Figure 2. 

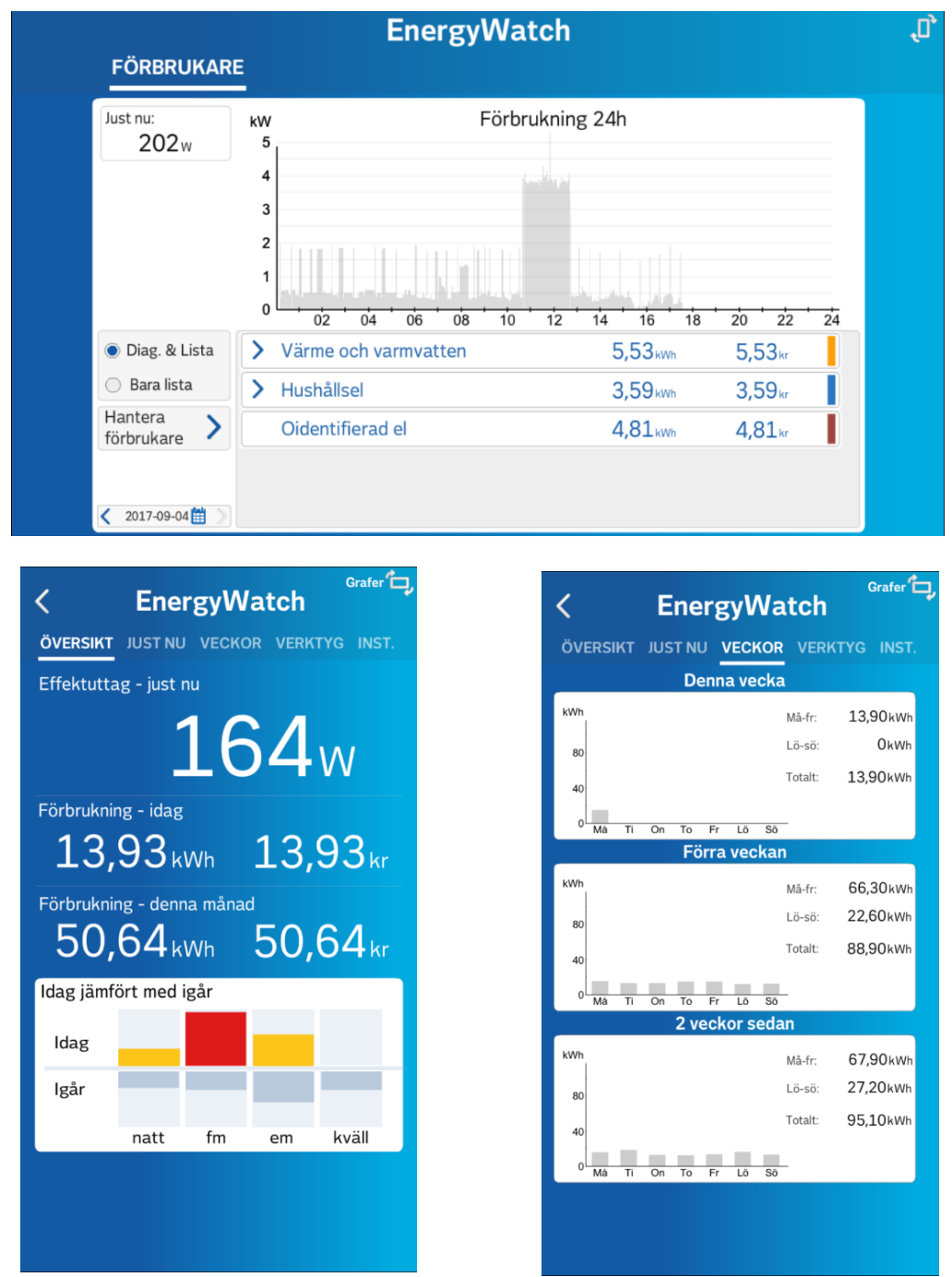

Figure 2. Examples of graphs, numbers and figures of electricity consumption (Smart Customer Gotland, 2017a)

These technologies were inscribed with a very different notion of users than the ideas that were inscribed in the remote control; here, the assumption was that users were technology-minded individuals who interpreted facts through figures and numbers, who engaged with technologies as a means of receiving detailed 
information and who wanted to enhance their knowledge about electricity consumption. The persons who worked within Smart Customer Gotland expressed various ideas about what this configuration implied. Some argued that the information provided to users would "enhance their knowledge" (Emma) and help them "keep track of their consumption in total" (Elin). Other expectations were that information about fluctuating prices would generate behavioural changes; in other words, project employees argued that users would "start the dryer at night; do the laundry or wash the dishes when it's cheap" (Elin). As Eskil described it, "we will not cook our slow-cooked beef tenderloin that needs to be in the oven for 12 hours on just that day [with high electricity prices]". In this way, the project employees expected the users to behave as economically rational individuals and alter their everyday routines based on price fluctuations.

Other employees seemed to disagree with such expectations, however; they claimed that enhanced information could generate measures to "reduce electricity consumption overall, but maybe not turn up and down from a load shift perspective" (Project leader, Smart Customer Gotland, 2014). The project leader of Smart Grid Gotland also argued that high prices could decrease consumption; however, he did not find it likely that a low price would trigger increased consumption. He illustrated his argument with an ironic comment about what kinds of engagements such a claim suggested: "'[when the price is low] I turn on the hairdryer, and then I turn the pool [temperature] up to 35 degrees"' (Project leader, Smart Grid Gotland, 2013). This comment also reveals doubts about whether people would engage with flexible consumption based on price signals doubts that further strengthened the project's configuration of assigning this task to remote control. 


\subsubsection{Encountering problems with existing entities in households}

The last members to be enrolled into the smart grid configuration assembled by Smart Customer Gotland were the households. These consisted of a wide collection of pre-existing human and non-human actors. As already mentioned, the project had the initial objective of including more than 2000 participating households (Smart Grid Gotland, 2016e; Swedish Energy Agency, 2012). In the end, however, the project came nowhere near fulfilling this target; only 214 households were enrolled in the project's original smart grid configuration (Svalstedt \& Löf, 2017). As a means of increasing this number, Smart Customer Gotland altered their configuration. I will return to these alterations; first, however, I will examine the reasons why the project encountered problems with enrolling households.

One reason that was frequently mentioned by the persons working within Smart Customer Gotland was that the set requirements (i.e. a detached house, a certain level of electricity consumption, electric heating that could be steered and GEAB as the electricity supplier) excluded more households on Gotland than was initially expected. As the project proceeded, the requirements became even more advanced, causing the exclusion process to continue. For example, the technical installations required that households have a wireless Internet, a condition that is taken for granted in sociotechnical smart grid imaginaries, and especially in the notion of digital dreams. However, the Gotlandic households did not always comply with this ideal; many completely lacked WiFi, and some houses had such thick stone walls that the signal could not reach the locations of the smart meters (Project leader, Smart Customer Gotland, 2014; Project leader, Technologies Smart Customer Gotland, 2014). The project leader for technical solutions further explained that there were many big houses and widespread farms on Gotland, in which smart meters could be placed in peripheral places: "In urban areas, the smart meter is always located on the cabinet on the wall of the house, or similar. It does not look 
like that here; rather, it can be placed on an outhouse" (Project leader, Technologies Smart Customer Gotland, 2014). She thus implied that the Gotlandic conditions did not meet the project's expectations. Her comment illustrates the difficulties that will arise if smart grids are scaled up and implemented in areas that are not newly built to comply with such solutions. Furthermore, the technical configuration that heated the houses differed from the initial expectations of those in charge of the project:

\begin{abstract}
Maybe you have a heat pump, you may have some radiators that use direct electricity, you can have heated floors and you can have a warm water heater. If you steer one heat source and not the other, then the one you do not steer is turned on. So then these things counteract each other, so the steering has no effect; you can even get a negative effect, and then it is not even certain that we can steer. (Project leader, Smart Customer Gotland, 2014)
\end{abstract}

This situation was further complicated by specific Gotlandic conditions. Gotlanders living on the countryside often have access to fire logs for free; therefore, many households did not see a reason why they should use electricity just because the project wanted to steer their devices. As Ellinor put it, "On Gotland, you put on fires”. These findings made the project leader of Smart Customer Gotland dubious about whether the smart grid established within this project would function in a large-scale implementation:

[W]e have so many different forms of heating in our Swedish homes and that is how it looks in reality. So if we go out into reality with this, if it indeed becomes serious and commercial and so on, these problems will exist. Parts of them, maybe you will be able to solve in the end, but not all. (Project leader, Smart Customer Gotland, 2014)

Another requirement that diminished the number of potential households - and that created doubts regarding whether the project's smart grid configuration would function in a broader smart grid roll-out - concerned the condition that electricity 
should be adopted to fluctuating electricity prices. Households were recruited with the condition that they should have an electricity contract based on a fluctuating price. This seemingly simple request eventually delimited a substantial number of households, whose fixed electricity contracts were considered too expensive to suspend from the project's budget (Project leader, Smart Customer Gotland, 2014; Project leader, Technologies Smart Customer Gotland, 2014). Smart Customer Gotland had based its smart grid on ideas that resonated with the notion of flexible futures, in which electricity tariffs with set prices belong to the past (see Chapter 5 ). However, such tariffs were still very much present on Gotland.

The employees who worked with electricity sales within GEAB said that they had huge problems convincing their customers to change electricity contracts. Using different campaigns, they had tried to get the message across that some contracts are better than others: "Wake up now, get yourself a price that's good for you - and yet, the customers do not care" (Sales representative, GEAB electricity sales, 2014). This remark illustrates the frustration of working within a framing in which households are assumed to base their decisions on what is economically rational; assumptions that have guided the Swedish energy system for decades (see Chapter 5). Those in contact with these households thus report from a reality that does not comply with such an assumption.

The economic incentive also became problematic because during the time of Smart Customer Gotland, electricity prices were substantially reduced; in other words: "we have had the electricity price against us. [...] If it had been the opposite, if the electricity price had gone up, the bills would have been more expensive, and then people would start to think about this" (Sales representative, GEAB electricity sales, 2014). In this sense, the project had based the smart grid on an assumption about prices that did not turn out as expected. This result shows how the fluctuating 
prices and economic incentives, which constitute cornerstones in the notion of flexible futures, were difficult to make functional within this demonstration project.

The persons working within Smart Customer Gotland gave yet another reason why the Gotlandic households were difficult to enrol, a reason that had to do with the people who lived on this island:

\begin{abstract}
Gotland is a test site in all its glory [..], but then it's the people you encounter here, they are a bit special. There is generally no drive; there are always exceptions, but say that this would be accepted in 10 years on the mainland, it would take about 15-20 years here on Gotland. (Ellinor)
\end{abstract}

This argument questions the framing of Gotland as an ideal place to conduct a smart grid demonstration project; it seems to suggest that such a claim did not take into account the people who live on this island, but was based on other conditions. The logic behind such an argument seem to suggest that a project with ambitions to be in the frontline of innovation demands users who comply with such ambitions.

Another central argument that pointed towards the nature of demonstration projects as a reason for why Smart Customer Gotland had encountered problems with enrolling households focused on issues in the recruitment process. Some project employees argued that the enrolment was carried out too early in the project: "We knew nothing. We were swamped with questions we could not answer. And it was, all the time, 'we'll get back to you, we'll get back, we'll get back"' (Einar). This confusion eventually resulted in households who were initially interested losing their engagement. Other employees in the project argued that such difficulties were natural in a demonstration project, as such projects entail nonstandard procedures by definition; as Ellinor put it, "the main difficulty in this project is that we build the road while we walk on it, and it took quite some time before we realized that this was the case". 
All in all, various reasons combined to prevent the project from enrolling all the households that were initially anticipated. In order to increase the number of enrolled households, Smart Customer Gotland eventually designed an alternative configuration to include households that received a price signal that only consisted of the spot price and did not include remote control. For these households, the users had to manually shift their consumption in accordance with the prices (Smart Customer Gotland, 2014a, 2014b). Fifty households were enrolled in this second configuration, so a total of 264 households took part in Smart Customer Gotland (field notes 2017; Svalstedt \& Löf, 2017); instead of the initial objective of 2300 households (GEAB et al., 2011). Smart Customer Gotland's ambition of enrolling a sufficiently large number of households in order to succeed as a demonstration project made it necessary to abandon the original idea of assembling a configuration that used remote control to make participation easy for users. This turn of events shows how this demonstration project had to adjust the smart grid it assembled, in order to meet the local conditions on Gotland such as materialities and users.

Let me briefly mention that the results of Smart Customer Gotland's assessments after the project was finished, showed that about half of the participating households had reduced their electricity consumption, while the other half had rather increased their consumption during the project's duration (field notes, 2017; Smart Customer Gotland, 2017b; Smart Grid Gotland, 2017) $)^{9}$. A mere 10\% of the participating households had adjusted $10 \%$ of their consumption according to the fluctuating electricity price, and thus met the project's initial ambition (ibid.). In

\footnotetext{
${ }^{9}$ The average electricity reduction in the project was $4 \%$, but the numbers differed significantly between participating households, since some households had increased their consumption substantially (Smart Customer Gotland, 2017b; Smart Grid Gotland, 2017). On one occasion, the increased consumption was explained with that the household had installed a home spa during their participation in the project (field notes, 2017).
} 
sum, these results show the difficulties to realize the notion of flexible futures as described in Chapter 5.

I have now followed how the socio-material configuration that emerged within Smart Customer Gotland was put in place, I have examined the various tensions, doubts and expectations this configuration generated among the people who worked within the project. I have shown that the established smart grid was influenced by the interests of the actors behind the project, and that it was not easy to construct a functional smart grid that made sense within the project. Entities (existing technologies in households, users and prices) that Smart Customer Gotland had targeted as members of their socio-material configuration did not act as they had expected. These events are indicative of some of the problems that could arise in a full-scale smart grid implementation - particularly since such a roll-out would entail an abundance of different pre-existing socio-material configurations that might be even more complex than those at play within this particular project.

\subsection{Justifying activeness}

As noted earlier, those who worked within the project frequently justified why the smart grid version they had assembled was preferable to possible alternatives. In these justifications, they frequently drew on sociotechnical smart grid imaginaries. As I showed in Chapter 5, the notion of empowered and active electricity users is a core concept in the smart grid future that is evoked in Swedish smart grid planning and strategy documents; smart grid users of the future appear as both active and empowered. In sociotechnical smart grid imaginaries, this notion takes the form of users who actively make decisions on the market, use enhanced information to make decisions about when to use technical appliances and produce their own electricity as prosumers. 
The fact that smart grid propagators praise activeness is also recognized in previous research that show how such actors envision electricity users to take on a more active role in the future energy system (Geelen et al., 2013; Verbong et al., 2013; Vesnic-Alujevic et al., 2016). Smart grid advocates seem to praise this ideal of activeness; as if this is a main feature of the smart grid that justify its implementation (See Chapter 5). The ideal of activeness would therefore be difficult for Smart Customer Gotland to ignore. As I will show in this section, the people working within the project tried to frame their smart grid version as aligned with this ideal. They frequently presented the project as an opportunity for electricity users to become active; this attribute was used in marketing folders, descriptions about the project and discussions between project employees and potential participants. For example, the CEO of GEAB referred to this ideal during her talk at a recruiting and information event:

Engage in Smart Grid Gotland - take the chance to become an active electricity customer. (CEO of GEAB, Recruiting and information event, field notes, 16 August 2013)

As a demonstration project, Smart Customer Gotland can be conceptualized as given the task of filling the ideal of an active electricity user with meaning. However, this translation was challenging, because the smart grid configuration in question rested on two seemingly inconsistent ideals: it aimed to make things easy for users who had neither the time nor the interest to engage with electricity consumption (as shown in the decision to make use of remote control); and it simultaneously aimed to enable users to become active. Technologies based on automatic solutions can be conceptualized as "tak[ing] care of most of the demand response underneath the nose of a happily ignorant user" (Throndsen, 2017:289). Thus making the active involvement of users less important. Strengers (2013:32) has noted that the imagined smart grid user both embodies passiveness (enabled by automatic solutions) and activeness (enabled by resource management tools). Such 
ideas thus entail contradicting implications as smart grid stakeholders both argue for passiveness and activeness at the same time (Christensen Haunstrup et al., 2013). People working within Smart Customer Gotland had to find a way to align these ideals; they had to find workable configurations that functioned within this project, while justifying how these configurations were aligned with the ideal of activeness that was foundational to the project and to smart grids in general. They tried to find ways to create coherence, despite the presence of tensions. In this section, I examine this struggle, as I analyse how the people who worked within Smart Customer Gotland explained how the smart grid that was established within this project enabled active electricity users.

\subsubsection{Active users care}

One way in which the persons who worked within Smart Customer Gotland explained that they were contributing to activeness was to refer to the project's existence. Ellinor argued that "in this project, it is actually that you have signed up, that you are aware of what happens, then you are an active customer". In this way, Ellinor connected the rather vague idea of activeness with the project by arguing that those who signed up for Smart Customer Gotland were active as opposed to those who had not. This viewpoint implies that individuals who were not aware of the project's existence, or who for some other reason had not signed up, were not active. Ellinor expanded on her viewpoint by arguing that participating in this project meant doing something, and that users in the project were taking a stance and not just sitting with crossed arms. Ellinor stated "that you care, is for me an active customer" implying that people were enacting their "care" by signing up for the project. This way of reasoning identified every individual who participated in the project as being active. However, the project employees divided this group of "active" participants into two subcategories: those who became "passively active" and those who became "actively active". 


\subsubsection{Passively active users}

The fact that the smart grid established within this project relied on remotely controlled devices generated tensions. These tensions were particularly stirred up because this configuration was chosen based on a belief that people did not want to engage with electricity consumption or, in other words, did not want to be active. Ernst argued that "if everything is automatic, the customer does not need to be active" and found that the project's configuration encouraged "a so-called active customer, which actually in practice is a rather passive customer". Ernst thus implied that "active" was just a word and had no real implication in the project; in fact, he argued that the smart grid established by the project enabled passiveness. However, through different arguments, the persons working within Smart Customer Gotland still held on to the notion of activeness. One way this concept was sustained was through Ellinor's claim that 'you've already been active in that you have signed up, that you let your system be controlled. You might say, then, that you are active even though you let someone else do it for you; it is amazingly comfortable". In this way, Ellinor held onto the notion of activeness even though the project configuration was fully automated. Ernst also supported this viewpoint by stating, "If the customer gets automatic solutions installed, you can say that he becomes an active customer. [...] The customer will be able to contribute by changing his consumption, even if the customer himself does engage directly with the system". According to this reasoning, activeness is achieved by delegating choices to technology; rather than demanding that users be completely aware of how the system works, it allows users to rely on other entities to achieve the desired changes.

The project employees explained that this configuration still generated activeness by turning attention away from the individual users and towards households: "it does not necessarily mean that you do anything active as a person; you might rather 
say that you become an active household by letting the automation steer for you" (Ernst). In this way, Ernst seems to justify activeness by understanding households as a socio-material configuration; he states that while remote control might not generate active humans, it does generate active households that include artefacts, practices, humans, technologies and so forth. Some project employees even introduced a new name for this kind of activeness:

We can send out the signals to a system so that the customer herself, in everyday life, does not need to be as active, but can be a little passively active. (Eva)

By introducing the concept of "passively active", Eva could rationalize that the smart grid that was established within the project was aligned with the ideal of activeness. This perspective illustrates the influence that sociotechnical smart grid imaginaries had on the project; the persons working within the project seemed to be obligated to follow these notions, even though doing so meant that they had to tweak the actual meaning of "activeness".

The "passively active" user described by Eva aligns strongly with the logic of "involvement made easy" that is presented by Marres (2012b). Marres claims that the technologies that are associated with sustainable transitions often have a kind of "change of no change" mechanism, as they enable people to become environmentally engaged without changing their lives in any profound way. She illustrates her logic with a story of a teapot that changes colour based on the demands of the national electricity grid, thus indicating whether it is a bad or good time to make a cup of tea; Marres points out that this technology is framed as a way of engaging with the environment with the least possible effort, cost or disruption. She finds that this way on enacting environmental participation as 'doable', configures users as generally uninterested in engaging with environmental issues in ways that influence their everyday lives. 


\subsubsection{Actively active users}

Another way in which the persons working within Smart Customer Gotland explained that their smart grid enabled activeness was by referring to the devices that enabled enhanced information. As Eskil put it: "Just the level of consciousness of being aware of how it looks makes you more active”. In this way, Eskil suggested that the project smart grid enabled active users by providing them with the means to learn more about their electricity consumption. However, other employees implied that although the project provided users with the tools to learn more, the individuals themselves needed to decide whether they wanted to use this information or not: "If you are an active customer, an active and interested customer, then you can get very good insight into your consumption" (Elin). In other words, "you have to be active to increase your understanding of energy-related issues" (Emma). This viewpoint suggests that although the project's smart grid can enhance people's knowledge, it requires users to be active, thus turning the argument around; rather than enabling activeness, the configuration made it possible for those who are active to learn more. Others argued that the project's smart grid made people active by providing users with the means to turn knowledge into practice - in other words, the project enabled people to actually do something to change their electricity consumption patterns:

Say that you get a signal from us indicating that the electricity price will be low tomorrow. Then you do not turn on your dishwasher and washing machine today; instead, you wait until the following day. Then you are an active customer. (Einar)

Other project employees added to this line of argument by pointing out that the project's technologies enabled people to monitor their electricity consumption by providing users with statistics and detailed information about how much electricity the devices in their homes used, and when this electricity was used. Some employees expressed anticipation that this configuration could result in decreased 
consumption: "maybe see if you can do any improvements and those kind of things, then it is more you as a person who becomes active" (Ernst). Ernst even introduced the notion of the "actively active customer" to denote an individual who is interested in electricity consumption and who personally engages in reducing consumption. He argued that these individuals take on their own initiatives, such as installing extra insulation in their houses. Elin added to this conceptualization by arguing "the customer can also be active by saying, 'yes, I accept a slightly lower temperature in my house, if it means that I save electricity". This idea of the "actively active" electricity user did not align with the ideas that were inscribed into the remote control configuration (i.e. that people could continue living as before they signed up to the project, and that the control should pass unnoticed).

This way of defining activeness resembles Marres (2012b) logic of "the more invested, the more engaged" - which is her denotation for environmental engagements that people perform in ways that amplify their investments for living in an environmentally friendly way. To illustrate her logic, Marres refers to blogs in which people present the everyday efforts, costs and disruptions they tolerate in order to strive for sustainable living. This ideal of Marres is reminiscent of the "actively active" electricity user, as both imply individuals who personally engage with environmental issues and who can tolerate certain restrictions in order to achieve this goal.

In this section, I have illustrated how the people who worked within Smart Customer Gotland argued that their smart grid version enabled active electricity users. Through various explanations, they attempted to create coherence between the notion of activeness and their established configuration. I have shown that their translations of activeness resulted in doubts and paradoxes, as they tried to redefine how activeness can be understood. I have also shown that in several cases, the persons who worked within the project were aware of these contradictions, and 
were not completely at ease with them. In particular, I traced such struggles as project employees used terms such as "passively active" versus "actively active" to denote the degrees of activeness their smart grid version enabled. Instead of rejecting the ideal of activeness, they held onto the notion but stretched the meaning of it. This can be understood as the project employees needing to make the concept of activeness trustworthy, since the project and smart grid were reliant on such a narrative; as Law puts it, "All it takes is for one translation to fail and the whole web of reality unravels" (Law, 2009:145). This analysis also shows the work that is needed to maintain a certain level of coherence and reduce contradictions when constructing a smart grid. The concept of activeness was part of project employees' justification of why smart grids are important; it was also an argument that they used in their campaign to interest households in signing up for the project. As I will show in the following section, this campaign included other means of persuasion as well, although these other means also resulted in tensions and contradictions.

\subsection{Making people interested: charging smart grids with matters of concern}

In previous sections, I showed that Smart Customer Gotland experienced problems in enrolling households into their smart grid configuration. In this chapter's final section, I will dig deeper into this process and pay special attention to how Smart Customer Gotland tried to persuade people who lived in these households to join the demonstration project. Smart Customer Gotland relied on different strategies to enrol actors to their smart grid. Although the project configuration was altered based on the attributes of the material entities in the households, the people living in these households could not directly influence the smart grid; rather, they were expected to be persuaded to take part in a pre-existing configuration. Other scholars have suggested that convincing households to participate in smart grids is 
a huge challenge for smart grid stakeholders, since they have to translate the needs of the energy system into something that is of value and is motivating to individuals (Schick \& Gad, 2015). The persons who worked within Smart Customer Gotland expressed their awareness of the challenge of enrolling users to their smart grid. They claimed that in the initial phases, they were already in doubt regarding whether they would succeed with this task or not. This was primarily expressed as a concern that the project could not offer users anything that the employees believed the users were especially interested in or desired: "We are not exactly selling a computer game or a mobile phone" (CEO of GEAB, 2013).

The project employees further argued that Swedish households take a secure electricity supply for granted, and claimed that it would have been much easier to enrol households if Swedes longed for or had problems with electricity; as Eva put it, "right now, it's far too cheap and far too good, which makes people very comfortable with electricity". As I showed in earlier sections, the scepticism that was held within the project regarding getting users involved helped to guide the decision to steer household devices using remote control, since this configuration did not demand anything from individuals, but relied on the logic of "involvement made easy". This logic was also apparent when project employees tried to persuade people to join: they claimed that people did not need to engage, since the project would take care of users' engagement for them (field notes 2013, 2014). However, this enrolment strategy clashed severely with the simultaneously used argument that the smart grid would activate electricity users.

In addition to arguments that focused on breaking down hesitation or resistance, the project relied on an enrolment strategy that stressed why this was an important and valuable project for people to sign up for. This strategy was conducted through a recruitment campaign that took the form of many announcements, which occurred through advertisements in local media, leaflets in envelopes for electricity 
bills, a designated website and information sheets in grocery stores. Besides this written campaign, the project employees convinced people to join through conversations with individuals at public events (Person in charge of recruitment campaign, 2013; Svalstedt \& Löf, 2014, 2017). When I asked Smart Customer Gotland employees who took part in such events which arguments they used to persuade people to join, they repeatedly referred to five different themes: economy, sustainability, the good of Gotland, the future and enhanced information. In the following sections, I will analyse how these themes were formulated, how the recruitment campaign unravelled and the tensions that resulted.

Inspired by Marres (2012a), I conceptualize this recruitment campaign as a way to frame the demonstration project and smart grids with relevance. Marres (2012a) argues that such campaigns can use visual, textual and technical hints to charge objects with certain issues, and claims that through this issuefication process, "an object comes to 'resonate' with particular matters of concerns" (Marres \& Rogers 2005 referred to in Marres, 2012a:265). This argument means that the object is granted the ability to bridge the divide between people "in here" and issues "out there", as people are told that they can engage with these larger issues through the charged object (Marres, 2010). In a similar way, I conceptualize this recruitment campaign as a means of charging smart grids and the demonstration project with matters of concern that the people working within Smart Customer Gotland hoped would encourage individuals to sign up for their project.

\subsubsection{Connecting the project with economy}

In Chapter 5, I showed that Swedish sociotechnical smart grid imaginaries suggest that economy will function as the main motivator for flexible consumption. This suggestion resonates with other studies that have shown that smart grid stakeholders primarily assume that economy will function as the main incentive for 
smart grid user engagements (Ballo, 2015; Mah et al., 2012; Verbong et al., 2013). The same tendencies guided the initial phases of Smart Customer Gotland's recruitment campaign:

Steer your electricity consumption and lower your expenses: You will be able to monitor your energy consumption and adapt it to the electricity price. For example, you can lower the heat when you are not at home, be sure that the water heater is turned on when the electricity is cheap and wash when the price is low. (GEAB, n.d.-a original emphasis)

Despite this initial focus, the recruitment campaign gradually decreased its focus on economy. One reason behind this decrease was uncertainty; as Emma put it, "we do not know how much money they will be able to save, and we do not want to give an expectation that we will not be able to live up to". The people who worked within Smart Customer Gotland thus began to questioning the project's economic framing; they doubted whether this framing would still be attractive if the prices did not change as expected. Some employees even argued that framing this demonstration project as a way of saving money was a mistake that could turn into a direct obstacle, and that might become a source of disappointment and controversy for participating households:

Another reason for those who have signed up, I think, is that they have decided based on this unfortunate statement that has been made that this is a possibility to save money, and they'll probably be very disappointed. (Emil)

Some of the concerns regarding the economic framing of the project were articulated in the form of scepticism towards the possibility of accurately assessing the influence of flexible consumption on households' electricity expenses, since these expenses were also influenced by parameters beyond the project's control (i.e. overall electricity price, the weather, changed habits, altered appliances or people moving in or out of the households). 
Another perspective was that fluctuating prices also imply periods with high prices, as Einar put it: "if you do not play your cards correctly, then you can of course get a more expensive bill”. Despite these doubts regarding the charging of the project with the idea of economy, some project employees still considered this to be an appropriate way of making users interested in flexible consumption in the future. These arguments were expressed as, "today, electricity is too cheap, it's too small of a part of your household budget, so for most people, comfort takes over" (Eva) but "in the future, when we have greater price fluctuations" (Ernst) more money can be saved with flexible consumption. This line of reasoning suggested that that the project's configuration was premature; in other words, it implied that Smart Customer Gotland had brought the future into a present that was not yet ready for these changes. In this way, project employees frequently expressed their certainty that electricity prices would fluctuate in the future; however, the question of when this would happen was referred to as "the so-called million dollar question, that no one knows the answer to" (Ernst). In this way, project employees drew on sociotechnical smart grid imaginaries and pointed towards the future in their explanations of why they enrolled users with economic incentives:

People need to understand this with the smart grid, why we do it now. [Some might say,] "But I do not make any money on it." But it's like I always say: no, you may not make money right now, but if you do nothing now then maybe in 15 years, we will have an unnecessarily high electricity price because we have not adapted. But if we adapt, we might get more reasonable prices in the future, that's what I think. (Elias)

According to this reasoning, a smart grid implementation will not result in any significant economic savings; rather, it is a way of guaranteeing that future generations will have the same conditions as we have today. Hence, a smart grid becomes associated with preservation rather than with alteration. It seems that Elias is suggesting that people should sign up for the project out of fear of what otherwise might happen. 
However, some project employees questioned the logic of using prices as motivators for electricity engagements. For example, scepticism was expressed with the following argument: in order for people to care about electricity for economic reasons, electricity needs to be extremely expensive; however, such a scenario is not likely because "then we have removed the advantage we have up here in the Nordic countries, with cheap and reliable access to electricity that made our industries strong" (Erik). This argument questions whether the notion of a successful Sreden is compatible with the high and fluctuating electricity prices that are suggested by the notion of flexible futures (Chapter 5). The project leader for Smart Grid Gotland also expressed concerns about positioning a fluctuating price as central to the concept of smart grids; he referred to classical demand-and-supply curves as the grounds for his argument:

Actually, it is pretty silly to invest in [appliances for flexible consumption] because if everyone else is doing it, there will not be any price difference because then the price will average out. So if everyone else is doing it, then I do not need to bother. (Project leader, Smart Grid Gotland, 2013)

The recruitment campaign was thus initially based on the assumption that people are economically driven; however, as the project unfolded, the initial economic framing of Smart Customer Gotland was challenged when put into practice. Callon (1998) denotes such tendencies, which do not fit into an economic framing, as overflows. In this case, the overflows consisted of various hesitations and doubts regarding whether the configuration would be able to deliver economic savings, whether users would actually be seduced by such motives and whether this was an appropriate representation of the future energy system. The people working in Smart Customer Gotland thus raised various concerns about the economic cornerstone that they had structured their smart grid around; these doubts caused them to turn to other ways of framing their project as appealing. 


\subsubsection{Connecting the project with sustainability}

Smart Customer Gotland also charged the project and smart grid with environmental issues. In the recruitment campaign, this incentive was phrased as, for example, "contribute to a better environment and future" (GEAB, n.d.-d) or "You help creating a sustainable society!" (Smart Grid Gotland, 2013). When I asked people working within Smart Customer Gotland why they thought people had signed up for the project, they pointed towards this environmental framing, and argued that those who had signed up were people who "want to contribute to a more sustainable society" (Elisabet). However, this sustainability argument was frequently formulated within an economic framing:

In the future, customers will need to follow the variation in the electricity price - preferably every hour - in order to be able to build more renewable wind production into a sustainable energy system. (Smart Customer Gotland, 2016)

Smart Customer Gotland thus created a connection between prices and being environmentally friendly; the recruitment campaign informed prospective users that those who wished to be sustainable had to follow electricity prices. This argument is aligned with the sociotechnical smart grid imaginaries in which the notions of flexible futures and sustainable society are closely entangled. Some of the project employees seemed to argue that they had no choice but to frame Smart Customer Gotland as a means of saving money because "it is the economic society in which we live, but we must do this in order to reduce the hole in the ozone layer in the future, to try to avoid flooding and storms" (Elias). Elias thus seemed to suggest that in order for other issues to become noticed, they need to be economically charged. However, this argument was opposed by references to activities that people engage in without economic interests: "We separate our waste without earning any money” (Elin), or as formulated by Ernst: 
We should not exaggerate the driving force that households change their consumption based on an incentive to save money; [it is rather so that] you contribute to the benefit of society. You can reduce your $\mathrm{CO}_{2}$ emissions by adjusting your consumption, so that we can run much more wind power and decrease coal power and those things, and that is basically much stronger than the money.

The recruitment campaign especially relied on an association between sustainability and wind power production, which for example was formulated as follows: "The smart grid is primarily developed to handle more wind power, thus creating a sustainable energy system" (GEAB, n.d.-a). Even though most of the interviewees who worked within the project supported the framing of smart grids as a means of achieving sustainability, others opposed these arguments. For example, Emil argued that "with the energy system we have in Sweden, there are no environmental arguments whatsoever for load shifting”. Erik supported this claim, and argued that "[w]e should remember that the environmental benefits in Sweden with smart grids and renewable production are limited". These employees primarily opposed the environmental framing with the argument that the current Swedish energy production (which is mostly nuclear power and hydropower) does not produce carbon dioxide emissions. Erik argued that there is a common misunderstanding that Sweden needs more renewable energy production, and considered that such arguments are not based on a thorough insight of how the current Swedish electricity production actually functions:

Actually, it's quite horrible that there are advertising clips that say "do not buy bad electricity", because in Sweden, we do not, actually, no matter what you buy, because it is produced in a good way when compared to how it is done on the continent, or in other countries such as China and the like. So we have an extremely good produced electricity. (Erik)

Erik thus argued that the Swedish energy system does not need to change for environmental reasons, and that such arguments are rather applicable to other countries. Since Sweden, unlike many other countries, relies on hydropower that 
functions as a large-scale battery, the need to adjust consumption to times of available electricity is not as urgent as it is in other countries that lack this arrangement. Emil held a similar viewpoint; he also considered smart grids to be more suitable for countries that do not have the Swedish energy system, and claimed that framing smart grids as environmental in a Swedish perspective is rather dubious:

We have the world's cleanest electricity production. The only reason would then be to shave the peaks to avoid import of coal-based electricity from the continent. But otherwise, there is no reason here. (Emil)

However, other persons who worked within the project argued that the need for smart grids in Sweden should be understood from the perspective that the current Swedish energy system might change; in particular, the future of Swedish nuclear power is not certain. In other words, the need for smart grids is closely related "to what will happen with nuclear power" (Elin). Aligned with the tensions I illustrated when describing the notion of sustainable futures, project employees frequently argued that intermittent energy sources cannot replace nuclear power: "wind power is not nearly as stable as, for example, nuclear power" (Elin). However, those who supported the framing of the demonstration project as an environmental project generally expressed doubts about nuclear power's future existence, while those who questioned the project's relation to sustainability argued: "We must have nuclear power, otherwise we are back in the Stone Age. We must have a cheap, environmentally friendly, reliable base production that must always be the foundation" (Emil). These opposing arguments represent the long Swedish debate of whether nuclear power can be regarded as sustainable or not (see Chapter 5). As I will show in Chapter 7, households who participated in Smart Customer Gotland also expressed strong opinions about the future of Swedish nuclear power. 


\subsubsection{Connecting the project with the good of Gotland}

Smart Customer Gotland further established associations between this demonstration project and the island of Gotland. Although these connections were made in different ways, they all spread the message that this project was good for the island. The person responsible for marketing Smart Customer Gotland argued that local questions are important for people on Gotland, and claimed that "locality will have a very important role in the future" (Responsible for marketing, Smart Customer Gotland, 2013). In line with such arguments, project employees often referred to the people they tried to enrol as "Gotlanders", as if these individuals identified with the island they lived on; this assumption was also reflected in the recruitment campaign:

The experiences from this project will be important for the entire Swedish society, even if we, as Gotlanders, are the first who get to test the new technology. (GEAB, n.d.-c)

This quote implies that the actors who are behind the project identify as Gotlanders. This self-identification probably referred to the local electricity company and grid owner, GEAB. GEAB is an abbreviation of Gotland's Energy AB, and this local connection is a large part of the company brand; for example, the company presents itself as "a Gotlandic company operating on Gotland for the Gotlanders" (GEAB, 2015). Even though GEAB is $75 \%$ owned by Vattenfall and $25 \%$ owned by the municipality ${ }^{10}$ (GEAB, 2016), the company emphasizes the local connection as a large part of its identity. The people working within Smart Customer Gotland also referred to the locality of their company brand as something that was important for the project; in the words of Eva:

Many like GEAB, they have a pretty good position here on Gotland and think it's fun to join because it's a company you like. I do not

\footnotetext{
${ }^{10}$ Region Gotland
} 
think it would have had the same effect if Vattenfall had done this on the mainland.

In Chapter 7 I will show that users who participated in Smart Customer Gotland supported this opinion. However, the recruitment campaign did not only tell people to join in order to support GEAB as a company; it also referred to the Gotlandic energy system. In particular, the project mentioned the island's future wind energy; for example: "Gotland will have very localized wind generation" (Smart Customer Gotland, 2015b). The recruitment campaign charged wind power production with locality and framed it as something that was beneficial for the locals. However, one can pose questions regarding how more local wind power production would benefit Gotlanders. It is not certain that large-scale wind power facilities in the future would be owned by Gotlanders; rather, they would likely be owned by international energy companies such as Vattenfall. Furthermore, it is not certain that the electricity produced on the island would be used by Gotlanders; it could be transferred to the mainland. As I already mentioned, the electricity already produced on the island did not influence the local electricity prices. Rather, a local increase of wind power production was associated with various issues, particularly because it enhanced the demands on the island's grid. Smart Customer Gotland was initially justified as a project that would use flexible consumption to decrease the demand on the grid that was caused by wind power. The CEO of GEAB, however, doubted that such a configuration was sufficient and expressed her certainty that "we need a cable for electricity exports, especially since there are plans to increase wind power production" (CEO of GEAB, 2013). Her claim was supported by the grid owner, who stated that "until we have a new cable, we will get more blackouts on the island" (Executive for GEAB's electricity grid, 2013). These actors apparently did not find flexible consumption to be enough to solve the demands on the local grid, and favoured a solution that involved a new cable. In this sense, they seemed to propose that increased wind energy production at present would generate 
problems for the locals, and that the recruitment campaign invoked connections that were not completely aligned with the reality on Gotland.

\subsubsection{Connecting the project with the future}

Smart Customer Gotland also framed the project as a way to engage with the future. The project employees could then disconnect from the economic framing by suggesting: "It is not the big money it is about; rather, it is that you get to participate in testing new technology in a future electricity system" (Ernst). This claim was also supported by Elin, who commented, "It's exciting just to be part of a research project, a future project", and by Eva, who stated, "some have joined mainly because they are interested in technology and think it's fun to get some new systems, they're probably just happy to be part of cutting-edge technology". Employees often described these individuals as technologically minded and referred to them as "early adopters". Words such as "intelligent" and "smart", and phrases such as "the world's most modern", were frequent in the recruitment campaign's descriptions about the project, which was presented as a future-oriented project at the forefront of science and research:

In the project Smart Customer Gotland, you will get opportunities and technologies that, as far as possible, will resemble the energy systems of the future. In other words, you get to live in the future for a while, at least when it comes to the area of energy. (GEAB, n.d.-c)

This description suggests that the configurations established within the project will become the future; however, a consequence of the project's assessments is that the configurations might be changed or even rejected; hence, the participants may not be part of the future after all. The project leader of Smart Customer Gotland was aware of such a possible scenario: "all we know with certainty is that in the future, it will not be exactly as it looks like in this project" (Project leader, Smart Customer 
Gotland, 2014). To charge the project with future associations, however, gave the impression that participating households would be part of something designed exclusively for them, and would have the opportunity to try the future before the common masses. This framing gives the project an aura of fascinating novelty; people will get to try something out of the ordinary. Similar ideas were present in recruitment folders through formulations such as "Do you like excitement? [In Swedish, 'excitement' is the same word as 'voltage'.] Become our test pilot” (GEAB, n.d.-a). The implication that "test pilots" will lead the way to the future carries traces of responsibility; the project employees referred to the participants as individuals who wanted to "take part in the development of society" (Eskil). In this way, the project employees described the participants as people who were willing to take on the responsibility of actively contributing to a changed energy system - an argument that resonated with the previously described claim that 'active users care'. However, such arguments dismiss those who support an energy system that differs from the one proposed by the project, and imply that such individuals do not care what the future will look like. In Chapter 7, however, I will examine one of the actor groups that was excluded from Smart Customer Gotland's configuration - the prosumers - and show that they enact their care in a different way than the way suggested by the project.

\subsubsection{Connecting the project with enhanced information}

Smart Customer Gotland was further framed as an opportunity for people to receive more information about their households' electricity consumption. People were told that they should sign up for Smart Customer Gotland because it was an opportunity to "educate yourself in the efficiency of your electricity consumption" (GEAB, n.d.e). This framing resonated with the notion of empowered and active electricity users, which suggests that users become empowered as they gain access to more detailed information. However, as I previously discussed, those who worked within 
the project questioned the kinds of changes this enhanced information could actually generate. Another dilemma was also raised: that more information could make it difficult to enrol electricity users in the future:

We have to see what happens when people realize that this shows exactly when I was at home and when we got home [...] You may not have been aware of it before, but [find that] this is after all my life curve. [...] I think you can definitely get an "aha" experience that can be a backlash. (Project leader, Smart Grid Gotland, 2013)

Smart Grid Gotland's project leader argued that more information could result in people becoming aware of how much data companies collect about their everyday routines. This concern resonates with the integrity issues I described in the notion of digital dreams as part of sociotechnical smart grid imaginaries (Chapter 5). In this way, the framing of the project as an enabler of enhanced information posed questions of for whom and with which purposes detailed information was relevant.

In this section, I have shown that the recruitment campaign illustrated the difficulties in creating coherence between the established configuration and the arguments for why users should engage with smart grids. The themes used in the recruitment campaign resonated with sociotechnical imaginaries, as they bore traces of the notions of sustainable society, flexible future, digital dreams, successful Sweden and empowered and active electricity users. However, the ways in which project employees reflected about the recruitment campaign, the established configuration and what their smart grid version could result in revealed struggles and unresolved tensions. As I will show in Chapter 7, the users who participated in Smart Customer Gotland could verify the arguments presented in the recruitment campaign to some extent; however, the users also described a more civic-centred and politically driven perspective on engagement that was not clearly articulated by Smart Customer Gotland. In the following chapter, I will argue that one reason behind this tension could be that the project, which was represented by utility 
companies, had a customer relation to smart grid users rather than, for example, a citizen relation.

\subsection{Summarizing discussion}

In this chapter, I have examined how the "partially existing object" (Schick \& Winthereik, 2013:83) of smart grids was translated into materialized form in the course of the Smart Customer Gotland project. As I have followed the assembling of this smart grid, I have also traced the different steps through which Callon (1986) characterizes translation processes: problematization, interessement, enrolment and mobilization. Through these steps, seemingly unrelated entities became associated, merged together and given meaning within this smart grid demonstration project. In this chapter, I have shown how the actors in charge of this demonstration project - or, in the words of Callon, the network builders - tried to impose their interests, worked in order to enrol different human and non-human actors, and mobilized sociotechnical smart grid imaginaries and national historic contexts such as nuclear power discussions. I have also shown that the network builders simultaneously struggled to establish a trustworthy problem definition, and had trouble maintaining coherence between their established configuration and their arguments for smart grids.

In the first step in Callon's (1986) translation process, problematization, the network builders define the problem that they should resolve, the elements that should be part of the solution and the elements that should not be included. The problem definition that guided Smart Customer Gotland's process of assembling a smart grid can be formulated as follows: Through which commercially viable products and electricity tariffs can flexible consumption be encouraged? This problem definition can be seen as a result of the commercial interest of the actors behind the project; however, I also trace an assumption that users should play the 
role of economically rational customers who choose products on the market. This is a suggestion that aligns well with the national sociotechnical imaginaries, which I described earlier as flexible futures and empowerment through market engagement (Chapter 5). Through this problem definition, Vattenfall and GEAB established themselves in a central position, since they provided the commercial appliances and fluctuating prices that were intended to encourage flexible consumption. When seen through the lens of translation processes, these companies thus established themselves as the project's obligatory passage point. In addition, they received a favourable position for future smart grid roll-outs, as the smart grid established by this project had the ambition to function as "an international model for a long-term sustainable electricity power system" (GEAB et al., 2011:13).

As a direct consequence of defining the problematic issue, other issues are simultaneously dismissed as being of less importance. In Smart Customer Gotland, this step refers to how alternative smart grid configurations and, as a consequence, alternative user roles were dismissed. Drawing on ideas from Galis and Lee (2014), I conceptualize the process of defining the actors that should be part of the configuration as being accompanied by a process of marginalizing alternatives; thus, for "every constructed 'obligatory passage point' there can be a number of 'points of irrelevance' that thwart actors in their desire to define a problem" (Galis \& Lee, 2014:160). In the process of narrowing down the kinds of flexibility providers that should be part of the project's smart grid, an abundance of alternatives were marginalized: all companies, all apartment dwellers, households with low energy consumption and households that did not have GEAB as an electricity supplier were excluded. In this case, the excluded comprised a fairly large group of alternatives that might actually constitute the overall majority of electricity users; those being included had to live up to a strict set of requirements. Furthermore, electrical vehicles, solar cells and small-scale wind power plants that could have been owned and operated by individual households were all excluded. In this way, 
the excluded elements represent alternatives that could have altered power relations within the energy system.

I conceptualize non-humans as being "capable of actively making a difference to the organization of social, political and economic arrangements" (Marres, 2010:188). In this sense, the exclusion process not only entailed a marginalization of neutral materialities, but also entailed exclusions of alternative socio-material configurations with societal implications. As I will show in Chapter 7, the excluded prosumers proposed different problem definitions than the one that guided Smart Customer Gotland.

In the next stage of Callon's (1986) translation process, interessement, the roles of the actors that are targeted as potential members of the socio-material configuration are imposed and stabilized. At this stage, the key is to build relations between the entities to be enrolled; this process is based on certain assumptions about the entities' attributes and desires, and about which elements they are associated with (Callon, 1986). The network builders of Smart Customer Gotland planned their smart grid based on assumptions of what would be technically feasible, how the electricity price would fluctuate, the features of the devices that were targeted as flexibility providers, the households' material attributes, and ideas about future users' desires, behaviours and motivations. These ideas were then inscribed into technical appliances that configured particular types of users. In this process, two alternative user categories appeared: in one category, the users were scripted to treasure convenience, and were able to delegate all activity to remote control; in the other category, the users were scripted to treasure information enhancement, and were able to engage with appliances' statistics and graphs of electricity consumption. Both these user groups were assumed to be primarily driven by economic incentives, as the technologies within the project emphasized 
the price users pay for electricity and the economic savings users can obtain by shifting the timing of their consumption.

These inscriptions shows that interessement entails the transformation of desires and goals; users were encouraged to perceive electricity consumption primarily as an economic engagement, while other potential perceptions were diminished. This process confirms Callon's conceptualization that "[t]o translate is to displace" (Callon, 1986:223). As Callon (1986) further points out, the process of establishing a network also weakens links to other configurations that would potentially define the actors' role, interest and motivations differently. For Smart Customer Gotland, establishing the network weakened connections to other configurations that could have encouraged alternative user roles; for example, the role of users as producers of electricity was weakened. In Chapter 7, I will show what this excluded engagement can entail, as I shed light on prosumers' engagements and preferable futures.

Even though Callon does not especially emphasize this point, interessement also applies to people; one way to convince people is through rhetoric, which creates "an association of interests that give people the will to do something" (Cooren, 2000:184 original emphasis). Thus, as Smart Customer Gotland tried to persuade users living in households to join the project's smart grid, their main tool or, in the words of Callon (1986), their interessement device, was a recruitment campaign. Through this campaign, Smart Customer Gotland communicated not only why users should sign up for the project, but also why smart grids in general are important. The assumption that people base their engagements on economy was inscribed in Smart Customer Gotland's configuration; in addition, the recruitment campaign was initially based on this connection, as users were encouraged to join as a means of saving money. However, as the project unfolded, the campaign tried to disconnect from this framing and instead tried to connect smart grids and the 
project to other issues of relevance. The recruitment campaign charged smart grids and this project with five different themes: economy, sustainability, the good of Gotland, the future and enhanced information. In this "issuefication process" (Marres \& Rogers 2005 referred to in Marres, 2012a:265), the employees tried to assign the project and smart grid with the ability to bridge the divide between people "in here" and larger societal issues "out there" (cf. Marres, 2010:179). In this sense, targeted users were told that they could engage with matters of societal importance through this project. The creation of such solid ties between particular and larger issues is key in the translation process (Latour, 1987:117). The project employees thus charged smart grids and the demonstration project with various issues: some stressed personal rewards, while others focused on societal benefits; some entailed promises of rather direct character, while others offered more distant and beneficial promises for future generations.

The recruitment campaign resonated with sociotechnical imaginaries, and I was able to trace the notions of sustainable society, flexible future, digital dreams, successful Srweden and empowered and active electricity users. These prospects about the future seemed to influence the narratives told in the recruitment campaign, even though they were not completely aligned with the smart grid that was established within the project. The project's connections, as described in the recruitment campaign, resulted in contradictions and hesitations among the project employees; this became especially visible in the employees' attempts to redefine the meaning of "activeness". Although the employees drew on the notion of empowered and active electricity users, they simultaneously expressed doubts regarding whether their configuration enabled such attributes. The long Swedish debate regarding whether nuclear power can be understood as sustainable or not (see Chapter 5) was also evoked in this process; in Chapter 7, I will show that this tension was highly prevalent among participating households as well. 
However, "[n]o matter how constraining the trapping device, no matter how convincing the argument, success is never assured" (Callon, 1986:10). In other words, the interessement does not necessarily lead to the next step in this translation process, enrolment. Smart Customer Gotland encountered problems in its enrolment process. To begin with, the project was unable to enrol companies or farmers, as initially intended. Instead, the project ended up with households as the sole representatives of smart grid users. Furthermore, neither the fluctuating electricity prices nor the pre-existing human and non-human actors in the households played the roles they were assigned. The electricity prices were initially established as the configuration's core; however, as the project unfolded, the prices were not as high as assumed. In addition, the households did not always comply with the required vital technicalities, such as having WiFi or the required electricity contracts. These difficulties caused the project to alter its configuration and to include an alternative configuration without remote control.

The last step in Callon's (1986) translation process, the mobilization of allies, entails attempts to standardize the established configuration. This step raises questions regarding whether the enrolled actors can be understood as representatives of larger populations. This is a question that is particularly relevant to ask in relation to demonstration projects, which are legitimized with a certain degree of generalizability; in other words, such projects are motivated by the claim "[t]hat which is true for a few is true for the whole population" (Callon, 1986:12). The undertakings in Smart Customer Gotland raised three specific questions in relation to generalizability: Do Gotlandic households represent Swedish households? Did the price structures in this case represent future prices? Did the technical appliances in this case represent future technological solutions? The persons who worked within Smart Customer Gotland had different answers to these questions, and only the future will show whether the smart grid that was established within the project will be possible to roll-out to larger populations. 
Nevertheless, it is important to recognize that the configuration that was established within Smart Customer Gotland will have a head start over all the excluded alternatives, which were not given the opportunity of being realized within a demonstration project with the ambition of becoming a role model for the future.

In this chapter, I followed how Smart Customer Gotland assembled a smart grid, and examined the justifications the project employees used to explain this particular configuration. I showed that the process of assembling a smart grid was not a neutral one; rather, translation is "about moving terms around, about linking and changing them" (Law, 2009:144). In the next chapter, I will examine what the people who lived in the enrolled households considered attractive, and how these participants made sense of smart grids and used the technologies installed in their homes. Furthermore, I will explore what some of the actors who were excluded from the project's smart grid - the prosumers - articulated as being sought after in the future energy system. 


\section{Becoming a smart grid household}

In this, the last empirical chapter, I turn my attention to households and explore how they participate in smart grids and their motives for this engagement. The previous chapter showed that Smart Customer Gotland established a technoeconomic smart grid that relied on remotely controlled devices and enhanced information about electricity consumption, and that primarily encouraged economically motivated engagements. I analysed how this project was framed as appealing towards potential participators, and illustrated the tensions that arose when the project employees conceptualized the users as information-hungry, economically driven and active, yet simultaneously lacking the time, desire or interest to engage with electricity consumption. I now explore how this configuration was taken up and conceptualized by the users who took part in Smart Customer Gotland and became an actor in the socio-material smart grid configuration of the demonstration project.

In this chapter I refer to this group of actors as the "enrolled users", and have given them names that start with the letter $\mathrm{H}$, for households. I engage with them using two different analytical perspectives. First, I explore the meanings that these users 
associate with smart grids and with Smart Customer Gotland. Why did these users find this to be an important project and what did partaking in a demonstration project imply for them? From the angle of material participation (Marres, 2012b), I conceptualize these individuals as being able to express how their engagement with smart grids relates to larger societal issues (cf. Throndsen \& Ryghaug, 2015). I will shed light on how their conceptualizations resonate with the project's smart grid and with the sociotechnical smart grid imaginaries. In addition to the associations these individuals attached to smart grids and to the demonstration project, I examine how the enrolled users used technologies installed in their homes. What kinds of engagement did these technologies accomplish, and what roles did the users take on in relation to the smart grid? In this analysis, I examine whether the users followed the scripts in the technology design or whether they modified them and acted differently. I also explore how participation was materialized in these households or, in other words, "how the material form of participation is actively accomplished with the aid of devices" (Marres, 2012b:66). Hence, by examining the users' interpretation of what smart grid means, how they use the technologies installed in their homes and why they use them in particular ways, I shed light on smart grids from their perspectives.

In addition to these enrolled users, I turn my attention to an actor group that was excluded from the smart grid established by Smart Customer Gotland: households that produce electricity in small-scale facilities - the so-called prosumers. I attend to individuals who either produce their own electricity or who work with prosumers through events such as educational courses or solar cell installations (for details, see Chapter 3). I have given them names that start with the letter P, for "prosumers". These actors play an essential part in the sociotechnical smart grid imaginaries that are analysed in Chapter 5, and were also part of the initial rationalization of this demonstration project (see Chapter 6). I explore the associations these actors attached to smart grids and to Smart Customer Gotland. I also examine what kinds 
of material smart grid participation they find attractive - that is, what kinds of smart grid they want to be a part of.

\subsection{Articulating participation in Smart Customer Gotland}

First, I explore how enrolled users articulated their participation in Smart Customer Gotland. I examine the associations they attached to smart grids and to this specific demonstration project, how they legitimized their signing up for this project and why they found this to be an attractive engagement. I base my analysis on Marres (2012b:145) argument that a technological artefact does not in itself possess the power to engage people. Rather, Marres emphasizes the socio-material relations that an artefact evokes. Following such a conceptualization, I examine the wider implications that arose as the enrolled users legitimized their participation in this demonstration project. I trace three different kinds of motivations: participation as a means of obtaining personal benefits, as a civic duty and as a means of changing the energy system. These categories hint at how the participants interpret smart grids, what they want to contribute to with their participation and what partaking in a demonstration project implies for them.

\subsubsection{Participating as a means of obtaining personal benefits}

One way in which enrolled users justified their choice to sign up for Smart Customer Gotland was by expecting the project to result in personal rewards. These expectations differed; however, by far the most prevalent reason within this category of motives was an expectation of economic profit. As previously mentioned, smart grid stakeholders primarily identify economic reasons as a motive for households to engage with smart grids (Ballo, 2015; Mah et al., 2012; Verbong et al., 2013). I illustrated this point in Chapter 5, where I showed that these ideas are reflected in the national sociotechnical smart grid imaginaries; in Chapter 6, I 
also showed that the smart grid established within Smart Customer Gotland was inscribed with ideas of economically driven users. Some of the enrolled users confirmed this assumption. For example, Hemming did not ascribe any societal benefits to the project, but rather signed up with the ambition of lowering his electricity expenses. As he proclaimed, "the gains are on a personal level, that you save money on it". Hjalmar formulated the same argument, commenting that "what motivates this is that you hopefully get a little cheaper electricity", while Helen frankly stated, "the customer benefit is lowered electricity costs". Despite Smart Customer Gotland's ambition to play down the economic motive in its recruitment campaign (see Chapter 6), mentions of lowered expenses recurred as an anticipated benefit among the enrolled users. Harriet said, "I hope our expenses will have decreased [after the project]", and Hjördis commented, "If the project is over and you see that you have not earned any money on it, then I would not continue”. These comments from participants illustrate how economic incentives can backfire, since people who participate because of such hopes will naturally be disappointed if their expectations are not met. In the end, their expectations might jeopardize the participants' future interest in smart grids, thus verifying the concerns that were expressed by some of the project employees (see Chapter 6).

Other lines of reasoning that fall under the category of personal benefits involved curiosity rather than economic gains. For example, some participants wanted to learn more about their consumption; as Helge put it, "this is a way to become aware of how much electricity we use every day", or in Hans' words, "I am interested in seeing which devices are turned on and what they consume”. This kind of reasoning were articulated from the individuals' point of view primarily as a desire to enhance personal knowledge. The arguments were closely aligned with the notion of empowered and active electricity users, enabled by enhanced information (see Chapter 5). The enrolled users also expressed other personal benefits that were less direct; for example, Harry was "curious" of what the project would entail, Herbert 
argued that it sounded like "a fun thing to be part of", and Henrik considered that "it was intriguing with the technology part". Such personally charged motives hint at the participants' overall conception of smart grids, since these reasons for participating focus on what smart grids can do for the individual in terms of economic savings, information enhancement, personal amusement or convenience. Such articulations thus associated the smart grid with relations of a highly personal nature and did not ascribe any particular societal importance to it. These associations resonated with the framing of this project by Smart Customer Gotland's recruitment campaign, which connected the project with the concepts of economy, future technologies and enhanced information. However, in addition to these personal motives, the enrolled users associated their participation with civic duty and with a changed energy system, thus acknowledging the role of smart grids in wider society.

\subsubsection{Participating as a civic duty}

The enrolled users used arguments relating to civic duty when they talked about their participation in Smart Customer Gotland. Such arguments were often articulated as a critique towards economically motivated configurations:

If you have financial incentives, there are those who are securely affluent; they just pay but they do not care to adapt. (Håkan)

Instead, these participants articulated their support for a smart grid that would encourage people to engage for the common good rather than for personal benefit. This line of argumentation was articulated by Hampus, who stated: "as citizens, you get some sort of obligation to support commitments and actions that will give us a better society". He thus ascribed the project with the potential to contribute to the formation of an improved society and, for this reason, regarded it as his civic responsibility to participate. These articulations present participation from a 
normative angle and thus as something that individuals ought to do, despite the potential lack of personal reward. In this sense, participation could be motivated by viewing the project as important "overall; not just for us, but it's overall" (Henrik) and by simply considering the project as "a really good opportunity to help" (Henrik) to enable societal benefits. Such articulations ascribed a high degree of societal importance to participation in a single demonstration project. In this sense, they seem to stress the civic side of engagement that had not been inscribed in Smart Customer Gotland's technologies and was neither dominant in the sociotechnical smart grid imaginaries. They particularly expressed these civic dutyladen motives for two main reasons: Smart Customer Gotland's potential to reduce and shift electricity consumption; and the possibility that the project would produce knowledge about smart grid implementation that could facilitate future rollouts. Both these reasons resulted in frictions.

\subsubsection{Reducing and shifting electricity consumption as a civic duty}

Enrolled users repeatedly legitimized their participation by their desire to reduce electricity consumption on a societal level; as Hampus put it, "we can be thriftier with our energy; this must be a societal interest - a large societal interest". In contrast to the project and to the sociotechnical smart grid imaginaries, they thus stressed reduced rather than flexible consumption as a main motive. However, participants frequently dwelled on their own role in achieving their ambitions, or on whether reducing electricity consumption should rather be the responsibility of commercial electricity consumers such as companies. A frequent argument was that companies depend on a reliable electricity supply that must be secured, since companies generate economic welfare. According to Helen, "If we cut the electricity too much for companies and they cannot produce, it becomes an even greater disaster", and Henrietta argued, "large companies need electricity [more than households]". In this sense, the enrolled users seem to understand their 
participation as a way to support a sustained societal welfare - argumentations that aligned well with the notion of successful Sreeden (see Chapter 5).

However, the enrolled users simultaneously expressed concern that reduced electricity consumption was not an easy task for households; as Helen put it, "they almost enforce kitchen supplies on you, and all those gadgets are electricity driven". In this way, participants articulated that they regarded an engagement with reduced consumption as beneficial for the common good, but that such an engagement clashed with strong forces encouraging the consumption of various devices and artefacts. This resonates with Bertoldo et al. (2015), that have found smart grid users criticizing the logic in that individuals need to personally handle societal structures that spur hyper-consumption.

When discussing their formulation of smart grids as a societal duty, some of the enrolled users argued that participation should not be optional but rather mandatory. This alternative was primarily articulated from a fairness perspective, and was motivated by the idea that if a smart grid is of such great importance to society, then everyone should comply and it should not be possible to avoid such commitments. In particular, Henrik argued that all households should steer their electricity consumption towards the hours of available electricity production, and stated that such behaviour should be "part of the package" for a household that uses electricity. He thus advocated an enrolment that basically means that authorities "should go to every home and business and say you have to do this, end of story". In this sense, Henrik's suggestion strongly opposes the market doctrine that is dominant in sociotechnical smart grid imaginaries, in which the notion of empowerment through market engagement emphasizes that individuals should be able to decide whether and how to engage with smart grids (see Chapter 5). In a sense, he also questioned the recruitment strategy behind Smart Customer Gotland that was based on the idea of framing the smart grid as so appealing that 
households could not refuse to sign up. Henrik does not seem to praise such an ideal; for him, this kind of a structure implies an unfair system that enables some individuals to "opt out".

However, other enrolled users disapproved of mandatory enrolments; for example, Henry declared that "it should not be a state initiative, a guarding thing". In this way, Henry and his like implied that someone other than persons participating in smart grids should not have a mandate to decide what is "right" or "wrong" regarding such participation. Overall, these articulations illustrate the tensions that arise when smart grid engagements are approached as a civic duty; on the one hand, the participants supported a widespread use of smart grid technologies, but on the other hand, the question of how such an ambition should be achieved evoked tension in the relation between fairness (i.e. everyone should contribute) and freedom (i.e. everyone needs to decide themselves).

\subsubsection{Contributing to knowledge production}

Another way in which enrolled users referred to civic duty was by pointing out that this was a demonstration project that aimed to generate knowledge. Some participants seem to base their argument on a perception that Smart Customer Gotland was at the frontier of innovative energy solutions; for example, Hampus commented, "I think it's ambitious of GEAB to initiate this project; one can sit with folded arms and not do anything, but through this they make a contribution". The motive of being part of a contribution to knowledge production also appeared to lie behind participants' recurrent description of themselves as test subjects or "Guinea pigs" (Holger). On these occasions, they mentioned that they did not expect any personal rewards from the project; on the contrary, they often explained that although they had encountered various problems, they referred to such problems as a means of generating knowledge, since "both those things that work and those that do not, ought to lead to learning" (Hampus). 
Hugo added another perspective on the project's relation to the general public by stressing that this kind of demonstration project enhances our understanding of electricity consumption on an aggregated level: "in order to see the big picture, you need to have these kinds of projects, it is not possible in any other way". The underlying assumption here presupposes that this project contributes to enhanced insights that will be passed on to society at large. For example, Håkan assigned Smart Customer Gotland with the role of delivering answers about possible kinds of futures:

It is something that is often highlighted in the energy debate: that we do not need to build any new nuclear power facilities, we can do this with, for example, a smarter grid. Is it true or is it not true? It's not black or white, but how true is it?

Such an articulation assumes that demonstration projects function as neutral arenas, with the ability to deliver objective answers on what the future energy system should look like. This rationale thus proposes that demonstration projects act in the best interest of the common good. These civic-duty-laden motives also bear traces of the households' overall conception of a smart grid, as they present the smart grid as a civic infrastructure that will benefit everyone. The participants seemed to justify that in signing up for Smart Customer Gotland, they were performing an action that would benefit all of society; as a result, they credited the project with producing unbiased facts and not being influenced by the interests of the actors behind the project. However, these expectations clashed with how the actors behind the project assembled the smart grid (see Chapter 6).

\subsubsection{Participating to actively support a certain kind of energy system}

Another way in which the enrolled users justified their participation was as a way of actively transforming the energy system. In contrast to the arguments that associated this project with the possibility of generating knowledge about future 
energy systems, the enrolled users on these occasions expressed strong opinions about what particular kind of system they wanted to contribute to. These rationales were frequently articulated in opposition to the idea of influencing the future energy system through market choices. In Chapter 5, I showed that the national sociotechnical smart grid imaginaries entailed an enhanced version of the liberalized electricity market, in the sense that the market would provide even more choices and that electricity users would engage even further with the market. However, enrolled users repeatedly expressed their distrust and disbelief in the idea that people can influence anything of importance through the choices they make on the market:

It is in everything from banks and interest rates: what to invest in, which telephone company you should have; and, in the end, very much of that may not lead to anything while it still needs a lot of work. (Herman)

Instead of influencing the future energy system indirectly through market choices, the enrolled users frequently mentioned that they viewed the demonstration project as an opportunity to actively influence the characteristics of the future energy system.

\subsubsection{On environmentally friendly electricity production}

The enrolled users frequently referred to coal and oil as unwanted energy sources for environmental reasons. However, like the general Swedish discourse (see Chapter 5), they raised different opinions about nuclear power's future role in the energy system. Some considered it necessary to phase out nuclear power, as they associated this energy source with highly negative values. For example, they referred to the danger of nuclear power for future generations: "We do not believe in nuclear power, we do not want to leave that behind" (Herman). They also referred to uncertainties regarding direct consequences for themselves: "it has been 
said that nothing will ever happen, but many things have actually happened, and we live quite close to [a Swedish city with a nuclear power plant]" (Hjördis). Some referred to personal experiences; for example, Henrietta mentioned that after the nuclear power accident in Chernobyl, she did not pick lingonberries for several years, since "you do not dare to eat those". Some enrolled users associated Smart Customer Gotland with the phasing out of nuclear power, an idea that was especially articulated by Herman. He mentioned that he voted against nuclear power in the Swedish referendum, and argued that he still has a responsibility to facilitate the vision he once voted for:

We must each do what we can, but ultimately the problem is collective: it depends on political decisions, it depends on what is decided higher up. But we as individuals can influence what is determined by what we do, and just by participating in this [project], for example.

For Herman, this project had a highly political dimension, as he formulated his participation as a way of exerting pressure on politicians. He seemed to regard Smart Customer Gotland as an opportunity to express a political opinion - an opinion that he had previously and unsuccessfully voiced through traditional democratic channels. Thus, through this project, Herman was trying to draw attention to a matter he cared about: phasing out nuclear power. Other enrolled users did not interpret smart grids or the demonstration project in the same way. Henry described himself as "one of those who advocates nuclear power", and Hampus supported a future with "super mega nuclear power plants". Nuclear energy was by some of the participants described as a cheap and effective method of producing a lot of energy in an environmentally friendly way. Economic references were also used when legitimizing nuclear power: Hans stated that "You cannot phase out nuclear power because then the electricity prices would skyrocket", and Hampus argued that this would as a result challenge the welfare of Sweden: 
In order for Sweden to be a developed country, with the kinds of industries that have built Sweden strong and that are the foundation for our prosperity, then our industries must get competitive prices on their electricity. (Hampus)

The message in Smart Customer Gotland's recruitment campaign - that this was an environmental project - had thus been translated to mean completely different things for the enrolled users: for some, a sustainable future meant a nuclear-free future, while for others, it meant the opposite. These tensions were also present in the notion of a sustainable society, as described in Chapter 5, and articulated by the project employees (see Chapter 6).

\subsubsection{On electricity production with strong local connections}

In addition to renewable energy sources, the enrolled users often argued that they supported an energy system with strong local connections. They gave motives for signing up that were aligned with Smart Customer Gotland's message in the recruitment campaign that this project was good for Gotland, but these reasons resulted in various tensions.

The desire for localization was articulated in different ways, such as in the frequently mentioned motive of supporting GEAB as a local company: Hugo stated, "I am very positive towards GEAB, they work very locally" and Holger commented, "I guess it is my way of being a local patriot". Herman also seemed to support this reasoning:

GEAB has been very good at making it feel local. GEAB sponsors Gotlandic sports, participates in all greater fairs and makes local donations here and there. Everybody knows someone who works at GEAB. GEAB is like electricity on Gotland.

When explaining why this localization was important, participants argued that living on an island creates social bonds, and frequently referred to themselves as Gotlanders. The island seemed to have had a strong influence on their identity, for 
example expressed as "when you hear someone who is from Gotland working at Radio Sweden or the state-owned Swedish Television, you get proud, we are a bit unique as islanders" (Henry). The enrolled users frequently mentioned that it was important to support local companies: "if possible, Gotlanders choose Gotlandic products" (Hjördis). This engagement in localization was not least motivated by economic reasons: "we want the money to stay here, jobs are few on Gotland" (Henry).

Some of the enrolled users expanded on what their support for localization could entail in relation to smart grids; for example, Holger advocated a regional smart grid that was based on the needs of a local community, and argued, "as a region, you get a completely different way of thinking the more you connect to this". $\mathrm{He}$ proposed a smart grid configuration that encompassed both companies and households, and argued that the two should jointly work towards a common regional goal. A central argument behind configurations that enhanced localization was that people are more likely to sign up for initiatives if they are invited by someone "you have a personal relationship with" (Hanna). Another reason behind this support for local configurations was that it made people in a certain area more aware of electricity production; for example, Herman argued that it is difficult to get an overview of where and how electricity is produced in today's international electricity system. He emphasized that when electricity is produced far away, it is easy to neglect potentially bad consequences of its production or use. He thus seemed to request other types of information than the ones suggested by the sociotechnical smart grid imaginaries. The notion of empowered and active electricity users, primarily stress that users desire enhanced information about electricity consumption, and this assumption was also inscribed in the project's technologies. On the contrary, Herman desired information about local electricity production and proposed a smart grid configuration based on such ideals: 
Everything has an environmental impact: if we should build a plant for biogas, well then, perhaps fine land might be destroyed here, but then people living here can make a judgement and decide that it might still be worth it.

According to this logic, bringing production closer to users can be a means of enhancing an awareness of electricity by emphasizing that electricity should not be produced "far away, but rather right here" (Herman). However, such articulations clashed with frequently mentioned perceptions of Vattenfall. Even though the enrolled users seemed to perceive GEAB as a local company, they were sceptical of Vattenfall, which owns $75 \%$ of that company. For example, Harald considered Vattenfall to be a contradictive company because "Outwardly, they are very environmentally conscious but in reality they are not; they base a large part of their electricity on coal plants in Germany”. Henrik supported this argument, as he also found such double standards problematic, and did not see the purpose of Vattenfall's international affairs: "They have electricity here in Sweden, and then they buy a foreign company running coal plants that belch out pollution; I mean, it blows right back to us living here". Henrik thus opposed Vattenfall's operations in other countries because it negatively influenced Gotland; in this sense, he problematized the argument that supporting GEAB (and thus this project) would generate local benefits. In a sense, he questioned the message told in the project's recruitment campaign, that connected this project to the god of Gotland (see Chapter 6). Herman noted that Vattenfall had abandoned its initial purpose as a state-owned company that provided Sweden with electricity:

It was a few years ago when [Vattenfall] invested in the world rather than in Sweden [...]. I do not really understand why we should use state money to invest in such activities. It seems like they are guided by making a profit rather than acting as a Swedish energy producer. 
Enrolled users had thus signed up for this project because they wanted to support local initiatives and seemed to be appealed by the framing of the project as being good for Gotland (see Chapter 6). However, this localization also created tensions, because supporting this project meant that the participants were also supporting Vattenfall, whose international affairs they strongly opposed.

Thus far, I have traced the associations the enrolled users made between smart grids and the demonstration project, their reasons for signing up and what they envisioned to achieve with their participation. The participants expressed how their engagement in the demonstration project resonated with larger issues of societal importance - in other words, how smart grids can bridge the divide between larger societal issues "out there" and people "in here" (Marres, 2010:179). The primary reason for engagement was not the smart grid technologies themselves, but rather the wider implications they evoked (cf. Marres, 2012b:145). For some, participating in this project was a political engagement or a civic duty; these participants acknowledged smart grids as a configuration with consequences for wider society. They thus presented other logics for engagement than those present in the sociotechnical smart grid imaginaries, that primarily position electricity users as self-oriented costumers motivated by economic incentives, users ideas that also were inscribed in Smart Customer Gotland's technologies. Against this backdrop, I will now explore how the participants used the smart grid technologies; that is, how they translated their motives for signing up into a material engagement within their own homes.

\subsection{Using smart grid technologies}

Taking on a device-centred approach, I will now examine "the artefactual nature of people's capacities to take environmental issues into account” (Marres, 2012b:145). In other words, I will shed light on what kind of participation the devices 
accomplished and which logics of engagement they evoked (cf. Marres, 2012b:66). I have traced three different ways in which the enrolled users interacted with the smart grid technologies installed in their homes: entrenched enthusiasm, automatically enabled convenience and constrained involvement. These categories illustrate not only different ways of using technologies, but also different ways of mobilizing technologies to achieve certain ambitions and different ways of being part of a configuration. They entail both de-inscription and processes of following the technologies' scripts; they thus represent different ways of taking part in the smart grid that was assembled by the Smart Customer Gotland project.

\subsubsection{Entrenched enthusiasm}

One way in which the participants used smart grid technologies was with enthusiasm, such as when following information about consumption patterns: as Hugo commented, "It is really fun to follow, you see directly when consumption starts; now the lamp is turned on, now you play videogames, now you cook food". These individuals often articulated an interest in graphs and statistics, and referred to themselves as "nerds", or as being "very active as a test subject" (Hugo). As an illustration of their interest, some participants mentioned that before joining Smart Customer Gotland, they used to read the electricity meter, calculate the household's electricity usage, and save the weather statistics and compare them with consumption; for example, Henrik used to "draw millimetre diagrams, insert numbers and memorize". However, these individuals expressed an enthusiasm for the more enhanced information provided by the smart grid technologies, since through these they could see, "both the day and time of day, so it's more detailed now" (Hugo); or, as Harald puts it:

You can keep track of your electricity consumption in a completely different way, how much you use; and you get an eye-opener, that you may not need to have the heat on around the clock. It is not 
needed, it is really stupid, why should the heat be on and consume a lot of electricity when you are not even home?

These individuals' engagement not only seem to entail an increased awareness or knowledge, but also resulted in measures being taken to reduce and shift consumption over time. For example, Harald bought extra timers and used these on the household's washing machine, dishwasher and dehumidifier, which he remotely turned on at times with a lower electricity price. A deep form of material engagement was visible in the way in which the participants regularly changed their steering schedules as suggested by the project - changes that were carried out with an awareness of their houses' functionalities. Harald stated, "When we are not at home, then I turn off the heat; and then I know that we come home at 4, so I turn it back on at 2". In this way, these participants used the override option more than was encouraged by the persons who worked within Smart Customer Gotland, who referred to the override option as a "mother-in-law" button that was only to be used on special occasions (see Chapter 6). However, the users who performed their participation with entrenched enthusiasm de-scripted these suggestions and used the override function on a daily basis.

Some of the participants argued that their activities resulted in decreased consumption; Harald mentioned that "on average, we use $30 \%$ less each month" and that their electricity costs had consequently decreased to an equal degree. In this sense, the households that performed their roles with entrenched enthusiasm resembled the Resource Man, as identified by Strengers (2013), who monitors and assesses electricity consumption, knows how to interpret the information and knows how to use it in order to change his consumption patterns. When considering how low they could decrease their consumption, these participants frequently mentioned that they tolerated more discomfort than the people they shared their lives with. Harald commented, "I have a pretty high level of acceptance, but my girlfriend constantly walks around freezing"; when speaking to his wife, 
Henrik quipped, "I am the one making the plans, and you are the one freezing". These articulations implied that the enthusiasm these participants had for the smart grid technologies was not necessarily shared by their family members (cf. Nyborg, 2015).

This entrenched enthusiasm was not limited to the technologies provided by Smart Customer Gotland; these individuals described profound engagements with electricity consumption that stretched beyond the project. They took material measures to decrease consumption, for example, house refurbishments were performed, or kitchen supplies were exchanged with more energy-efficient versions. In this way, the participants with entrenched enthusiasm performed the actions that had been envisioned for the "actively active" electricity user by the project employees of Smart Customer Gotland (see Chapter 6). This participation showed a level of engagement that rested on the same logic as Marres (2012b) ideal of "the more invested, the more engaged". Marres applies this ideal to operations that amplify investments and seek to produce material effects from environmental engagement; such operations focus on the everyday efforts, costs and disruptions that people can tolerate for sustainable living. Like the environmental blogs Marres bases her study on, the stories told by these individuals in the Smart Customer Gotland project offered accounts of the material, economic and social implications of allowing concern for the environment to enter one's life. In this sense, the participants enacting entrenched enthusiasm showed a very different logic than those who participated in the form of automatically enabled convenience.

\subsubsection{Automatically enabled convenience}

Another way in which enrolled users engaged with smart grid technologies was by relying on the remote-controlled automation to shift their consumption over time. Some participants had not really taken note of the technologies and did not look at 
the information provided in the app and computers particularly often: "No, maybe once a month, when it strikes me that we have them; I think very little about it" (Håkan). In contrast to those who enthusiastically performed an entrenched engagement with the smart grid technologies, these individuals commented that they "had no idea" (Håkan) whether their electricity consumption or costs had changed since they became enrolled in the project, and that they had not personally taken any measures to shift their consumption in accordance with the fluctuating prices. These individuals frequently stated that not having to spend time on and engagement with the project was one of the reasons why they signed up for the project in the first place. They commented that "you cannot run around and stare at various digital meters every evening, you actually have other things to do" (Håkan) and expressed reluctance to put in "effort and a lot of commitment" (Hampus); or, as formulated by Holger:

This was also one of the reasons why I dared to sign up, because it is no problem if your engagement drops. It demands very little involvement, your large contribution is that someone else looks at the numbers, that they have something to compare against. [...] In this way, you contribute even if you do not actually do anything. They were quite clear that either you can be very committed and engage with this all day, or you do not need to do anything and it will still work. And then it's easier to get involved.

According to these claims, these users based their smart grid participation on not having to carry out any kind of involvement in practice. In this way, they embody the "passively active" electricity user that was envisioned by the Smart Customer Gotland employees: an individual whose participation is restricted to signing up, and who then delegates further engagement to the project (see Chapter 6).

Previous smart grid studies have suggested that the use of remote-controlled devices can be shadowed by integrity or privacy issues (Naus, van Vliet, \& Hendriksen, 2015). These issues were also part of the sociotechnical smart grid 
imaginary of digital dreams (See Chapter 5) However, such concerns were not prevalent among the users interviewed for this study. The participants did not express any concern that the remote control might interrupt or control their everyday lives; rather, they stated that the project should steer their devices was part of the deal when they signed up, and that the steering schedules were not forced upon them, since "we can turn off their shutdown" (Hjördis). They did not express any integrity issues, either (i.e. concerns that their devices were navigated by a person outside of the household); for example, Henry stated that "the steering is general; it is not a special kind just for me". Neither did they complain that the remote control negatively affected their comfort; for example, Harriet commented that "although they can turn the heat off, we have never noticed that we have colder water". In this sense, the participants who performed automatic convenience gave the impression that the smart grid technologies were seamlessly integrated into their lives. This mode of material participation resonates with the logic of "involvement made easy" that was presented by Marres (2012b), because these individuals' participation was achieved with the least possible effort and disruption. As these individuals often did not even take note of the technologies or change any of their practices, the technologies in this case helped to realize "a change of no change" (Marres, 2012b:66). This finding resonates with Throndsen and Ryghaug (2015), that also found articulations of "involvement made easy" among electricity users discussing smart meter installations and automatic solutions.

\subsubsection{Constrained involvement}

In addition to the other two modes of participation, which primarily portrayed smooth engagement, the enrolled users also expressed difficulties in interacting with or interpreting the information provided by the smart grid technologies installed in their homes. A frequent comment concerned difficulties in making sense of the statistics showing what electricity had been used for. Holger argued 
that representatives from Smart Customer Gotland had "mentioned that the device that read the electricity meter would learn to identify machines, recognize which one was the oven or the stove, but that has not happened, a lot of electricity is labelled "unidentified". In the words of Hjördis, "it is not specified, so I have no idea what it is". In this way, the participants expressed frustration of not being able to translate the information provided by the technologies into something that made sense to engage with. This limitation restricted their ability to participate in consumption reduction: "I do not know what we could reduce, I do not think it is especially hot in here, we do not have a lot of lights on either, so we cannot reduce more than we have already done" (Hjördis). As Holger stated, "we do not have any luxury consumption, we do not wash or put on the dishwasher unnecessarily”.

Another frequent comment concerned difficulties in adjusting household consumption in accordance with fluctuating prices. Some argued that this was simply too much interference with their lives: as Hanna said, "I cannot imagine cooking later, just because it's cheaper then"; and as Hjördis noted, "I do not get up and bake at 12 at night, seriously I do not”. Hemming was even more blunt about it, and frankly stated: "I use the stove when I want to". These comments illustrate the difficulties the participants encountered in practically shifting their electricity consumption to cheaper hours. Other complains concerned that the technologies in their homes restricted flexible consumption: "The freezer cannot be turned off, it does not work" (Hemming). Henrietta worried that a dishwasher or washing machine that was turned on during the night might "catch fire or start leaking". These are all examples of de-inscription processes (Akrich \& Latour, 1992) in which the users refuse to follow the script suggested by the smart grid technologies. These individuals seem to express that the smart grid technologies should adopt to them rather than the other way around (Hargreaves et al., 2017). 
How these participants actually used the technologies was not necessarily how they had envisioned it when starting the project; on the contrary, they argued that having small children, changing jobs and maintaining everyday routines made their engagement "fall a bit between the cracks; the whole picture of what I thought I would do and how it turned out does not add up" (Holger). Others argued that their engagement had decreased during the time of the project, noting that "It was more in the beginning" (Hemming). Another example of such a constrained engagement was mentioned by Henrietta, who argued that although her household was initially deeply engaged in shifting their consumption to the cheap hours ("we watched the phone all the time"), doing so eventually became too cumbersome:

I do not have my own phone so I had to run and check his all the time. Now I do not care about it, so now I wash when I want, clean when I want, vacuum when I want.

This remark illustrates a gendered composition, in that the man possesses the technology that scripts the actions that are performed by the woman - a script that she eventually refuses to follow. Another reason why the enrolled users did not adjust their consumption to price signals was that the devices using the most electricity were steered automatically anyway; as a result, the additional efforts that the households could make were not meaningful, since "all small lamps and those trivia, they are just a drop in the ocean in the larger context" (Hemming). Others questioned the material logic behind the script, arguing that using a timer makes "the light on the machine's lamp use electricity, which costs more than you earn on shifting consumption" (Helen). Henry proposed another reason for why he refused to follow the fluctuating prices, arguing that his children need their training clothes to "be ready for the next day, otherwise they need double or triple of everything, and that is an expense too". This kind of reasoning supports Katzeff and Wangel (2015) suggestion that smart grid design should acknowledge users as humans who are busy with everyday practices. 
There were also those users who said that the prices were not an incentive for them because they were affluent enough not to care; as Henry put it, "we both have jobs with good salaries, so we do not need to think about this, really". Arguments like Henry's resonated with the previous critique against framing flexible consumption as an opportunity to save money because doing so suggested that those who were wealthy enough did not need to engage in changing their consumption. In Henry's case, the smart grid did not encourage the sought-after behaviour because the economic script was aimed at another kind of user. All in all, the enrolled users raised various questions concerning the logic and likelihood to achieve flexible futures, as suggested by the sociotechnical smart grid imaginaries.

In this section, I shed light on how the participants used the smart grid technologies installed in their homes. I provided examples of various de-inscription processes that questioned the overall logic and design of this particular smart grid, and gave examples of opposite engagements that followed the scripts. I described both smooth operations and the difficulties that were inherent in assimilating smart grid technologies into everyday practices. I found that the smart grid technologies induced different kinds of material participation, the enrolled users took part in the smart grid configuration in different ways, and therefore became different kinds of smart grid households.

Thus far, I have attended to the users who took part in the smart grid demonstration project. Among them, I found both support for and scepticism of the configuration installed by Smart Customer Gotland. However, when I turned to one of the actor groups that was excluded from the project - the prosumers - I found even more critical articulations, along with alternative stories of how smart grids can be assembled differently than in this demonstration project. 


\subsection{Prosumers reasoning about attractive smart grids}

In this final section of the chapter, I examine how prosumers articulate what kind of smart grid they find attractive and what roles they ascribe to users living in households. The voices I include in this section belong either to private individuals who produce their own electricity, or to individuals who work with prosumers and who thus have good knowledge of their perspectives. Even though prosumers were not included in the project's smart grid, some of the households that participated in the project produced their own electricity and thus also acted as prosumers; their reasoning will therefore also be included in this section. I thus end this thesis' final empirical part by examining how prosumers reason about possible smart grid configurations; I shed light on their material engagements and their visions of future energy systems. Their accounts illustrate some of the alternatives that were foreclosed upon by not enrolling prosumers in the project's smart grid. However, before I engage with such an analysis, I will present the primary critique the prosumers directed towards the smart grid that was established by Smart Customer Gotland.

\subsubsection{Questioning the market and economic doctrine of smart grids}

The prosumers frequently made the criticism that Smart Customer Gotland was assembled by actors who were motivated by economic profit and who already had an economic relation with electricity users. The prosumers considered that this setup guided the kind of smart grid that could be constructed within the project and the roles that were assigned to households. Pernilla argued that a smart grid constructed by electricity companies needs to provide economic savings, since the companies already have a relationship with their customers that rests on economic transactions. She argued that for the companies to convince households to engage in a smart grid for civic or environmental reasons "might be a bit tricky" since these 
companies "have a few skeletons in their own closets". Her reasoning implies that utility companies will have a hard time constructing a smart grid that is based on any other enrolment strategy than economic incentives; it is not trustworthy for them to claim an environmental engagement when they themselves do not do their share in contributing to a more sustainable energy system. This argument resonates with those formulated by Pontus, who commented that Smart Customer Gotland was set up as a "disciplining activity" of how households should behave rather than as a configuration that could empower them. He argued that electricity users are fooled into believing that they can change things by participating in projects such as Smart Customer Gotland:

I get irritated every time I see a utility bill where there are lot of numbers, as if I could influence anything, when in fact I can affect so very little: not even when they start Smart Customer Gotland can I influence anything of importance.

This scepticism resonates with findings from Throndsen and Ryghaug (2015), who suggest that the primary difficulty with making electricity users interested in smart grids is that due to decades of neoliberal market logics, they feel undermined; when utility companies want to activate them, they answer with distrust and scepticism. In a similar vein of reasoning, Pontus argued that the market logic simply displaces focus from the questions he finds important:

So we keep on playing some kind of business, marketing, marketing managers; but all of those things are a bit silly, really - I think we should rather just do what we know is needed.

This argument criticizes the logic that the actors on a market should frame smart grids as so appealing so that electricity users simply cannot refuse them, and suggests a more honest approach instead. It thus resonates with Ballo's (2015) finding that smart grid stakeholders tend to present smart grids in a polished version - a strategy that, she argues, risks alienating households and preventing them from participating. However, the prosumers did not just criticize the project's 
configuration and enrolment strategies; they also presented a few ideas of what kinds of smart grid they found attractive, and how they envisioned a future energy system.

\subsubsection{Producing electricity as part of a larger transition}

As expected, the prosumers suggested that households should participate in smart grids not only as consumers but also as producers of electricity. Prosumers who participated in the demonstration project argued that they through their homemade electricity enacted practices that differed from those encouraged by the project. For example, Hugo produced his own electricity through solar panels, and thereby covered his household's summertime electricity needs altogether. Rather than following the project's fluctuating prices, he adjusted his household's consumption to when he had access to home-made electricity. As a result, Hugo did not find rising electricity prices to be especially problematic because "if the price goes up [..] the installation is repaid faster". In this sense, the solar panels diminished the effect of the economic script and made Hugo's household less dependent on how electricity prices fluctuated.

As I showed in Chapter 5, sociotechnical smart grid imaginaries entail the notion of empowered and active electricity users, and one way smart grid stakeholders propose that smart grids enable empowerment is through autonomous prosumers who are independent from electricity companies. The prosumers discussed whether autonomy was attractive, and what implications it might have for larger energy systems. For some prosumers, independence was simply associated with positive connotations, without any wider societal implications: "it's fun to be independent; if there is a power failure, the light in my house is still on" (Herbert), or "some think it's fun to grow your own potatoes, while I think it is fun to produce my own electricity" (Pär). Other arguments stressed that producing electricity empowered 
households because "one produces for oneself" (Pernilla), or because as soon as the installations are repaid, "its energy for free" (Pär). When proposing smart grids that enhance household independence, prosumers mentioned the need for new kinds of objects and devices, such as "a battery pack in every house" (Pontus) and "electrical vehicles" (Pernilla), to store electricity, as well as energy-efficiency measures to make the home-made electricity last longer (Paul). In fact, these prosumers are demanding different smart grid configurations than the one that was installed within Smart Customer Gotland.

Other arguments opposed the objective of creating independent households with reference to that doing so rests on standalone solutions based on the logic that "I only care about by myself and do not give a damn about the rest" (Pontus). Rather than a smart grid that enhances detachment, these prosumers proposed a smart grid that binds society together. For example, Pamela supported a future in which "we produce our electricity locally; my neighbour might not have any electricity but receive it from me". They thus argued that the ability to produce your own electricity should be understood as an enabler that creates bonds between households rather than as something that enables autonomous households. For some prosumers, empowerment was not connected to standalone ideals, but was rather a question of distributing power relations within the electricity grid; for example, Pontus claimed that citizens should "reclaim the power from the companies" that currently own and operate grids and electricity production facilities. This comment resonates with suggestions from Stephens et al. (2015:148), who find that prosumers' empowerment rest on that they are able to actively construct a more horizontal energy system, rather than on a desire for alienation. This finding suggests that producing electricity is not only a question of having access to home-made electricity; rather, it is a political act with implications beyond the walls of the household: 
We produce electricity at home; it is a vanishingly small piece of what we all consume, but it's a little contribution; it does not solve the whole nuclear problem, but it contributes to making it needed less. (Hugo)

Herman expands on this reasoning as he argues that he cannot produce enough electricity to phase out unwanted energy sources; however, through his solar cell installation, he can show politicians and electricity companies that such engagements have societal support. Herman claimed that in this way, he shows that his vision of a future electricity system is "not a distant dream", but is a realistic, functional and practical engagement that is already happening. Thus he proposed another way of influencing the future energy system than through making choices on the market as suggested by the notion of empowerment through market engagement (see Chapter 5).

The prosumers frequently positioned themselves as part of a larger transition of the energy system. For example, this was illustrated in Peter and Petra's ways of actively incorporating energy matters into their daily lives; for them, reducing energy consumption was a lifestyle, and producing electricity was a natural step in living a more environmentally friendly life. As Peter put it, "we know how to live in order to feel good". Using environmentally friendly materials, Peter and Petra had refurbished their whole house into a more energy-efficient version; when their home-made electricity was insufficient, they heated their house with a fire that used logs they had cut down in their own forest. They proposed configurations that enabled insight into and influence on the entire process, from production to consumption. This viewpoint resonates with findings by Bladh (2007), who studied the transformation of the Swedish energy system and found that households lost their awareness and technological know-how when electricity production units were transferred from their close proximity and ownership to large companies producing electricity in foreign countries. The smart grid configurations that were proposed by the prosumers were not owned and established by already-powerful 
actors who enrolled users based on economic incentives; neither did they position electricity users as customers buying goods and services from others. Rather, some prosumers argued for material participation that placed the people living in households in charge of production facilities as well as grid structures. Thus these prosumers suggested a very different smart grid configuration than the one assembled by Smart Customer Gotland.

\subsection{Summarizing discussion}

In this chapter, I explored how users participating in Smart Customer Gotland made sense of smart grids, used technologies installed in their homes and justified their project participation. Building on Marres (2012b) notion of material participation, I conceptualized smart grid technologies as devices that can enable participation in larger societal issues, and regarded them as mediators between everyday practices and political matters. Following her suggestion that devices do not, in themselves, have the capacity to engage people, and focusing rather on the issues such devices evoke, I analysed why these users found Smart Customer Gotland and smart grids appealing - in other words, what kinds of issues they attached to the project. I traced three different motivations behind the enrolled users' participation: personal benefits, civic duty and the desire to change the energy system.

From the enrolled users' point of view, the smart grid was not a necessity in its own right; rather, it was a means of achieving certain goals or tackling specific problems. In associating smart grids with civic duty, the enrolled users challenged the sociotechnical smart grid imaginaries that were mobilized by smart grid stakeholders. While these imaginaries positioned households as primarily interested in personal gain, primarily in the form of economic savings, the enrolled users rather articulated engagements that showed that they associated smart grids 
with societal implications. This finding suggests that participants' engagement with smart grids and this demonstration project was associated with morality and a contribution towards the common good. Some enrolled users thus expressed their electricity engagement in a way that was not isolated to the borders of the homes; rather, they regarded their participation as a political engagement that stretched beyond the walls of the household. Some participated in this project in a way that gave it a deeper significance, and based their engagement on their trust that they were contributing towards a particular kind of future. In this way, some participants seemed to conceptualize smart grid technologies as having the potential to bridge the divide between the larger societal issues "out there" and people "in here" (Marres, 2010:179). This finding suggests that there is potential in enrolling households with a more frank approach rather than seducing them with personal benefits (cf. Ballo, 2015); that is, that it is possible to simply enrol individuals as members of an engaged public with a sincere interest in the common good (cf. Schick \& Winthereik, 2013; Throndsen \& Ryghaug, 2015).

Aligned with Marres (2012a) argument, however, I found that the enrolled users loaded the smart grid and demonstration project with conflicting matters. For some, the smart grid meant the phasing out of nuclear power; for others, smart grids were compatible with a nuclear-powered future. Also, the aspiration to boost welfare and contribute to technological achievements clashed with the ambition to lower electricity consumption. Some found their participation in the project to be a means of supporting local interests, which conflicted with the frequent perception of Vattenfall as a company that represents the opposite tendency. These contradicting associations and rationalizations for participation imply different kinds of energy systems with different kinds of households' roles.

The flexibility of what smart grids can actually achieve thus resulted in users becoming part of the same configuration, even though their desired futures were 
not necessarily alike or even compatible. The fact that the enrolled users regarded this demonstration project and smart grids as the enablers of different kinds of futures had not risen as a possible problem among those who worked with the project; they were more anxious regarding whether they had promised too much in relation to the households' economic rewards (see Chapter 6). However, since some of the enrolled users justified their participation as desire to phase out nuclear power and create a more distributed energy system with closer connections between users and producers, they positioned Smart Customer Gotland as playing the role to facilitate such a transition. Such conflicting ambitions need to be taken seriously, since when people realize that smart grids may not lead to their desired futures, they will probably feel disappointed, misled or even betrayed, and the success of future smart grid implementations will in such cases be jeopardized.

Furthermore, in this chapter, I examined how participants used the smart grid technologies. I traced three different forms of engagement among the enrolled users: entrenched enthusiasm, automatically enabled convenience and constrained involvements. These levels of engagement show that smart grid technologies can be integrated very differently in different homes; therefore, users take part in determining what the smart grid becomes. This finding illustrates how smart grids cannot be understood as fixed and how they are not about "getting the technology right". Rather the question of what a smart grid becomes depends on how it is taken up and integrated into people's everyday lives. Smart grid technologies, however, evoked different logics of engagement; in other words, they codified different forms of engagements. Home automation through steering schedules materialized participation as "do-able" and rested on the ideal of "involvement made easy". In these cases, the households often did not even take note of the technologies or change any of their practices, suggesting that they helped to realize "a change of no change" (Marres, 2012b:66). However, some of the enrolled users enacted material participation above this level of engagement, and told stories about analysing 
statistics provided by the app, manually altering the suggested steering schedules, renovating houses and freezing families. Even though the material accounts of these engagements were not explicitly uttered, their stories illustrates support for the concept of taking the environment into account in their everyday lives - an idea that resonates with the ideal of 'the more invested the more engaged' (Marres, 2012b). This finding illustrates how these participants were willing to adopt and alter settings in their lives in order to achieve the goals and ambitions they associated with participation in the demonstration project.

Upon turning my attention to prosumers, I illustrated forms of material participation with smart grid technologies that were not included in Smart Customer Gotland. I showed that the prosumers already engaged with flexible consumption, and that by not taking them on board, the project's smart grid can be seen as a lost opportunity in relation to the project's ambition to assess opportunities in shifting consumption over time (see Chapter 6). The prosumers would probably have shaped the smart grid differently, since they could adopt their consumption to when they had access to home-made electricity rather than to price signals. In this sense, the prosumers suggested another form of smart grid user than the one inscribed in Smart Customer Gotland's technologies. The prosumers did not act as the utility companies' customers; rather, they can be perceived as competitors challenging the dominant positions of such companies within the energy sector. In line with such a conceptualization, the prosumers also directed criticism towards the type of smart grid that was constructed by the actors behind Smart Customer Gotland. Such a smart grid, some prosumers argued, could only be configured around economic incentives, since utility companies do not have the credibility to use any other means of persuasion.

This is a severe critique of the setting up of demonstration projects as arenas that possess the mandate to influence the future energy system. Such a critique 
emphasizes the need to ask questions regarding whose interests are guiding the smart grid and whose interest are excluded. Some prosumers proposed the production of electricity as a means of actively changing utility companies' dominant position within the energy system; excluding these prosumers from Smart Customer Gotland diminished the likelihood of realizing such an ambition. In this chapter, I have shown that different kinds of smart grid configurations evoke different forms of engagements with different economic, social and political implications. 



\section{Concluding discussion}

In this last chapter, I will discuss the findings of my empirical chapters and revisit the research questions that have guided this thesis. The purpose of this study has been to describe and analyse the process of assembling a smart grid within a Swedish demonstration project. My ambition was to seek an enhanced understanding of how smart grids are made, of the different forces that shape this process and, ultimately, of the reality of Swedish households as part of a smart grid in the making. My explorations of the making of the smart grid as an unfolding socio-material practice have covered issues at both the national and local level and have also moved between the present and the future.

Although the development of smart grids is an ongoing process, I now conclude my explorations by discussing what the stories that have been told in the empirical chapters indicate about the role of a demonstration project in assembling a smart grid. What can this particular case tell us about demonstration projects as tools for smart grid development? Are the undertakings on Gotland only valid on this remote island in the Baltic Sea, or do they have relevance outside of this specific case? I will not claim that the findings from this study are generalizable to other 
demonstration projects or to other processes of assembling smart grids. However, given that this study followed the first Swedish large-scale smart grid demonstration project that was conducted by a powerful actor on the European energy market, and that set out with ambitions of international recognition, I believe that the lessons learned from this case are important to recognize for future smart grid implementations. This chapter starts with a condensed version of the findings presented in the empirical chapters, followed by some of the themes that have reoccurred throughout this study. I end with comments on certain issues that I would particularly like to stress as important for taking smart grids forward.

\subsection{Following the assembling of a smart grid through time and space}

In this study, I have combined various concepts from Science and Technology Studies (STS): concepts about imaginaries, processes of establishing socio-material configurations, the inscription of ideas about users into technologies, and material engagements in domestic settings. The empirical chapters of this thesis are entangled since they examine how smart grids emerge, even though they tell stories about this process from different actors' perspectives.

\subsubsection{Demonstration projects as arenas intended to influence the future}

Smart Grid Gotland was carried out by a consortium of powerful actors, primarily from the energy sector. It was conducted on the island of Gotland, in a setting with local connections that came to play an important role as the project unfolded. Based on the idea of a "smart grid evolution", this demonstration project was launched as a facilitator of an inevitable and even natural process of change towards a future smart grid roll-out. The project's initiators held aspirations of international recognition, as they set out to construct "one of the smartest electricity grids in the 
world" and aimed towards constructing a grid that could become "an international model for a long term sustainable electricity power system". Rather than reinforcing the existing grid to cope with the challenges caused by large amounts of electricity being produced by intermittent energy sources, the project aimed to explore how the current grid could be modernized using improved control and monitoring systems along with a more active demand side. The subproject Smart Customer Gotland was intended to establish a configuration that could encourage users, by means of price signals and commercial appliances, to shift the timing of their consumption in order to decrease the pressure on the grid. Local factors such as aims, ambitions, materialities, geographical conditions, main actors and their interests influenced the kind of configuration that could be constructed within the project.

\subsubsection{Sociotechnical smart grid imaginaries as performative frameworks}

In addition to this already existing local context, sociotechnical imaginaries of a smart grid future played an important part in the unfolding of the smart grid in this project. Thus, both the past and the future influenced what was materialized in the present (cf. Jasanoff, 2015). For me, imaginaries constitute an important part of what Law (2004) defines as a "hinterland" - a geography of associations that hold relational webs together and that enable certain human and non-human connections above others.

As I analysed Swedish smart grid planning and strategy documents, I traced five recurring notions of the smart grid future: sustainable society, flexible futures, digital dreams, successful Sweden and empowered and active electricity users. In the way that it is evoked in these documents, the smart grid future is a sustainable society in which set climate and energy ambitions are fulfilled. It is a flexible future 
were electricity flows in different directions in the grid while electricity consumption follows the times of available electricity produced by intermittent energy sources. Digitalization encompasses many parts of social life, electricity consumption is measured in real-time and the grid is constantly monitored and surveilled. In this future, Sweden is a prosperous country, both due to a reliable grid that provides a secured electricity quality and due to companies that export smart grid appliances and services generating economic welfare. Electricity users living in this future are empowered in the sense that they can choose services and products that suit their individual needs, they receive detailed information about their electricity consumption and they produce their own electricity using solar and wind power.

In some ways, these notions entail reconfigurations of the current energy system; in other ways, they sustain the current demand-and-supply logics. These imaginaries are flexible and vague enough to enrol different types of interests, and they entail ambiguities regarding, for example, what is considered sustainable, where flexible consumption can be found and who will eventually profit from smart grid technologies. Through these notions of the future, smart grid advocates attach different meanings to smart grids - connotations they present as attractive and sought-after. These notions "project visions of what is good, desirable, and worth attaining for a political community; they articulate feasible futures" (Jasanoff \& Kim, 2009:123). These notions thus set the direction for the kinds of smart grids that were achievable within Smart Customer Gotland. Furthermore, they established a path for the kinds of realities that were more or less likely to be fulfilled; they functioned as a template of associations that made certain configurations thinkable and meaningful. Thus, Smart Customer Gotland did not emerge from a vacuum. Rather, it was necessary for the project to resonate with existing sociotechnical smart grid imaginaries, as they legitimized a Swedish smart 
grid project in the first place. However, as shown in this thesis, making the smart grid functional was not as feasible as these imaginaries suggest.

\subsubsection{Making the smart grid functional}

The assembling of a smart grid configuration on Gotland was achieved through the different steps of translation: problematization, interessement, enrolment and mobilization (Callon, 1986). In this process, seemingly unrelated entities became associated, merged together and given meaning. The network builders tried to impose their interests, enrol different human and non-human actors, and mobilize imaginaries of the future when putting their smart grid together. They translated the original problem, of intermittent energy resources posing a challenge to the grid, into a solution in which the timing of electricity consumption could be shifted in order to reduce the pressure on the grid. The network builders set out with the assumption that price signals and commercial appliances could function as tools to encourage flexible consumption. Since the project's network builders would also be providing these tools, they established themselves as an obligatory passage point in the emerging smart grid, thus situating themselves in a favourable role for future smart grid implementations.

In such translation processes, however, it is important to recognize the excluded options. As Galis and Lee (2014) observe, a direct consequence of defining what is problematic is that other issues are simultaneously dismissed as being of less importance, because for "every constructed 'obligatory passage point' there can be a number of 'points of irrelevance' that thwart actors in their desire to define a problem" (Galis \& Lee, 2014:160). An abundance of alternatives were marginalized on Gotland: all companies, apartment dwellers, households with low energy consumption and households with electricity suppliers other than the one in charge of the project were excluded. Electrical vehicles, solar cells and small-scale wind 
power plants were also excluded - actors that represent alternatives that can potentially alter power relations within the energy system. In other words, the exclusion process was not neutral; rather, it was an example of how "whole sections of reality [can be] pushed into the shadows" (Callon, 1981:209).

In the interessement and enrolment phases of the smart grid project on Gotland, these exclusion mechanisms were further entrenched, until the smart grid emerged into a narrow configuration. The network builders planned their smart grid based on assumptions of what would be technically feasible, how electricity prices would fluctuate, how the features of the chosen devices would provide flexibility and what the households' material attributes would be; they also based their smart grid on their ideas of future users' desires, behaviours and motivations. Ideas of future users were inscribed into the technical appliances, which scripted two main types of users. Remotely controlled solutions scripted convenient engagements by coding participation as something that was "doable" and presenting an ideal of "involvement-made-easy" (Marres, 2012b). On the other hand, the provision of statistics, graphs and override options to users encouraged more active involvement. However, both of these assumed user groups were scripted to behave as economically motivated individuals, and were encouraged to perceive electricity consumption primarily as an economic engagement.

As the project unfolded, the network builders encountered difficulties in enrolling all targeted actors to the smart grid. Materialities, users and prices did not fall into place as anticipated, it was difficult to enrol devices for remote control, electricity prices did not behave as expected and users did not sign up for the project to the same extent as had been predicted. The recruitment campaign, which functioned as the main interessement device to attract users, initially stressed economic incentives. Over time, however, it became highly uncertain whether the project would be able to live up to its economic promises. The network builders then began 
charging the concept of smart grids with other issues as well; in addition to direct and personal motives, the network builders tried to position the project as bridging the divide between people "in here" and larger societal issues "out there" (cf. Marres, 2010:179). The recruitment campaign charged smart grids and this project with five different themes: economy, sustainability, the good of Gotland, the future and enhanced information. Potential participants were told that through this project, they could engage with both local and societal issues; they were given promises of rewards, some of rather direct character, while others offered more distant and beneficial promises for future generations.

During this demonstration project, imaginaries, materialities and users became woven together and mutually shaped how the smart grid was put together. As shown in this thesis, however, the people who worked within the project had different opinions on whether the smart grid being assembled on Gotland could function as a role model; meaning that some questioned the potential for mobilizing allies for future smart grid roll-outs.

\subsubsection{Becoming a smart grid household}

I traced three different motivations among the enrolled users' explanations for why they signed up for the project: personal benefits, civic duty and a desire to change the energy system. By voicing these motives, some of the users challenged the sociotechnical smart grid imaginaries that were evoked in the Swedish strategy and planning documents, as well as the user ideas that were inscribed in the demonstration project's technologies. Instead of engaging in the project for personal benefits alone, some enrolled users seemed to base their engagement on the implications smart grids held for society in general; they thus associated their participation with morality and with contributing to the common good. Some users expressed their engagement in political terms that stretched beyond the borders of 
their home. In a way, they thus conceptualized smart grid technologies and the project as mediators between everyday practices and political matters (cf. Marres, 2012b). However, such conceptualizations were not straightforward, as the enrolled users attributed smart grids with conflicting associations that implied different kinds of energy systems and different forms of household roles. For example, the users held different views on the position of nuclear power in a future smart grid society.

As shown in this thesis, the enrolled users took part in making the smart grid because they enacted different forms of engagements. Some participants did not perform any actual change in their everyday lives; they simply relied on the remote control to participate on their behalf and to realize their sought-after motives. The remote control technologies thus helped realize "a change of no change" (Marres, 2012b:66). Other households enacted their material participation at a higher level of engagement, and seemed to express their support for the ideal of "the more invested the more engaged" (Marres, 2012). In other words, these households seem to find that material changes in their everyday lives were a natural consequence of caring for the environment. The abovementioned two modes of participation implied smooth engagements with the smart grid, the enrolled users also expressed the difficulties they encountered while interacting with or interpreting information provided by the smart grid technologies. Some users told stories of how they opposed the inscribed behaviours and enacted various de-inscription processes instead (Akrich \& Latour, 1992).

Among the prosumers, some expressed profound criticism of the project, and suggested a different form of user than the one inscribed in Smart Customer Gotland's technologies - a user who based flexible consumption on homemade electricity rather than on price signals. In this sense, the exclusion of prosumers 
from the project can be seen as a lost opportunity to fulfil the project's ambitions to assess the possibilities of shifting electricity consumption in time.

\subsection{Tracing tensions, doubts and contradictions in smart grid translations}

With these summarized findings as a backdrop, I will now discuss what these stories indicate about the assembling of smart grids within demonstration projects; I will discuss the findings from the empirical chapters along with themes that have reoccurred throughout this thesis.

Stephens et al. (2015:187) noted that smart grids have the potential either to move the energy system away from hierarchical arrangements and towards a flatter organization that is characterized by distributed power structures, or to help further strengthen the consolidation of the influence of a small but already powerful elite. Smart grids are thus configurations with societal implications in which the social relations between actors such as utility companies, grid owners, households and so forth are at stake. This thesis shows that while the smart grid demonstration project makes distinct attempts to narrow down sprawling ideas about the future, it is still an open and much-contested process.

This study started by showing that demonstration projects are given a key role by influential actors in the development of smart grids; these projects function as tools to translate a "partially existing object" (Schick \& Winthereik, 2013:83) into a concrete solution. Given that these projects are intended to test and show functionality, I approach them as arenas that are set up in order to reduce the extent to which smart grids appear as a catchphrase with "a lot of secrets" (Wissner, 2011:2509). By following a consolidation process performed within such a demonstration project, this thesis shed light on the different forces that shape how a smart grid is negotiated and put in place. This study reveals a process that is far 
from straightforward, neat or easy. Rather, the making of a functional smart grid evoked numerous doubts and contradictions in the demonstration project. I will now recap the tensions that I would particularly like to emphasize as important for future smart grid developments.

\subsubsection{On the mobilization and tweaking of imaginaries}

In line with the work of previous scholars, I have shown that smart grids have a highly flexible nature (Christensen Haunstrup et al., 2013; Hledik, 2009; Skjølsvold et al., 2015; Stephens et al., 2015). This flexibility can explain why the concept has received so much attention in the first place; its elasticity enables various actors to support smart grids even though their respective desired futures may not be the same or even be compatible. In the course of this thesis, I have shown that sociotechnical smart grid imaginaries function as frameworks that set the course for what is thinkable within a smart grid demonstration project. These imaginaries emerged during the legitimizations of the project and were used to justify why smart grids are needed. As they were selectively woven into the story, the imaginaries seemed to provide some stability to the emergent smart grid; they had some agency, in that they could influence what was taking shape and what was not. However, as these imaginaries were flexible enough to simultaneously hold many different futures, they held the potential to become grounds for disappointments as well.

As I discussed in this thesis, when a smart grid is put into place, future imaginaries are tweaked and woven into configurations that barely resemble the futures that once motivated their emergence. Even though sociotechnical smart grid imaginaries, for example, contain promise of a future in which climate-related ambitions have been fulfilled, there is a clear risk that such an objective would be superseded by other notions. In other words, a flexible, digital and successful smart 
grid future with empowered and active users might require deviations from sustainability. For example, it is valid to ask whether all implemented smart grid appliances really will contribute to sustainability, when taking into consideration all the energy and resources that are required to produce them (Strengers, 2013).

This study illustrated how the people who were assigned with the task of making the smart grid functional showed an awareness of such inconsistences. The people working within the demonstration project recurrently seemed uneasy with the many promises being evoked by the smart grid; they argued that they were expected to deliver some kind of "magic formula", and expressed their concern that their smart grid might not be able to realize all of its promises. Nevertheless, the recruitment campaign to enrol households drew on the sociotechnical smart grid imaginaries even though they were tweaked within the project. The tensions that arise in such situations need to be taken seriously. If users realize that smart grids do not live up to their expectations, there is a serious risk that they may end up feeling betrayed. Such feelings could arise, for example, if users do not feel empowered, or do not save money to the hoped-for extent; if Swedish nuclear power is not phased out; or if jobs or economic prosperity for the local community are not realized. Such disappointments would likely create a destabilization of the smart grid configuration as a whole, since "[a]ll it takes is for one translation to fail and the whole web of reality unravels" (Law, 2009:145).

However, this observation also illustrates an intrinsic dilemma of large-scale demonstration projects such as the one studied in this thesis. Such projects seem to rely on a narrative of success, given their inherent propensity to ensure functionality, the publicity and attention directed towards them, and the amount of investments they attract. Exposing all the tensions and doubts that actually accompany a smart grid implementation does not seem to be an option within such a project; rather, there seems to be a need to display a stable configuration with an 
appealing narrative. However, presenting a glorified version of smart grids will just postpone all these contradictions to be handled in the future. Simply put, a polished smart grid version might result in that users feel alienated (Ballo, 2015).

\subsubsection{Paying attention to inclusion and exclusion processes}

While sociotechnical smart grid imaginaries influenced what was taking shape within the demonstration project, I also argue for the opposite relation: namely, that demonstration projects preconfigure the future, and open up certain alternatives at the expense of others. Demonstration projects do not determine the future, but they set the scene for what will come next. They are set out to function as incubators for configurations that can be scaled up and implemented for larger audiences; thus, these projects are assigned the role of affecting the future. Indeed, this role is used as justifying the existence of demonstration projects in the first place. In other words, demonstration projects are assigned a certain degree of generalizability; their performance carries the claim that what "is true for a few is true for the whole population" (Callon, 1986:12).

Barry (2001:178) argues that public demonstrations of technologies have much in common with political demonstrations, in the sense that both are set up with the intent of affecting people. Thus, demonstration projects, like sociotechnical imaginaries, should be understood as performative. They pave the way for the kinds of technologies that are more or less likely to be realized in the future; as part of this process, they also alter "the wider social-material relations among which the new object is to be accommodated" (Marres, 2009:119). As I have shown, the making of a smart grid is not about "getting the technology right", or about simply materializing and implementing a concept or an idea. Rather, a demonstration project functions as a tool through which certain ideas congeal into socio-material configurations at the expense of other alternatives. The continuous decline of 
alternative options results in lock-ins that lay the ground for trajectories of future solutions, while leaving many other desires, demands and expectations unfulfilled (Callon, 2007a). Recognizing the influence of these projects makes it important to pay attention to what kinds of organizations are involved in them.

The network builders of Smart Customer Gotland represent powerful players; they set up a smart grid that aligned with their own commercial interests in a way that did not undermine their positions on the future energy market. For example, I observed how they excluded prosumers, who offered a different kind of smart grid one that positioned households as being in charge of electricity production. It seems naïve to think that a demonstration project performed by actors who already hold dominant positions within the energy system would result in any dramatic changes in power relations. It seems unlikely that such actors would assemble a smart grid that threatens their future status and position. Therefore, it is necessary to ask whether other ways of facilitating the development and implementation of smart grids are more suitable, in order to enable smart grids to produce more distributed power relations. I call for increased scrutiny of those who are actually being represented by such projects and of those who are not; of those who steer the smart grid development, and of those whose interests are being served when smart grids are implemented.

\subsubsection{Tensions in a market-based regime with economic incentives}

Another recurring theme of this thesis is the dominance of a market-based regime in which economic incentives are presented as the main drivers for human actions. This study not only showed that this regime prevails, but also shed light on the tensions that arise when such logics are applied in a Swedish smart grid demonstration project. The Swedish smart grid strategy and planning documents implicitly position the market in a central role in the smart grid future; by offering 
an abundance of different alternatives to choose from, the future market appears as an enhanced version of the current liberalized electricity market. The documents' dominant parlance of electricity users as customers enhances the impression of users being primarily oriented towards the market. Such a market-based logic guided the setup of the demonstration project on Gotland, this was illustrated in that one of the project's main objectives was to facilitate the construction of devices that could become competitive on the market, and in that the role of users as customers seemed so self-evident that it even appeared in the project's name.

However, it is important to recognize that markets are not neutral; they are structured to facilitate actions that are considered to be economic, and favour individuals who possess such a mind-set (Callon, 2007a). The entangled relation between markets and economy was also prevalent in this study; the sociotechnical smart grid imaginaries emphasized economic savings as the main incentive for user engagements. Such ideas were also inscribed in Smart Customer Gotland's technologies, and were initially stressed in the project's recruitment campaign. As the project unfolded, various overflows (Callon, 1998) continuously occurred that did not fit into this economic framing. For example, project employees expressed hesitation regarding whether users would actually be attracted to this motive; they also doubted the likelihood that the project could deliver economic savings and questioned whether a smart grid with an economic cornerstone was an appropriate representation of the future energy system.

Disbelief towards economic incentives was even more profound among the enrolled users and prosumers; some of these actors argued that a smart grid based on economic incentives is an unfair construction, because it suggests that affluent people do not need to engage with initiatives that will serve the common good. Some opposed the neoliberal idea that increasing the choices on the electricity market empowers people, as they found that they were unable to change anything 
of importance through the choices they were enabled to make. In this way, these actors showed their distrust of the entire idea that people can influence the future energy system through their market choices. Such findings support Throndsen and Ryghaug's (2015) suggestion that after decades of neoliberal market logics and promises of empowerment made by stakeholders favouring deregulation initiatives, electricity users feel undermined and let down. When utility companies now ask for their smart grid engagement, these users therefore answer with great distrust and scepticism (Throndsen \& Ryghaug, 2015). In this thesis, I elaborated further on the problematic relation between utility companies and households. For example, some prosumers argued that utility companies will have a hard time constructing a smart grid that is based on any enrolment strategy other than economic incentives - an argument that emphasizes how dubious it is for such companies to present smart grids as an environmental engagement, since they themselves do not take on enough responsibility for accomplishing such a transition.

Throughout this thesis, I have shown how several actors expressed their doubts regarding economic incentives and their reluctance towards the idea that people significantly can influence the future energy system through market choices. Nevertheless, this regime appears to be hegemonic and non-negotiable. It might be possible to conceive the construction and implementation of smart grids as a project that is performed within a post-political frame. This condition is characterized by an assumption of capitalism and the market economy as inevitable and fundamental for the organization of society. More precisely, a core tenet of post-political arrangements is that socio-environmental problems can be solved through agreement-seeking governance and techno-managerial and neoliberal solutions, rather than through debates between oppositions (Mouffe, 2005:20; Swyngedouw, 2009; Swyngedouw, 2010). Similarly, smart grids are presented as a techno-economic solution with the ability to combine various desires, hopes and dreams without causing any form of disharmony; a logic that does not recognize 
that different opinions might exist regarding what is sought-after since no conflicting values seems to be widely acknowledged.

However, as shown in this thesis, smart grids are associated with various conflicting interests; they involve significant contradictions regarding what is sought-after in relation to the future role of users, what kinds of energy sources should be part of the future energy system, how future power relations should be managed and so forth. In a post-political frame, such tensions are not handled using democratic channels; rather, they are delegated to the market to sort out - a structure that make smart grids appear as a market problem rather than a problem for the public.

\subsubsection{Empowerment and activeness: re-negotiated notions of users}

Another recurrent theme in this thesis was the user notions of empowerment and activeness, and the tensions that arise as these notions are filled with concrete meanings and content. Activeness and empowerment appear to be entangled in the Swedish smart grid strategy and planning documents; active users are portrayed as being empowered through enhanced market choices, through enriched information about electricity consumption and as prosumers who produce their own electricity. The ideal of activeness also appears in rationalizations of the demonstration project. However, I discovered that the project employees hesitated when they tried to explain how the smart grid they assembled aligned with the notion of activeness. Their hesitations were particularly visible when they tried to justify how their automatic solution, which was based on remote control, enabled activeness. When describing users as "passively active" and "actively active", they seemed to hold on to the ideal of activeness while tweaking the actual implications of this word. They established a narrow configuration of activeness that primarily scripted people to behave as economically motivated individuals; however, this configuration did not really contain any changes regarding the power structures of the energy system. 
Rather, it was based on the traditional supply-and-demand logic, in which households are given the role as consumers.

This setup was contested by the arguments that were voiced by enrolled users and prosumers; instead, some of these actors suggested a smart grid future in which households are positioned as being in charge of the transition, in their role as members of an engaged community. In a sense, these actors suggested that the public should act as the network builders of the emerging new energy system. For them, the notion of empowerment seemed to be associated with a more direct and concrete influence on what the future energy system would look like.

One way to enable this kind of empowerment is to invite users to participate and to actively listen to them in their role as a concerned public, rather than enrolling them through market structures and economic incentives. Marres supports the idea that " $[\mathrm{i}] \mathrm{t}$ is the emergence of an issue that sparks public involvement in politics" (Marres, 2005:9), meaning that the public does not exist without issues to settle. Schick and Winthereik make use of this conceptualization, as they urge smart grid stakeholders to involve lay people in the discussion of how smart grids should be designed and they thus recognize the need to articulate smart grids as a "public problem" (Schick \& Winthereik, 2013:98). The results of this dissertation support these lines of argument, and call for a greater inclusion of actors to define what smart grids can be; that is to recognize the wider range of voices that exists with respect to how smart grids should be assembled to create desired futures. Instead of striving for consensus through market engagements, this study calls for recognizing the issues related to smart grids that can spark a public into being.

Devine-Wright presents the concept of energy-citizenship which suggest that the public's role can be "framed by notions of equitable rights and responsibilities across society for dealing with the consequences of energy consumption" (DevineWright, 2007:71). Goulden et al. (2014) follow such a conceptualization and argue 
that engaging people in their role as energy citizens, rather than as electricty consumers, is crucial to achieve the full potential of smart grids. In this study, I have shown that some enrolled users and prosumers articulated engagements that are in line with the notion of such an energy citizen. They voiced desires to fulfill larger societal changes rather than engaging with smart grids for purely personal motives. The findings of this dissertation call for an invitation to the public to discuss the essence of empowerment and how this can be enabled through smart grids. Furthermore, this study encourages discussions about why activeness is sought-after, how it should be understood and what its implications are for users who either cannot or do not want to become active.

\subsection{Taking smart grids forward}

This thesis started by describing the huge amount of attention that is directed towards smart grids, and how influential actors assign a great deal of hope to the idea of a revamped and updated electricity system. However, the undertakings within the Swedish smart grid demonstration project that this thesis is based on showed that these expectations are not always easy to fulfil. Nevertheless, this study reveals users who long for a different role in the energy system: a role that does not position them as the passive receivers of pre-made solutions, but that positions them as active participants who help to shape what the smart grid can become. Some users longed for a future in which electricity is not produced by international energy companies but is produced in facilities owned and operated by private individuals or communities. The findings of this thesis show that users can be interested in supporting changes in the energy system, and that they can be motivated not by their own personal benefits, but by societal benefits in the long run. Based on these promises, how can we move forward in realizing the potential of smart grids? 
Heiskanen et al. (2015) argue that today's energy system marginalizes people in their roles as both consumers and citizens. They find that consumers' opportunities to achieve change are constrained by their peripheral position in a large-scale system that is driven by experts. As citizens, people are also constrained, because many decisions about the energy system are not part of the democratic political system but are instead made through other channels of decision-making, for example by experts (Heiskanen et al., 2015). Despite the wide support that exists for a transformed energy system, smart grids and flexible consumption, as illustrated in this thesis, the realization of these potentials seems to be difficult to achieve within the neoliberal market regime that focuses on economic incentives. It seems that there is an unrealized potential that is suppressed within this hegemonic structuring of the electricity system. This thesis brings forward the various credibility problems that appear when utility companies try to enrol users with environmental arguments or for the sake of the common good. We need to ask whether there are other, more stable, ways to shape smart grids - ways that move beyond utility-driven grid structures and that harness civic duty or the public's desire for sustainability. We need to ask how smart grid users can be mobilized as members of an engaged public rather than in their traditional role as electricity users. We need to ask whether smart grids can be assembled in a way that takes people's wishes, dreams and desires regarding a transformed energy system more seriously. 



\section{References}

Here I present all the references referred to in the thesis, except interviews and field notes that are presented in Appendix B.

4C Strategies. (2013). Risker och sårbarheter $i$ smarta elsystem - en förstudie. Retrieved from: http://www.swedishsmartgrid.se/om-forumet/publika tioner/index.html [01-25-2016]

Akrich, M. (1992). The de-scription of technical objects. In W. E. Bijker \& J. Law (Eds.), Shaping technology/building society: Studies in sociotechnical change. Cambridge, Mass.: MIT Press.

Akrich, M., \& Latour, B. (1992). A summary of a convenient vocabulary for the semiotics of human and nonhuman assemblies. In W. E. Bijker \& J. Law (Eds.), Shaping technology/building society: Studies in sociotechnical change. Cambridge, Mass.: MIT Press.

Alvesson, M. (2011). Intervjuer: Genomförande, tolkning och reflexivitet. Malmö: Liber.

Anshelm, J. (2000). Mellan frälsning och domedag: Om kärnkraftens politiska idéhistoria i Sverige 1945-1999. Eslöv: B. Östlings bokförl. Symposion.

Aune, M., Godbolt, Å. L., \& Sørensen, K. H. (2016). Mismatch or misunderstanding? Calculation and qualculation among economists and consumers in their framings of the electricity market. Acta Sociologica (Sage Publications, Ltd.), 59(4), 347-361. doi.org/10.1177/ 0001699316657397

Ballo, I. F. (2015). Imagining energy futures: Sociotechnical imaginaries of the future Smart Grid in Norway. Energy Research E Social Science, 9, 9-20. doi.org/10.1016/j.erss.2015.08.015

Barry, A. (2001). Political machines: Governing a technological society. London: Athlone.

Bartusch, C., Juslin, P., Persson-Fischier, U., \& Stenberg, J. ( 2014). Elkonsumenters drivkrafter för en ökad förbrukningsflexibilitet (14:41). Stockholm: Elforsk. 
Baxter, J., \& Eyles, J. (1997). Evaluating qualitative research in social geography: Establishing 'rigour' in interview analysis. Transactions of the Institute of British Geographers(4), 505.

Bell, S., Judson, E., Bulkeley, H., Powells, G., Capova, K. A., \& Lynch, D. (2015). Sociality and electricity in the United Kingdom: The influence of household dynamics on everyday consumption. Energy Research छ Social Science, 9, 98-106.

Bennett, J. (2005). The agency of assemblages and the North American blackout. Public Culture, 17(3), 445-465.

Berner, B. (2007). Kunskapens vägar: Teknik och lärande i skola och arbetsliv. (Tema T Rapport No. 47). Linköping: Linköping University, Department of Thematic Studies - Technology and Social Change.

Bertoft, J. (2012). “Smarta elnät - men för vem?”. Ny Teknik, September 25. https://www.nyteknik.se/opinion/smarta-elnat-men-for-vem-6416380

Bertoldo, R., Poumadère, M., \& Rodrigues Jr, L. C. (2015). When meters start to talk: The public's encounter with smart meters in France. Energy Research and Social Science, 9, 146-156.

Bladh, M. (2007). El nära och långt borta- Hur kan hushållen agera på elmarknaden? (Perspektiv på tekniken No. 3). Linköping: Linköping University, Department of Thematic Studies - Technology and Social Change.

Bollen, M. (2010). Anpassning av elnäten till ett uthålligt energisystem-Smarta mätare och intelligenta nät. (EI R2010:18). Stockholm: Swedish Energy Markets Inspectorate.

Borup, M., Brown, N., Konrad, K., \& van Lente, H. (2006). The Sociology of expectations in science and technology. Technology Analysis Eீ Strategic Management, 18(3/4), 285-298.

Brinkmann, S., \& Kvale, S. (2015). InterVieres: Learning the craft of qualitative research interviewing. 3rd ed., Denmark, Europe: Sage Publications, Incorporated. 
Brown, J., \& Hendry, C. (2009). Public demonstration projects and field trials: Accelerating commercialisation of sustainable technology in solar photovoltaics. Energy Policy, 37(7), 2560-2573.

Brown, N., \& Michael, M. (2003). A sociology of expectations: Retrospecting prospects and prospecting retrospects. Technology Analysis \& Strategic Management, 15(1),3-18.

Brühl Hjort, P. (2016). De smarta elnäten behövs för att behålla vår standard. http://swedishsmartgrid.se/pia-bruhl-hjort-de-smarta-elnaten-behovs-foratt-behalla-standard [05-20-2016]

Business Sweden. (2013). Smarta elnät - En kartläggning av företag $i$ Sverige. Retrieved from: http://www.swedishsmartgrid.se/om-forumet/publika tioner/index.html [01-25-2016]

Byrne, B. (2004). Qualitative interviewing. In C. Seale (Ed.), Researching society and culture. 2nd. ed., London: SAGE.

Çalıskan, K., \& Callon, M. (2010). Economization, part 2: A research programme for the study of markets. Economy and Society, 39(1), 1-32.

Callon, M. (1981). Struggles and negotiations to define what is problematic and what is not: The socio-logic of translation. In K. D. Knorr, R. Krohn, \& R. Whitley (Eds.), The social process of scientific investigation. Dordrecht: D. Reidel Publishing Company.

Callon, M. (1986). Some elements of a sociology of translation: Domestication of the scallops and the fishermen of St Brieuc Bay. In J. Law (Ed.), Power, action and belief: A new sociology of knowledge? London: Routledge and Kegan Paul.

Callon, M. (1998). An essay on framing and overflowing: Economic externalities revisited by sociology. In M. Callon (Ed.), The laws of the markets. Oxford: Blackwell Publishers.

Callon, M. (2007a). An essay on the growing contribution of economic markets to the proliferation of the social. Theory, Culture \& Society, 24(7-8), 139-163. doi.org/10.1177/0263276407084701 
Callon, M. (2007b). What does it mean to say that economics is performative? In D. MacKenzie, F. Muniesa, \& L. Siu (Eds.), Do economists make markets? On the performativity of economics. Princeton: Princeton University Press.

Callon, M., Millo, Y., \& Muniesa, F. (2007). Market devices. Oxford: Blackwell.

Christensen Haunstrup, T., Gram-Hanssen, K., \& Friis, F. (2013). Households in the smart grid: Existing knowledge and new approaches. In L. Hansson, U. Holmberg, \& H. Brembeck (Eds.), Making sense of consumption: Selections from the 2nd Nordic conference on consumer research 2012. Centre for Consumer Science, University of Gothenburg, Göteborg.

City of Stockholm. (2016). Norra Djurgårdsstaden. http://bygg.stockholm.se/ norradjurgardsstaden [09-27-2016]

Coffey, A., \& Atkinson, P. (1996). Making sense of qualitative data: complementary research strategies. Thousand Oaks, Calif.: Sage.

Cooren, F. (2000). The organizing property of communication. Philadelphia: J. Benjamins.

Cotton, M., \& Devine-Wright, P. (2012). Making electricity networks "visible": Industry actor representations of "publics" and public engagement in infrastructure planning. Public Understanding of Science, 21(1), 17-35. doi:10.1177/0963662510362658

Covrig, C. F., Ardelean, M., Vasiljevska, J., Mengolini, A., Fulli, G., \& Amoiralis, E. (2014). Smart grid projects outlook 2014 (JRC90290, EUR 26651 EN). Luxembourg: Publications Office of the European Union.

Creswell, J. W., \& Miller, D. L. (2000). Determining validity in qualitative inquiry. Theory Into Practice, 39(3),124-130.

Devine-Wright, P. (2007). Energy citizenship: Psychological aspects of evolution in sustainable energy technologies. In J. Murphy (Ed.), Governing technology for sustainbility. London: Earthscan.

European Commission. (2006). European technology platform smartgrids: Vision and strategy for europe's electricity networks of the future. (EUR 22040). http://ec.europa.eu/research/energy/pdf/smartgrids_en.pdf 2018-08-08 
European Regulators Group for Electricity and Gas. (2010). Position paper on smart grids - An ERGEG conclusions paper (E10-EQS-38-05). Retrieved from: http://www.smartgrids-cre.fr/media/documents/regulation/ 100610_ ERGEG_Position_paper.pdf [01-27-2016]

Flyvbjerg, B. (2001). Making social science matter: Why social inquiry fails and how it can succeed again. Cambridge: Cambridge University Press.

Forum for Swedish Smart grid. (2017). Ibrahim Baylan - ny ordförande för Forum för smarta elnät. http://swedishsmartgrid.se/ibrahim-baylan-ny-ordfor ande-for-forum-for-smarta-elnat [09-20-2017]

Gad, C., \& Jensen, C. B. (2010). On the consequences of post-ANT. Science, Technology छ Human Values, 35(1), 55-80. doi:10.1177/ 0162243908329567

Galis, V., \& Lee, F. (2014). A sociology of treason: The construction of weakness. Science, Technology $\odot$ Human Values, 39(1), 154-179. doi:10.1177/ 0162243913512681

Gangale, F., Mengolini, A., \& Onyeji, I. (2013). Consumer engagement: An insight from smart grid projects in Europe. Energy Policy, 60, 621-628. doi.org/10.1016/j.enpol.2013.05.031

GEAB. (2015). Samhället. http://www.gotlandsenergi.se/samhallet [08-20-2015]

GEAB. (2016). Om Geab. http://www.gotlandsenergi.se/om-geab [12-07-2016]

GEAB. (n.d.-a). Gillar du spänning? Bli vår testpilot [pamphlet]. Visby: GEAB.

GEAB. (n.d.-b). Smart Kund Installationsmanual, Android [folder]. Visby: GEAB.

GEAB. (n.d.-c). Välkommen till Smart Kund Gotland [folder]. Visby: GEAB.

GEAB. (n.d.-d). Vill du minska dina elkostnader och bidra till en bättre miljö? [candy case]. Visby: GEAB.

GEAB. (n.d.-e). Vill du styra din elförbrukning och bidra till en bättre miljö? [pamphlet]. Visby: GEAB.

GEAB, Vattenfall, ABB, \& KTH. (2011). Pre-study Smart Grid Gotland. Retrieved from: http://www.smartgridgotland.se/Rapporter.pab [08-04-2016] 
Geelen, D., Reinders, A., \& Keyson, D. (2013). Empowering the end-user in smart grids: Recommendations for the design of products and services. Energy Policy, 61, 151-161. 10.1016/j.enpol.2013.05.107

George, A. L., \& Bennett, A. (2005). Case studies and theory development in the social sciences. Cambridge, Mass.: MIT Press

Ghanem, D. A., \& Mander, S. (2014). Designing consumer engagement with the smart grids of the future: Bringing active demand technology to everyday life. Technology Analysis $छ$ Strategic Management, 26(10), 1163-1175. 10.1080/ 09537325.2014.974531

Giordano, V., Gangale, F., Fulli, G., Sanchez Jimenez, M., Papaioannou, I., Colta, A., .. . Alecu, E. (2011). Smart grid projects in Europe - Lessons learned and current developments (JRC65215, EUR 24856 EN). Luxembourg: Publications Office of the European Union.

Goulden, M., Bedwell, B., Rennick-Egglestone, S., Rodden, T., \& Spence, A. (2014). Smart grids, smart users? The role of the user in demand side management. Energy Research छ Social Science, 2, 21-29.

Government Office of Sweden. (2002). Vissa elmarknadsfrågor (Proposition 2002/03:85). Stockholm: Ministry of Enterprise and Innovation.

Government Office of Sweden. (2011). Timmätning för aktiva elkonsumenter (Proposition 2011/12:98). Stockholm: Ministry of Enterprise and Innovation.

Government Office of Sweden. (2012). Samordningsråd med kunskapsplattform för smarta elnät (Committee directive Dir. 2012:48). Stockholm: Ministry of the Environment and Energy.

Government Office of Sweden. (2015). Inrättande av forum för smarta elnät (Protocol from cabinet meeting M2015/04312/Ee). Stockholm: Ministry of the Environment and Energy.

Government Office of Sweden. (2016). Ramöverenskommelse mellan Socialdemokraterna, Moderaterna, Miljöpartiet de gröna, Centerpartiet och Kristdemokraterna (Framework agreement between parliamentary parties). 
Retrieved from: http://www.regeringen.se/contentassets/b88fod28eb0e48e39eb4411de2aabe76/energioverenskommelse-20160610.pdf [01-27-2017]

Grandclément, C., \& Nadaï, A. (2015). Scripting the electricity consumer in the meter - an exploration of the French smart meter dispute. In Proceedings of EGOS conference, session 'Devising Markets and Other Valuation Sites. Athenes, Greece.

Hammersley, M., \& Atkinson, P. (2007). Ethnography: Principles in practice. 3rd ed., London, New York: Routledge.

Hargreaves, T., Wilson, C., \& Hauxwell-Baldwin, R. (2017). Learning to live in a smart home. Building Research and Information, 1-13.

Hatt, A.-K. (2012). Varför ett råd för smarta elnät? (Press release May 30). http://www.regeringen.se/sb/d/15728/a/194008 [04-03-2014]

Hatt, A.-K., \& Khorsand, M. (2012). "Nytt råd ska bädda för smarta elnät”. Ny Teknik, May 30. http://www.nyteknik.se/opinion/nytt-rad-ska-badda-forsmarta-elnat-6417367

Heiskanen, E., Matschoss, K., \& Repo, P. (2015). Engaging consumers and citizens in the creation of low-carbon energy markets. In Proceedings of ECEEE summer study on energy efficiency. Dynamics of consumption. Presqu'île de Giens Toulon/Hyères, France.

Hellsmark, H., Frishammar, J., Söderholm, P., \& Ylinenpää, H. (2016). The role of pilot and demonstration plants in technology development and innovation policy. Research Policy, 45(9), 1743-1761.

Hesselgren, B. (2016). Viktigt att det blir enkelt för kunderna. http://swedish smartgrid.se/bo-hesselgren-viktigt-att-det-blir-enkelt-for-kunderna [05-202016]

Hledik, R. (2009). How green is the smart grid? The Electricity Journal, 22(3), 2941 .

Honebein, P. C., Cammarano, R. F., \& Boice, C. (2011). Building a social roadmap for the smart grid. The Electricity Journal, 24(4), 78-85. 
Högselius, P., \& Kaijser, A. (2007). När folkhemselen blev internationell: Elavregleringen i historiskt perspektiv. Stockholm: SNS förlag.

Högselius, P., \& Kaijser, A. (2010). The politics of electricity deregulation in Sweden: The art of acting on multiple arenas. Energy Policy, 38(5), 22452254.

International Energy Agency. (2011). Technology roadmap: Smart grids. Retrieved from: https://www.iea.org/publications/freepublications/ publication/smart grids_roadmap.pdf [08-07-2017]

Jasanoff, S. (2015). Future imperfect: Science, technolgy, and the imagination of modernity. In S. Jasanoff \& S.-H. Kim (Eds.), Dreamscapes of modernity: Sociotechnical imaginaries and the fabrication of power. Chicago: The University of Chicago Press.

Jasanoff, S., \& Kim, S.-H. (2009). Containing the atom: Sociotechnical imaginaries and nuclear power in the United States and South Korea. Minerva, 47(2), 119-146. doi.org/10.1007/s11024-009-9124-4

Jasanoff, S., \& Kim, S.-H. (2013). Sociotechnical imaginaries and national energy policies. Science as Culture, 22(2), 189-196. doi.org/10.1080/09505431. 2013.786990

Kall, A.-S. (2011). Förnyelse med förhinder: Den riksdagspolitiska debatten om omställningen av energisystemet 1980-2010. Diss. Linköping: Linköping University, Department of Thematic Studies - Technology and Social Change.

Karlström, M., \& Sandén, B. A. (2004). Selecting and assessing demonstration projects: The cases of fuel cells and hydrogen systems in Sweden. Innovation: Management, Policy and Practice, 6(23), 286-293.

Katzeff, C., \& Wangel, J. (2015). Social practices, households, and design in the smart grid. In L. M. Hilty \& B. Aebischer (Eds.), ICT innovations for sustainability. Cham: Springer International Publishing.

Khorsand, M. (2016). Smarta elnät ska bli ett tillväxtområde. http:// swedishsmartgrid.se/om-forumet/manadens-intervju-maria-khorsand [0520-2016] 
Konrad, K., van Lente, H., Groves, C., \& Selin, C. (2016). Performing and governing the future in science and technology. In U. Felt, R. Fouche, C. A. Miller, \& L. Smith-Doerr (Eds.), The handbook of science and technology studies. 4th. ed., Cambridge, Mass.: MIT Press.

Kuutti, K. (2001), Hunting for the lost user: From sources of errors to active actors - and beyond. In Proceedings of the Seminar Cultural Usability-Towards a critical design sensibility. University of Art and Design, Helsinki, Finland.

Larsson, Ö., \& Ståhl, B. (2011). Smart ledning - Drivkrafter och förutsättningar för utveckling av avancerade elnät. (VA 2011:01). Stockholm: Vinnova/ Blue Institute.

Latour, B. (1987). Science in action. How to follow scientists and engineers through Society. Cambridge, Mass.: Harvard Univ. Press.

Latour, B. (2004). Why has critique run out of steam? From matters of fact to matters of concern. Critical Inquiry, 30(2), 225-248. doi.org/10.1086/ 421123

Latour, B. (2005). Reassembling the social: An introduction to actor-networktheory. Oxford: Oxford University Press.

Latour, B., \& Woolgar, S. (1986). Laboratory life. The construction of scientific facts. 2nd. ed., Princeton, NJ: Princeton University Press.

Law, J. (2004). After method: Mess in social science research. Abingdon and New York: Routledge.

Law, J. (2009). Actor-network theory and material semiotics. In B. S. Turner (Ed.), The new blackwell companion to social theory. Chichester, West Sussex, United Kingdom; Malden, MA, USA: Wiley-Blackwell.

Lidskog, R., \& Elander, I. (2012). Ecological modernization in practice? The case of sustainable development in Sweden. Journal of Environmental Policy $\xi^{\circ}$ Planning, 14(4), 411-427. doi.org/10.1080/1523908X.2012.737234

Luque, A., McFarlane, C., \& Marvin, S. (2014). Smart urbanism: Cities, grids and alternatives? In M. Hodson \& S. Marvin (Eds.), After sustainable cities. Abingdon, Oxon: Routledge. 
Mah, D. N.-y., van der Vleuten, J. M., Hills, P., \& Tao, J. (2012). Consumer perceptions of smart grid development: Results of a Hong Kong survey and policy implications. Energy Policy, 49, 204-216.

Malmgren, R., \& Johansson, E. (2014). Rapport rörande säkerhet $i$ smarta elnät. Retrieved from: http://www.swedishsmartgrid.se/om-forumet/publika tioner/index.html [01-25-2016]

Marres, N. (2005). Issues spark a public into being: A key but often forgotten point of the Lippmann-Dewey debate. In B. Latour \& P. Weibel (Eds.), Making things public: Atmospheres of democracy. Cambridge, Mass.: MIT Press.

Marres, N. (2007). Dilemmas of home improvement: Can clean energy technology mediate civic involvement in climate change? In M. Feher, G. Krikorian, \& Y. McKee (Eds.), Nongovernmental politics. New York: Zone Books.

Marres, N. (2009). Testing powers of engagement: Green living experiments, the ontological turn and the undoability of involvement. European Journal of Social Theory, 12(1), 117-133. doi.org/10.1177/1368431008099647

Marres, N. (2010). Front-staging nonhumans: Publicity as a constraint on the political activity of things. In B. Braun, S. Whatmore, \& I. Stengers (Eds.), Political matter: technoscience, democracy and public life. Minneapolis: University of Minnesota Press.

Marres, N. (2012a). The environmental teapot and other loaded household objects: Reconnecting the politics of technology, issues and things. In P. Harvey, E. Casella, G. Evans, H. Knox, C. McLean, E. Silva, N. Thoburn, \& K. Woodward (Eds.), Objects and materials: A Routledge companion. London: Routledge.

Marres, N. (2012b). Material participation: Technology, the environment and everyday publics. Basingstoke: Palgrave Macmillan.

Mouffe, C. (2005). On the political. London: Routledge.

Naus, J., van Vliet, B. J. M., \& Hendriksen, A. (2015). Households as change agents in a Dutch smart energy transition: On power, privacy and participation. Energy Research Eं Social Science, 9, 125-136. 
Nilsson, J., Leymann, J., \& Näselius, S. (2014). Uppföljning av timmätningsreformen (R2014:05). Stockholm: Swedish Energy Markets Inspectorate.

North European Power Perspectives. (2013a). Beskrivning av de konkreta utmaningar som det svenska elnätet står inför med anledning av den pågående omställningen av energisystemet. Retrieved from: http://www. swedishsmartgrid.se/om-forumet/publikationer/index.html [01-25-2016]

North European Power Perspectives. (2013b). Hur utvecklingen av kraftsystemet utanför Sveriges gränser påverkar behovet av smarta elnät $i$ Sverige. Retrieved from: http://www.swedishsmartgrid.se/om-forumet/publika tioner/index.html [01-25-2016]

North European Power Perspectives. (2013c). Förutsättningar och drivkrafter för olika typer av elkunder att justera förbrukningsmönster och minska sin elförbrukning idag och $i$ framtiden. Retrieved from: http://www. swedishsmartgrid.se/om-forumet/publikationer/index.html [01-25-2016]

North European Power Perspectives. (2014a). Analys av vad $i$ samhällsutvecklingen som driver utvecklingen av smarta nät. Retrieved from: http://www.swedishsmartgrid.se/om-forumet/publikationer/index. html [01-25-2016]

North European Power Perspectives. (2014b). Analysera effekten av olika förändringar $i$ regelverk, rollfördelning och marknadsmodeller som kan bidra till att utnyttja möjligheterna till efterfrågeflexibilitet bättre. Retrieved from: http://www.swedishsmartgrid.se/om-forumet/publikationer/index. html [01-25-2016]

North European Power Perspectives. (2014c). Bedömning av det bidrag som smarta elnät kan ge för att uppfylla energi- och klimatmål. Retrieved from: http://www.swedishsmartgrid.se/om-forumet/publikationer/index. html [01-25-2016]

North European Power Perspectives. (2014d). Krav på framtidens elnät - smarta nät. Retrieved from: http://www.swedishsmartgrid.se/om-forumet/publika tioner/index.html [01-25-2016]

Nyborg, S. (2015). Pilot users and their families: Inventing flexible practices in the smart grid. Science E Technology Studies, 28(3), 54-80. 
Nyborg, S., \& Røpke, I. (2011). Energy impacts of the smart home - conflicting visions. In Energy Efficiency First: The foundation of a low-carbon society. Stockholm: European Council for an Energy Efficient Economy.

Nyborg, S., \& Røpke, I. (2013). Constructing users in the smart grid - Insights from the Danish eFlex project. Energy Efficiency, 6(4), 655-670.doi.org/ 10.1007/s12053-013-9210-1

Ramböll. (2013). Smart grid forskningsprojekt $i$ Sverige - kartläggning april-juni 2013. Retrieved from: http://www.swedishsmartgrid.se/om-forumet/ publikationer/index.html [01-25-2016]

Region Gotland. (2016). Gotland $i$ siffror 2016. Visby: Region Gotland.

Rohracher, H. (2006). The mutual shaping of design and use: Innovations for sustainable buildings as a process of social learning. München: Profil Verlag.

Samsyn Hyllie. (2015). En plats $i$ världen [folder]. Malmö: Malmö Stad.

Schick, L., \& Gad, C. (2015). Flexible and inflexible energy engagements - A study of the Danish smart grid strategy. Energy Research E Social Science, 9, 51-59. doi.org/10.1016/j.erss.2015.08.013

Schick, L., \& Winthereik, B. R. (2013). Innovating relations - Or why smart grid is not too complex for the public. Science छ Technology Studies, 26(3), 82-102.

Shove, E. (2010). Beyond the ABC: Climate change policy and theories of social change. Environment and Planning A, 42(6), 1273-1285.

Silverman, D. (2006). Interpreting qualitative data: Methods for analyzing talk, text and interaction. 3rd ed., London: SAGE.

Skjølsvold, T. M. (2014). Back to the futures: Retrospecting the prospects of smart grid technology. Futures, 63, 26-36. doi.org/10.1016/ j.futures.2014.08.001

Skjølsvold, T. M., \& Lindkvist, C. (2015). Ambivalence, designing users and user imaginaries in the European smart grid: Insights from an interdisciplinary demonstration project. Energy Research छ Social Science, 9, 43-50. doi.org/10.1016/j.erss.2015.08.026 
Skjølsvold, T. M., \& Ryghaug, M. (2015). Embedding smart energy technology in built environments: A comparative study of four smart grid demonstration projects. Indoor and Built Environment, 24(7), 878-890. doi.org/ 10.1177/1420326X15596210

Skjølsvold, T. M., Ryghaug, M., \& Berker, T. (2015). A traveler's guide to smart grids and the social sciences. Energy Research Eं Social Science, 9, 1-8.

Smart Customer Gotland. (2014a). Om Smart Kund Gotland. http:// www.gotlandsenergi.se/smartkundgotland [12-19-2014]

Smart Customer Gotland. (2014b). Smart Kund Pris. http://www.gotlands energi.se/ smartkundpris [12-19-2014]

Smart Customer Gotland. (2015a). Automatisk styrning. http://www.gotlands energi.se//SmartKundGotland/Automatiskstyrning.pab [12-19-2016]

Smart Customer Gotland. (2015b). Om Smart Kund Gotland. http://www. gotlandsenergi.se/omsmartkundgotland.pab [08-20-2015]

Smart Customer Gotland. (2015c). Styrscheman. http://www.gotlandsenergi.se/ styrschemaSKG [12-19-2016]

Smart Customer Gotland. (2016). Om Smart Kund Gotland. http://www. gotlandsenergi.se/omsmartkundgotland.pab [01-20-2016]

Smart Customer Gotland. (2017a). SKG-bilder [slideshow] [email: 09-21-2017]

Smart Customer Gotland. (2017b). Smart Kund Gotland [slideshow presented on final seminar Mars 7]. Retrieved from: http://www.smartgridgotland.se/ pdf/Smart_Kund_Gotland.pdf [08-04-2017]

Smart Grid Gotland. (2013). Go Live 1 [slideshow presented on recruitment event November 4] [email: 02-09-2014]

Smart Grid Gotland. (2016a). Delprojekt Elkvalitet. http://www.smartgrid gotland.se/researchplatform.pab [09-27-2016]

Smart Grid Gotland. (2016b). Delprojekt Wind Power Integration. http://www. smartgridgotland.se/subprojects.pab [09-27-2016] 
Smart Grid Gotland. (2016c). Gotland - Ett smart val. http://www. smartgridgotland.se/gotland.pab [09-27-2016]

Smart Grid Gotland. (2016d). På Gotland byggs ett av världens modernaste elnät. http://www.smartgridgotland.se/index.pab [09-27-2016]

Smart Grid Gotland. (2016e). Projektmål. http://www.smartgrid gotland.se/aim.pab [09-27-2016]

Smart Grid Gotland. (2016f). Solcellsinstallation. http://www.smartgrid gotland.se/solceller.pab [09-27-2016]

Smart Grid Gotland. (2016g). Storföretag bakom storsatsning. http://www.smart gridgotland.se/partners.pab [09-27-2016]

Smart Grid Gotland. (2017). Nyhetsbrev Smart Grid Gotland [Project Newsletter] [email: 06-29-2017]

Star, S. L., \& Griesemer, J. R. (1989). Institutional ecology, 'translations', and boundary objects: Amateurs and professionals in Berkeley's Museum of Vertebrate Zoology, 1907-39. Social Studies of Science, 19(3), 387-420.

Statistics Sweden. (2015). Electricity supply, district heating and supply of natural gas 2015 (EN11SM1601). Stockholm: Statistics Sweden.

Stephens, J. C., Wilson, E. J., \& Peterson, T. R. (2015). Smart grid (R)evolution: Electric power struggles. Cambridge: Cambridge University Press.

Strengers, Y. (2013). Smart energy technologies in everyday life: Smart utopia? New York: Palgrave Macmillan.

STRI. (2013). Utmaningar för det smarta elnätet. Retrieved from: http://www.swedishsmartgrid.se/om-forumet/publikationer/index.html [01-25-2016]

Summerton, J. (2004). Do electrons have politics? Constructing user identities in Swedish electricity. Science, Technology छ Human Values, 29(4), 486-511.

Svalstedt, C., \& Löf, M. (2014). Smart Customer Gotland. In Proceedings of the International Conference Eं Exhibition on Electricity Distribution (CIRED). 
Workshop: Challenges of Implementing Active Distribution System Management. Rome, Italy.

Svalstedt, C., \& Löf, M. (2017). Behaviour of active household customers on the electricity market - findings from market test Smart Grid Gotland. In Proceedings of the International Conference $\mathcal{E}^{\circ}$ Exhibition on Electricity Distribution (CIRED). Glasgow, Scotland.

Swedenergy. (2014a). Elåret Eீ Verksamheten 2013. Stockholm: Swedenergy.

Swedenergy. (2014b). Några data om Sverige och energin [folder]. Stockholm: Swedenergy.

Swedish Coordination Council for Smart Grid. (2012). Referat inklusive inlägg från dialogforum: Hur kan konsumentinflytandet öka med smarta elnät? Retrieved from: http://www.swedishsmartgrid.se/om-forumet/publika tioner/index.html [01-25-2016]

Swedish Coordination Council for Smart Grid. (2013a). Delårsrapport 2013: Kunskapsplattformen och nuläge $i$ Samordningsrådets arbete. Retrieved from: http://www.swedishsmartgrid.se/om-forumet/publikationer/index. html [01-25-2016]

Swedish Coordination Council for Smart Grid. (2013b). Smart Grid for a sustainable energy society [folder]. Stockholm: Swedish Coordination Council for Smart Grid.

Swedish Coordination Council for Smart Grid. (2014a). Planera för effekt! Slutbetänkande från Samordningsrådet för smarta elnät (SOU 2014:84). Stockholm: Ministry of the Environment and Energy.

Swedish Coordination Council for Smart Grid. (2014b). Rapport om rådets arbete inom incitamentstuktur och kundinflytande - vilka är aktörernas roller och drivkrafter $i$ utvecklingen av smarta elnät? Retrieved from: http://www.swedishsmartgrid.se/om-forumet/publikationer/index.html [01-25-2016]

Swedish Coordination Council for Smart Grid. (2014c). Rapport om rådets framtidsscenarier. Retrieved from: http://www.swedishsmartgrid.se/omforumet/publikationer/index.html [01-25-2016] 
Swedish Energy Agency. (2012). Smart Grid Gotland: Beslut enskilt projekt (Dnr 2011-001089). Eskilstuna: Swedish Energy Agency.

Swedish Energy Agency. (2015). Energiläget 2015 (ET2015:08). Eskilstuna: Swedish Energy Agency.

Swedish Energy Agency. (2016a). Projektdatabas. http://www.energimyndig heten.se/forskning-och-innovation/projekt-databas [09-27-2016]

Swedish Energy Agency. (2016b). Vindkraftstatistik 2015: Nationell, länsvis och kommunal statistik (ES2016:01). Eskilstuna: Swedish Energy Agency.

Swedish Energy Agency. (2017). Elcertifikatsystemet - ett stödsystem för förnybar elproduktion [folder]. Eskilstuna: Swedish Energy Agency.

Swedish Energy Markets Inspectorate. (2014). Sverige är indelat i fyra elområden [folder]. Stockholm: Swedish Energy Markets Inspectorate.

Swyngedouw, E. (2009). The antinomies of the postpolitical city: In search of a democratic politics of environmental production. International Journal of Urban and Regional Research, 33(3), 601-620.

Swyngedouw, E. (2010). Apocalypse forever? Post-political populism and the spectre of climate change. Theory Culture Eं Society, 27(2-3), 213-232.

Throndsen, W. (2017). What do experts talk about when they talk about users? Expectations and imagined users in the smart grid. Energy Efficiency, 10(2), 283-297.

Throndsen, W., \& Ryghaug, M. (2015). Material participation and the smart grid: Exploring different modes of articulation. Energy Research $\Xi^{\circ}$ Social Science, 9, 157-165.

Tutton, R. (2017). Wicked futures: Meaning, matter and the sociology of the future. The Sociological Review, 65(3), 478-492.

US Department of Energy. (2016). Recovery Act Smart Grid Document Collection. Retrieved from: https://www.smartgrid.gov/files/Document_of_Documents _20160225.pdf [08-08-2017] 
US Department of Energy. (2017). What is the Smart Grid? https://www. smartgrid.gov/the_smart_grid/smart_grid.html [08-08-2017]

van Lente, H. (2012). Navigating foresight in a sea of expectations: Lessons from the sociology of expectations. Technology Analysis छ Strategic Management, 24(8), 769-782.

van Lente, H., \& Bakker, S. (2010). Competing expectations: The case of hydrogen storage technologies. Technology Analysis छ Strategic Management, 22(6), $693-709$.

Van Lente, H., \& Rip, A. (1998). The rise of membrane technology: From rhetorics to social reality. Social Studies of Science, 28(2), 221-254.

Vattenfall. (2016). Vattenfall: Om oss. https://corporate.vattenfall.se/om-oss [1122-2016]

Verbong, G. P. J., Beemsterboer, S., \& Sengers, F. (2013). Smart grids or smart users? Involving users in developing a low carbon electricity economy. Energy Policy, 52, 117-125.

Verbong, G. P. J., Verkade, N., Verhees, B., Huijben, J. C. C. M., \& Höffken, J. I. (2016). Smart business for smart users? A social science agenda for developing smart grids. In A. Beaulieu, J. de Wilde \& J. M. A. Scherpen (Eds.), Smart grids from a global perspective: bridging old and new energy systems. Berlin: Springer.

Vesnic-Alujevic, L., Breitegger, M., \& Pereira, Â. G. (2016). What smart grids tell about innovation narratives in the European Union: Hopes, imaginaries and policy. Energy Research छ Social Science, 12, 16-26.

Wangel, J. (2015). Developing Sweden's transmission grid: What are the drivers and barriers? (No. 2015-06). Stockholm: Stockholm Environment Institute.

Winner, L. (1980). Do artefacts have politics? Daedalus, 109(1), 121-136.

Wissner, M. (2011). The smart grid - a saucerful of secrets? Applied Energy, 88(7), 2509-2518. 
Wolsink, M. (2012). The research agenda on social acceptance of distributed generation in smart grids: Renewable as common pool resources. Renewable and Sustainable Energy Revieres, 16(1), 822-835.

Woolgar, S. (1991). Configuring the user: The case of usability trials. In J. Law (Ed.), A sociology of monsters: Essays on power, technology and domination. London: Routledge.

Woolgar, S., \& Lezaun, J. (2013). The wrong bin bag: A turn to ontology in science and technology studies? Social Studies of Science, 43(3), 321-340. 


\section{Appendices}

\section{Appendix A: Interview guides}

These interview guides were guidelines rather than strict protocols. In practice, this meant that the exact phrasing of the questions varied. I asked follow-up questions whenever I found that to be relevant.

\section{Examples of questions to project employees}

General questions about smart grids, Smart Grid Gotland and Smart Customer Gotland:

What characterizes a smart grid, according to you? What makes it "smart", and how does it differ from the current grid?

Tell me about Smart Grid Gotland (i.e. its objectives, ambitions and time perspective).

Tell me about Smart Customer Gotland (i.e. its objectives, ambitions and time perspective).

Why are these projects being conducted? What do you want to find out? Do all the involved actors have the same interests in the project, or do they differ?

Why are these projects important for society at large? Why are they important for you as a company? How do you benefit?

Households' role in smart grids:

What do you think households' role should be in smart grids? What are their needs for smart grids? 
You have chosen the name "Smart Customer Gotland". What is a "Smart Customer", according to you?

In discussions about smart grids, the "active electricity customer" often appears. What does that mean for you? How does this project relate to such a definition?

\section{Project implementation:}

Tell me about Smart Customer Gotland over time. Have visions and goals changed? If so, in what way?

Has something been more difficult/gone more smoothly than you initially thought?

What kinds of households can participate in the project?

Tell me about the kinds of solutions you will install in the households. How do they work? Why did you choose this solution?

How can the households interact with the appliances? What kinds of information can they see?

How do you think the households will interact with these appliances? What will they look at, when and how often? How would you like them to interact?

Do you expect any controversies between the project and the participants?

\section{Recruitment process:}

How do you explain what the project is about to households?

Why do you think households have signed up for the project? What do they get out of participating?

Why do you think households have refrained from signing up? 
What do you think is needed in order for more households to get involved in smart grid?

\section{Visions about the future:}

Do you think the solutions tested in this project will be implemented on a large scale? Why or why not?

How do you think we will produce and use electricity in the future? What will be the role of households? What would you like it to be?

In what way does this project contribute to fulfilling such a vision? What do you think is needed for that vision to be met? Who will hold responsibility, and in what ways?

\section{Examples of questions to enrolled users}

Initial questions about Smart Customer Gotland:

Why did you choose to participate in Smart Customer Gotland? What are your motives?

Is this project important for you to participate in? Why or why not?

Is this project important for society at large? Why or why not? Does this project make you feel like you are part of these matters? If so, how?

Why do you think this project is being implemented? What are the drivers of the people behind the project? How do you regard GEAB and Vattenfall as companies in general?

Is this project important for Gotland? If so, why? What is it like living on Gotland? 
The project is called "Smart Customer Gotland". What is a "Smart Customer", according to you?

In discussions about smart grids, the "active electricity customer" often appears. What does that mean for you? How do you relate to that definition?

Commitment during the project:

What has Smart Customer Gotland meant for you? What have you gotten out of the project so far? What do you hope to get out of the project in the future?

Have you reduced/shifted your electricity consumption during the project? Have you saved any money? How much and how?

What do you think about the remote control of your devices? Have you chosen a specific schedule for your control?

How often do you look at the Smart Customer app? What are you looking at?

Is everyone in the household equally interested in the project, or do peoples' engagement differ?

What do you think is required for more households to be interested in engagements such as these?

\section{Visions about the future:}

Do you think the solutions tested in this project will be implemented on a large scale? Why or why not?

How do you think we will produce and use electricity in the future? What will be the role of households? What would you like it be? 
In what way does this project contribute to fulfilling such a vision? What do you think is needed for that vision to be met? Who will hold responsibility, and in what ways?

\section{Examples of questions to prosumers}

Initial questions about electricity production:

Tell me about how, why and when you started producing your own electricity.

Why do you produce your own electricity? What are your driving forces?

How much electricity do you produce? Has this changed how you use electricity?

What are the benefits of producing your own electricity for you as an individual?

What are the disadvantages?

What are the benefits for society at large? What are the disadvantages?

\section{Questions related to smart grids:}

Do you know about smart grids as a concept? What does it mean to you? Does it appeal to you?

Do you think smart grids will be implemented on a larger scale? Why or why not?

Why do you think projects like Smart Customer Gotland are implemented? What are the driving forces? Does it appeal to you?

In discussions about smart grids, the "active electricity customer" often appears. What does that mean for you? How do you relate to that definition? 
Appendices

Visions about the future:

How do you think we will produce and use electricity in the future? What will be the role of households? What would you like it to be?

In what way do projects such as Smart Customer Gotland contribute to fulfilling such a vision?

What do you think is needed for that vision to be met? Who will hold responsibility, and in what ways? 


\section{Appendix B: Participant observations and fictitious names of interviewees}

Below, I present a list of all the public events that I attended that were arranged by the demonstration project under study, as well as a list of the fictitious names of interviewees used in the thesis. Field notes, recorded interviews and transcripts are in my possession.

\section{Participant observations}

Recruiting and information event (full day fair) $\quad$ August 16, 2013.

Recruiting and information event (full day fair) $\quad$ August 17, 2013.

Recruiting and information events (two events) December 10, 2013

Recruiting and information events (two events) December 11, 2013

Recruiting and information event (one event) $\quad$ February 4, 2014

Recruiting and information events (two events) February 5, 2014

Recruiting and information event (one event) $\quad$ February 6, 2014

Final seminar Smart Grid Gotland $\quad$ March 7, 2017

Fictitious names of interviewees:

Persons working with or in close relation to Smart Customer Gotland/Smart Grid Gotland

Emma June 4, 2013

Ernst June 4, 2013 


$\begin{array}{ll}\text { Edvin } & \text { June 5, 2013 } \\ \text { Eskil } & \text { June 5, 2013 } \\ \text { Elin } & \text { June 24, 2013; February 5, 2014 } \\ \text { Erik } & \text { September 17, 2013 } \\ \text { Einar } & \text { September 17, 2013; February 6, 2014 } \\ \text { Ellinor } & \text { September 17, 2013; February 6, 2014 } \\ \text { Elias } & \text { September 17, 2013; February 6, 2014 } \\ \text { Emil } & \text { September 19, 2013; February 6, 2014 } \\ \text { Elisabet } & \text { September 20, 2013 } \\ \text { Ester } & \text { September 19, 2013, } \\ \text { Ebbe } & \text { February 5, 2014 } \\ \text { Eva } & \text { February 6, 2014 } \\ & \end{array}$

Users participating in Smart Customer Gotland

Harry and Harriet February 5, 2014

Helge and Helen February 5, 2014

Herbert December 8, 2014

Hjördis and Hjalmar December 8, 2014

Hemming December 8, 2014

Harald December 9, 2014 
Henrietta and Henrik December 9, 2014

Henry December 10, 2014

Holger December 10, 2014

Hampus December 11, 2014

Hans and Hanna December 11, 2014

Håkan December 12, 2014

Hugo December 12, 2014

Herman December 13, 2014

Representatives for prosumers on Gotland

Pontus September 18, 2013

Pamela $\quad$ September 18, 2013

Paul and Paula September 18, 2013

Pär September 19, 2013

Peter and Petra December 11, 2014

Pernilla December 12, 2014 